\title{
Gait dynamics on a cross-slope walking surface
}

\author{
Philippe Dixon
}

Department of Kinesiology and Physical Education

McGill University, Montreal

Quebec, Canada

\section{March 2008}

A thesis submitted to McGill University in partial fulfillment of the of requirements of the degree of Master of Science in Kinesiology

(C) Philippe Dixon, 2008 


$\begin{array}{ll}\begin{array}{l}\text { Library and } \\ \text { Archives Canada }\end{array} & \begin{array}{l}\text { Bibliothèque et } \\ \text { Archives Canada }\end{array} \\ \begin{array}{l}\text { Published Heritage } \\ \text { Branch }\end{array} & \begin{array}{l}\text { Direction du } \\ \text { Patrimoine de l'édition }\end{array} \\ \begin{array}{l}\text { 395 Wellington Street } \\ \text { Ottawa ON K1A 0N4 } \\ \text { Canada }\end{array} & \begin{array}{l}\text { 395, rue Wellington } \\ \text { Ottawa ON K1A 0N4 } \\ \text { Canada }\end{array}\end{array}$

Your file Votre référence ISBN: 978-0-494-51261-6

Our file Notre référence

ISBN: 978-0-494-51261-6

NOTICE:

The author has granted a nonexclusive license allowing Library and Archives Canada to reproduce, publish, archive, preserve, conserve, communicate to the public by telecommunication or on the Internet, loan, distribute and sell theses worldwide, for commercial or noncommercial purposes, in microform, paper, electronic and/or any other formats.

The author retains copyright ownership and moral rights in this thesis. Neither the thesis nor substantial extracts from it may be printed or otherwise reproduced without the author's permission.
AVIS:

L'auteur a accordé une licence non exclusive permettant à la Bibliothèque et Archives Canada de reproduire, publier, archiver, sauvegarder, conserver, transmettre au public par télécommunication ou par l'Internet, prêter, distribuer et vendre des thèses partout dans le monde, à des fins commerciales ou autres, sur support microforme, papier, électronique et/ou autres formats.

L'auteur conserve la propriété du droit d'auteur et des droits moraux qui protège cette thèse. $\mathrm{Ni}$ la thèse ni des extraits substantiels de celle-ci ne doivent être imprimés ou autrement reproduits sans son autorisation.
In compliance with the Canadian Privacy Act some supporting forms may have been removed from this thesis.

While these forms may be included in the document page count, their removal does not represent any loss of content from the thesis.
Conformément à la loi canadienne sur la protection de la vie privée, quelques formulaires secondaires ont été enlevés de cette thèse.

Bien que ces formulaires aient inclus dans la pagination, il n'y aura aucun contenu manquant.

\section{Canada}




\section{STATEMENT OF ORIGINALITY}

All material in this thesis contains original work by the authors except where references indicate outside contributions. It is the belief of the authors that the material presented here contributes to the field of gait analysis by providing an exhaustive analysis of a yet understudied phenomenon: cross-slope walking. 


\section{ACKNOLEDGEMENTS}

I would first like to thank my supervisor Dr. David Pearsall for his guidance throughout my Master's studies. He has always made time for my questions and has provided insightful thoughts on everything from biomechanics to politics and still had time to share a laugh. I would also like to thank $\mathrm{JJ}$ Loh for his incredible technical assistance during the data processing phase of my research. Sitting by his side for numerous hours, I not only learned MatLab programming, but also gain many insights on life. Good luck in Africa $\mathrm{JJ}$, your presence will be greatly missed in the biomechanics lab. It is also important to thank Ryan Ouckama who always had an answer to my infinitely obscure questions and drew the experimental set-up three-dimensional diagram, Yannick Michaud-Paquette who drew the experimental set-up overhead diagram, and Jenny Maisonneuve who spent countless hours labelling my walking trials and reviewing this document- your help was very much appreciated.

On a personal note I would like to thank my family for their continued support during my long, long studies, my former band mates from General Rudie for understanding my need to leave the group to complete my master's degree and to Brown Town for their encouragement. 


\section{CONTRIBUTION OF AUTHORS}

This thesis has been presented in manuscript form and the main body (chapters 3,4 and 5) will be submitted as three papers to the Journal of Biomechanics for publication. Each paper will be co-authored by Dr. David Pearsall. The contributions of each author are summarized below: I was responsible for the collection, processing and statistical analysis of the data as well as for the writing this thesis and generating figures (expect as noted in acknowledgments). Dr. Pearsall designed the experimental protocol, recruited subjects and provided comments on the initial drafts of this thesis. 


\begin{abstract}
Though the biomechanics of level walking have been studied extensively, the adaptations required for cross-slope locomotion are still largely unknown despite being a common terrain characteristic. The goals of this thesis were to determine (1) ground reaction forces (GRF) and moments (GRM), (2) lower-limb kinematics, and (3) lower-limb joint reaction forces (JRF) and moments (JRM) during level and cross-slope walking. Statistical analyses were made across limbs (down-slope (DS) and up-slope (US)) and across slope condition (level $\left(0^{\circ}\right)$ and cross-slope $\left.\left(6^{\circ}\right)\right)(2 \mathrm{X} 2$ ANOVA). Ten healthy male volunteers performed several barefoot walking trials. The lower-limbs responded asymmetrically to the cross-slope condition by substantially changing (1) the medio-lateral GRF, (2) the sagittal and frontal plane kinematics as well as step-width, and (3) the medio-lateral JRF and frontal plane JRM. The modest cross-slope induced important asymmetrical changes in locomotor patterns and may represent a substantial physical obstacle to populations with restricted mobility.
\end{abstract}




\begin{abstract}
ABRÉGÉ
La biomécanique de la marche est un sujet qui a été maintes fois étudié, mais les adaptations du corps nécessaires pour la marche sur une pente transversale sont méconnues. Pourtant les pentes transversales sont très communes dans les terrains ruraux et urbains. Les principaux objectifs de cette étude étaient de déterminer (1) les forces de réaction et les moments de force du sol, (2) la cinétique des membres inferieurs et (3) les forces et les moments de force des articulations des membres inferieurs durant la marche sur terrain plat et sur une pente transversale. L'analyse statistique (2X2 ANOVA) a comparé chaque jambe (jambe basse et jambe haute) et chaque condition d'inclinaison (à plat $\left(0^{\circ}\right)$ et pente transversale $\left.\left(6^{\circ}\right)\right)$ pour en déterminer les différences. Dix sujets mâles n'ayant aucun trouble de santé ont marché nu-pieds à plusieurs reprises sur une plateforme de marche dans la zone de capture. Les résultats ont démontré que la marche sur un plan transversal apporte des changements importants: (1) une modification des forces médio-latérales, (2) des différences cinétiques au plan sagittal et frontal ainsi qu'une réduction de la distance séparant les pieds et (3) l'altération des forces de réaction médio-latérales et des moments de force des articulations dans le plan frontal. Ces résultats soutiennentque même une pente transversale minime peut amener aux membres inferieurs du corps plusieurs changements asymétriques et que cette condition pourrait être un obstacle considérable pour les populations ayant des déficiences motrices.
\end{abstract}




\section{TABLE OF CONTENTS}

Gait dynamics on a cross-slope walking surface.........................................................................

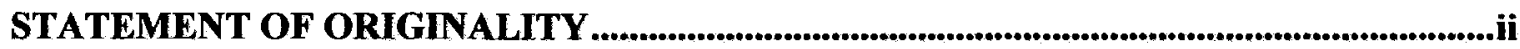

ACKNOLEDGEMENTS ..............................................................................................................................iii

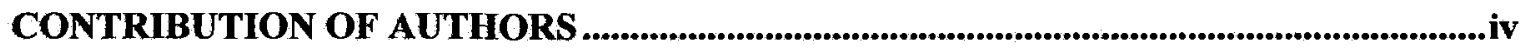

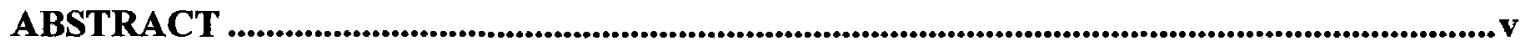

ABRÉGÉ

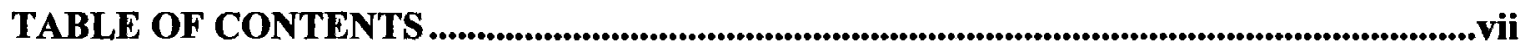

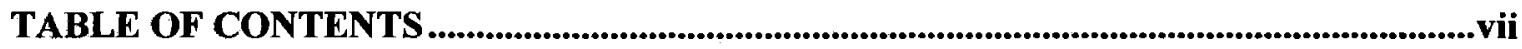

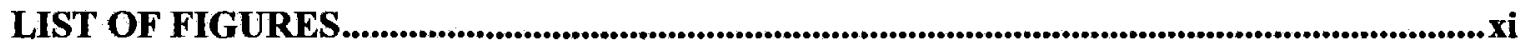

LIST OF TABLES..................................................................................................................................................xii

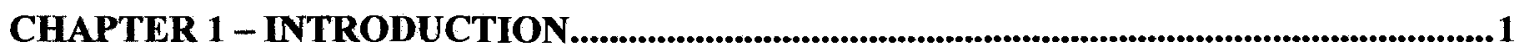

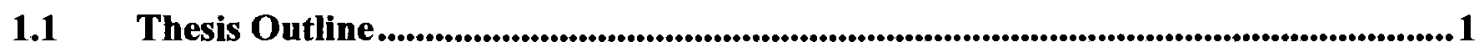

1.2 Nomenclature, Definitions and Abbreviations ......................................................2

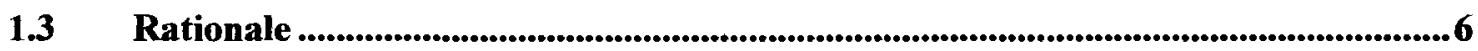

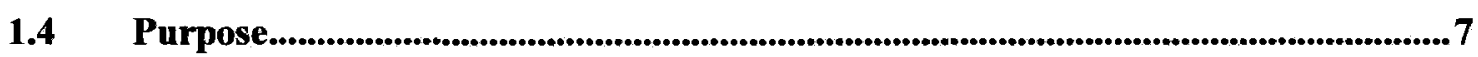

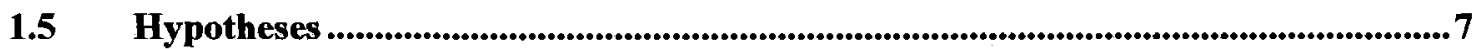

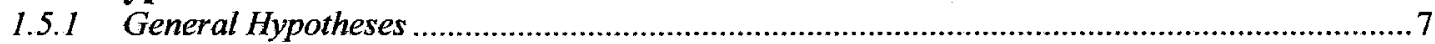

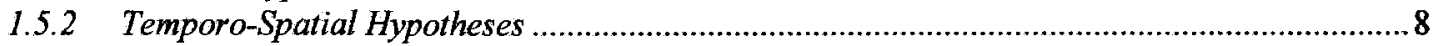

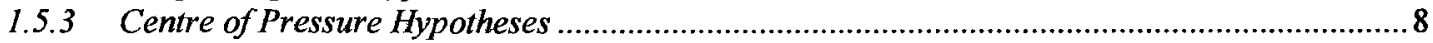

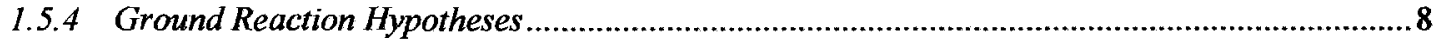

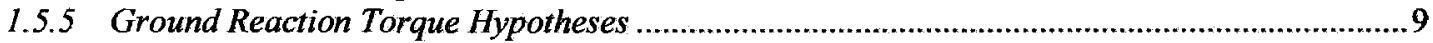

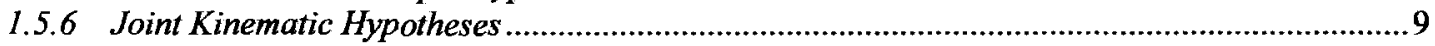

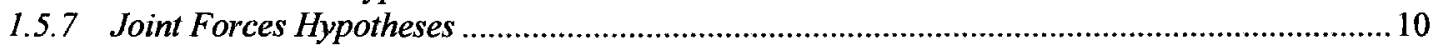

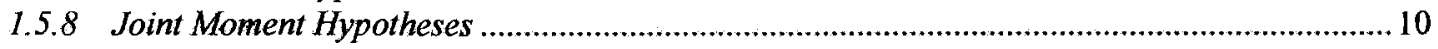

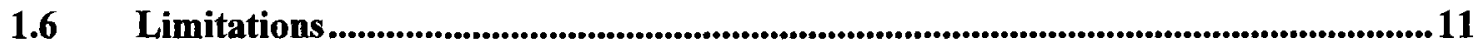

1.7 Delimitations..............................................................................................................11

1.8 Independent (IV) \& Dependent (DV) Variables...............................................................11

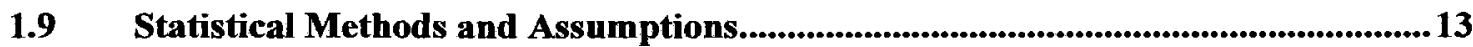

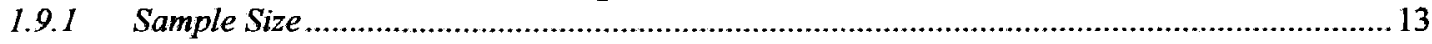

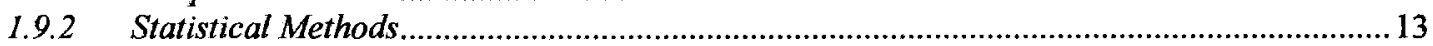

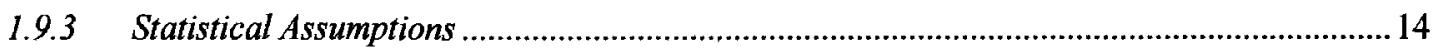

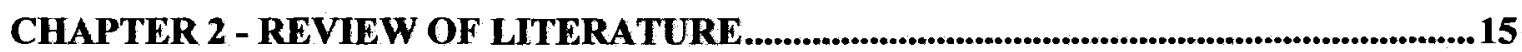

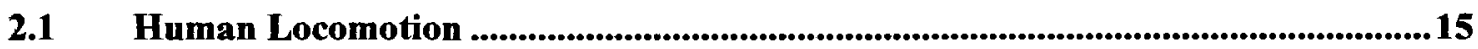

2.2 Ground Reaction Forces During Level Walking........................................................16

2.3 Ground Reaction Torques During Level Walking....................................................17

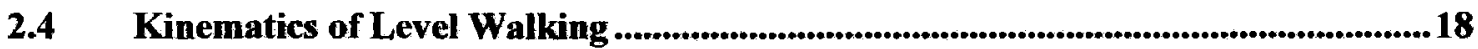

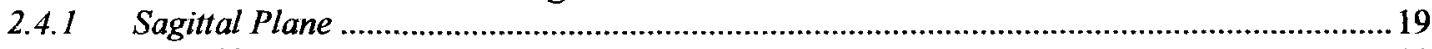

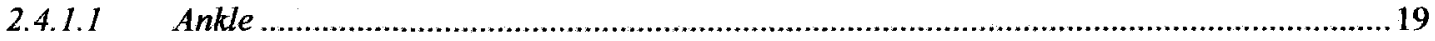




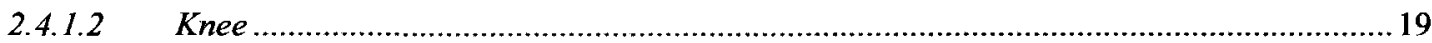

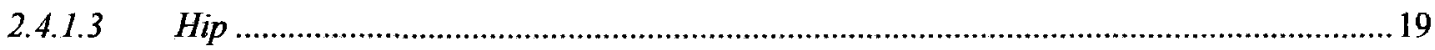

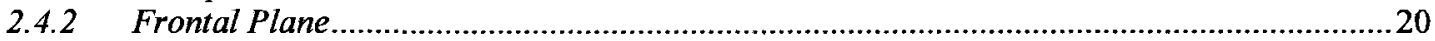

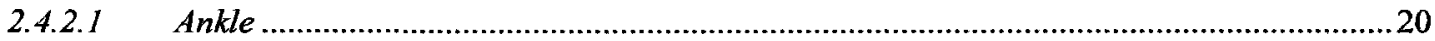

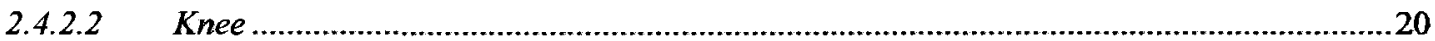

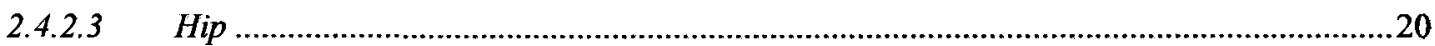

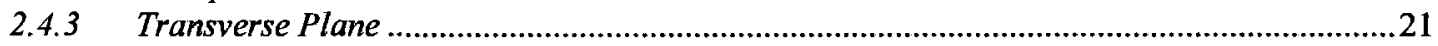

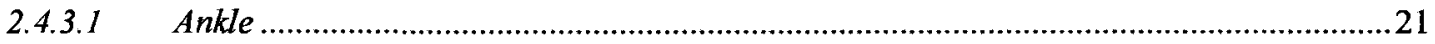

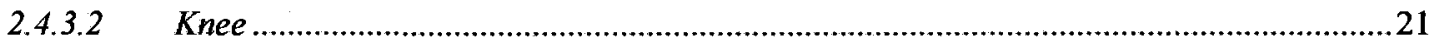

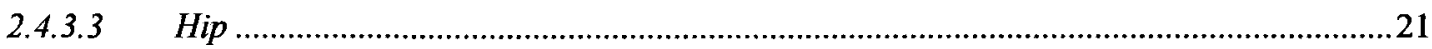

2.5 Joint Reaction Forces During Level Walking.......................................................22

2.6 Joint Reaction Moments During Level Walking ...........................................................22

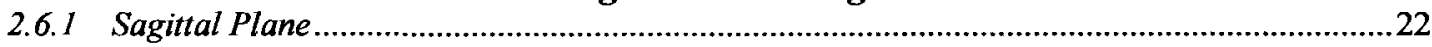

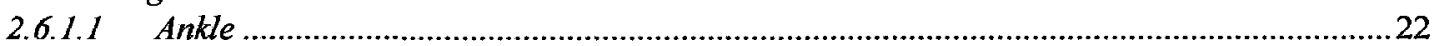

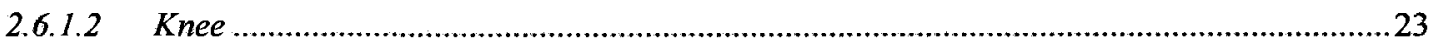

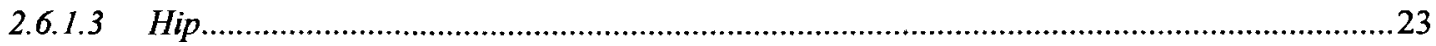

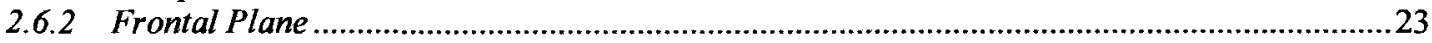

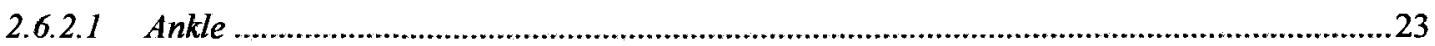

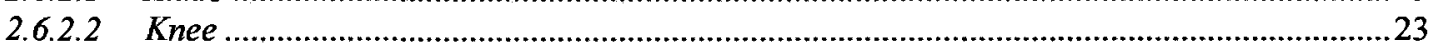

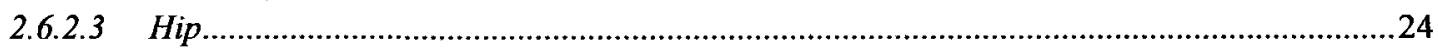

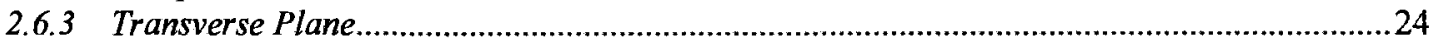

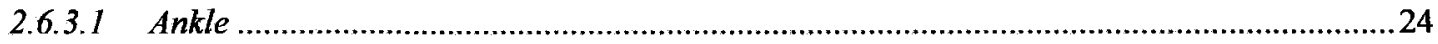

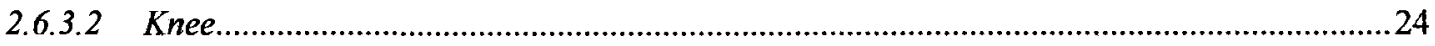

2.6.3.3 Hip

2.7 Kinematics of Cross-Slope Walking ...........................................................................25

2.8 Kinematics of Cross-Slope Running .........................................................................26

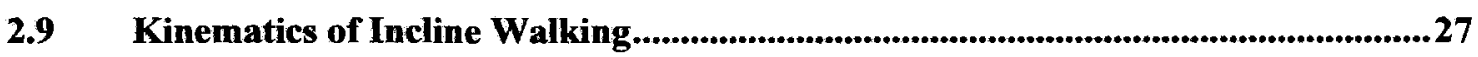

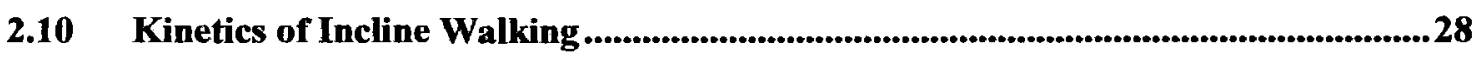

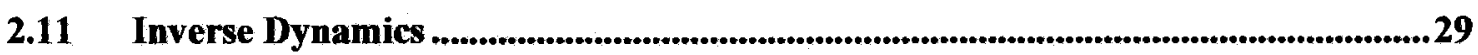

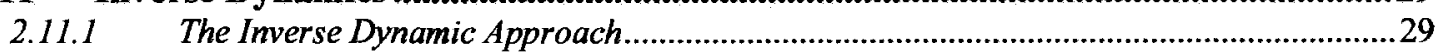

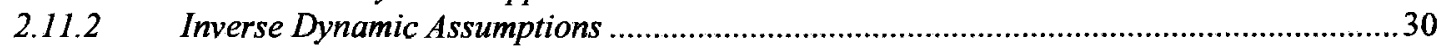

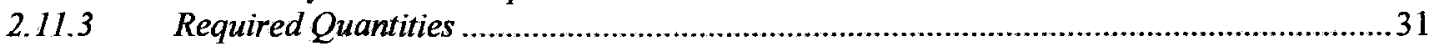

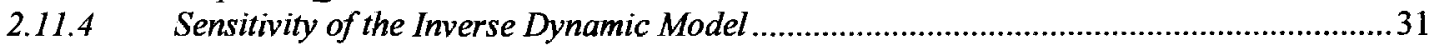

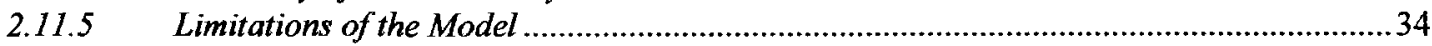

CHAPTER 3 - GROUND REACTION FORCES AND FREE VERTICAL TORQUE DURING LEVEL AND CROSS-SLOPE WALKING IN HEATHY

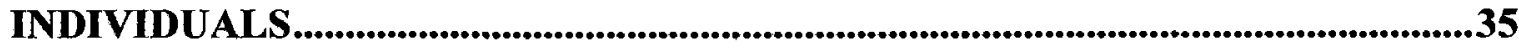

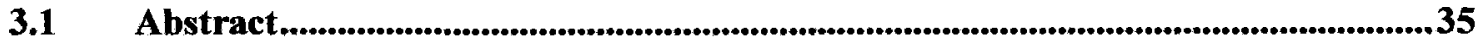

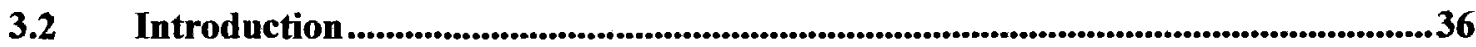

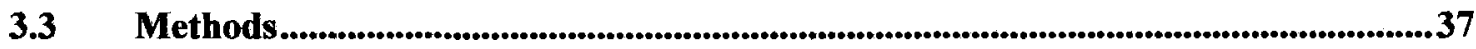

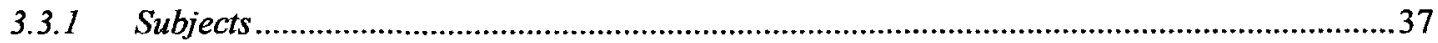

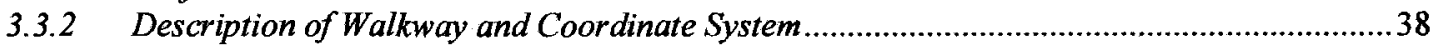

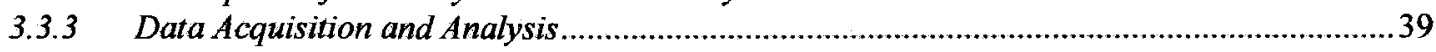

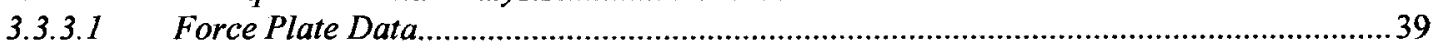

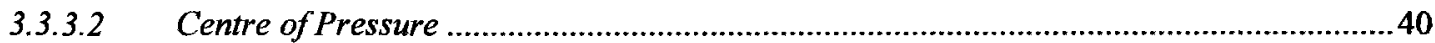

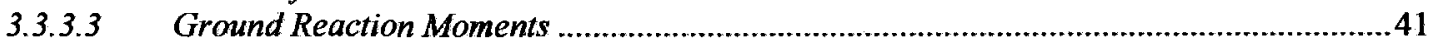

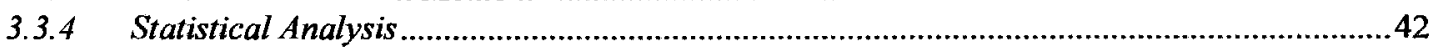

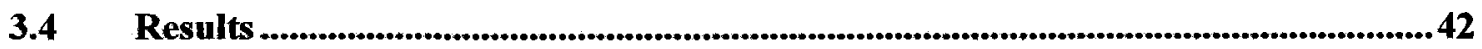




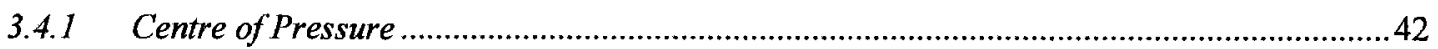

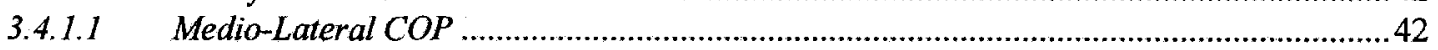

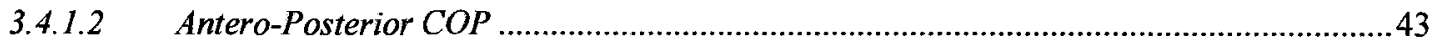

3.4.2 Ground Reaction Forces...............................................................................................4

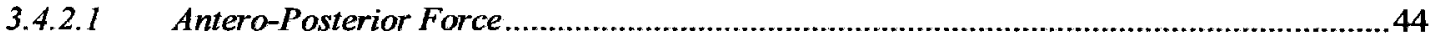

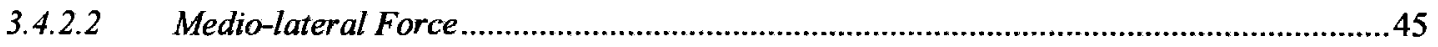

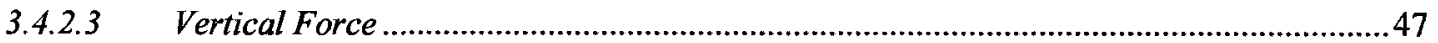

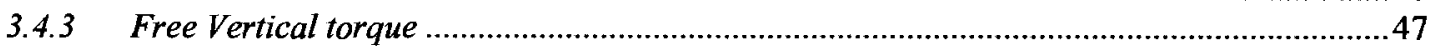

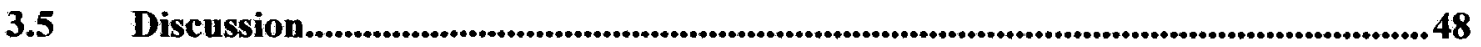

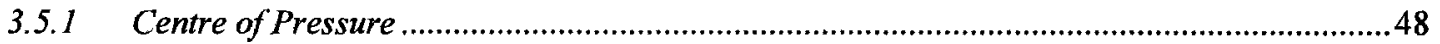

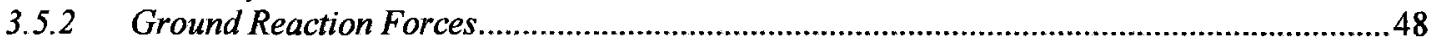

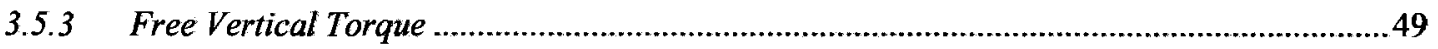

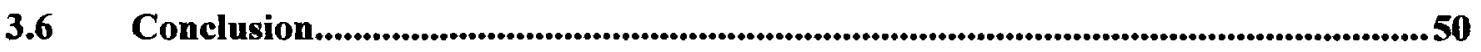

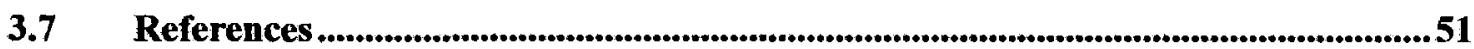

CHAPTER 4 - LOWER-LIMB KINEMATICS DURING FLAT AND CROSSSLOPE WALKING IN HEALTHY INDIVIDUALS......................................................53

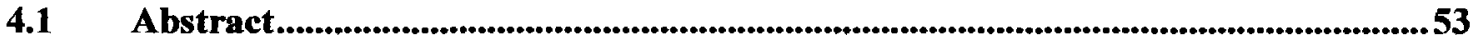

4.2 Introduction .......................................................................................................................54

4.3 Methods........................................................................................................................................56

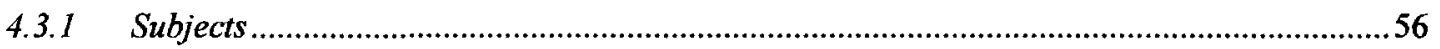

4.3.2 Description of Walkway and Coordinate System

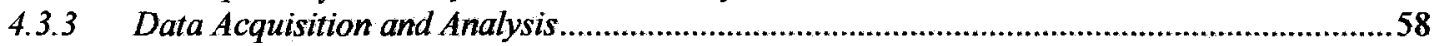

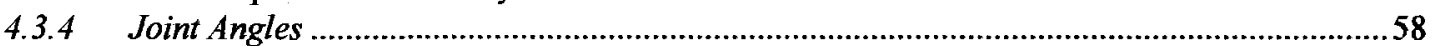

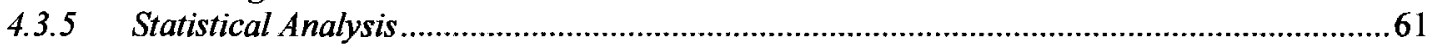

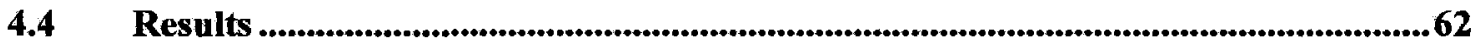

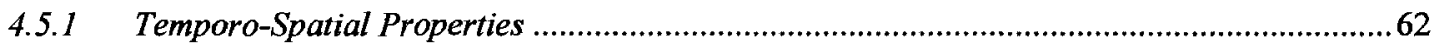

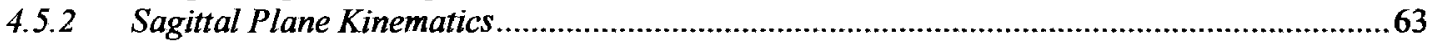

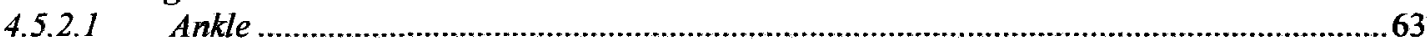

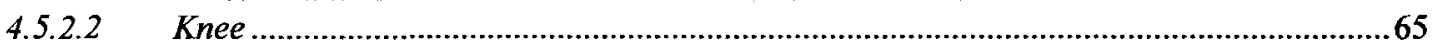

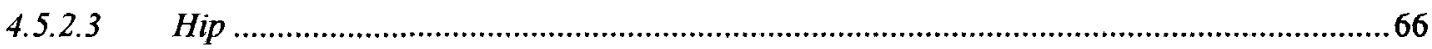

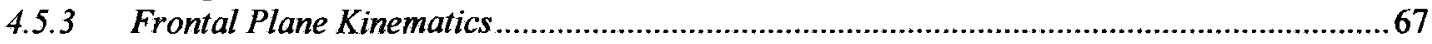

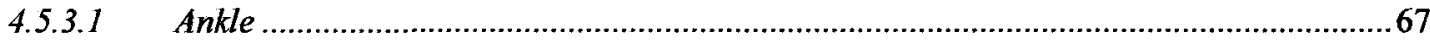

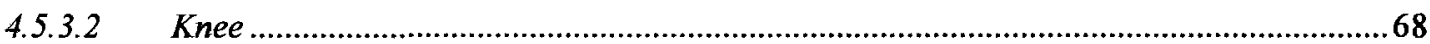

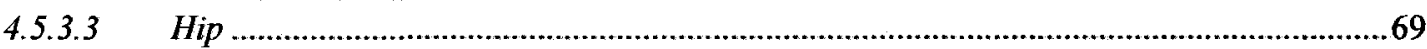

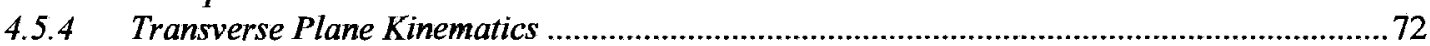

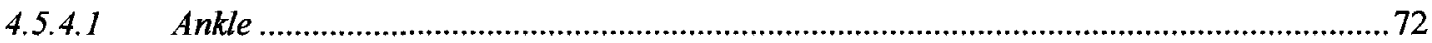

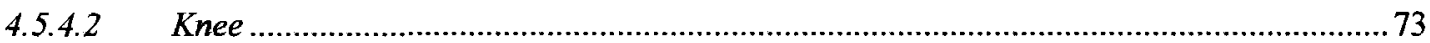

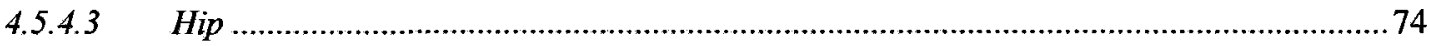

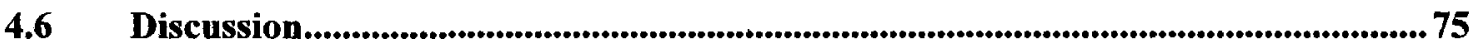

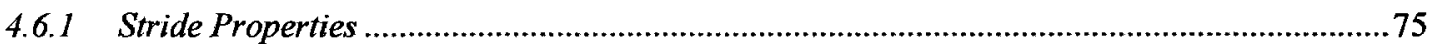

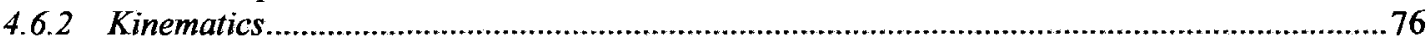

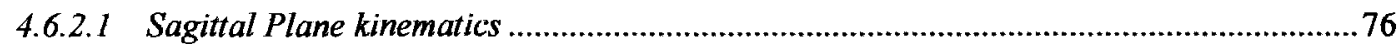

4.6.2.2 Frontal Plane Kinematics.....................................................................................77

4.6.2.3 Transverse Plane Kinematics ....................................................................................... 78

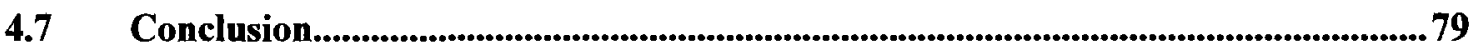

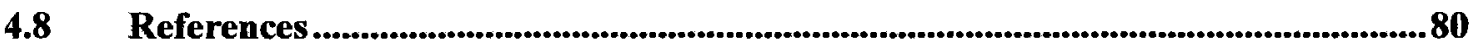




\section{CHAPTER 5 - LOWER-LIMB KINETICS DURING FLAT AND CROSS-SLOPE}

WALKING IN HEALTHY INDIVIDUALS ...........................................................8

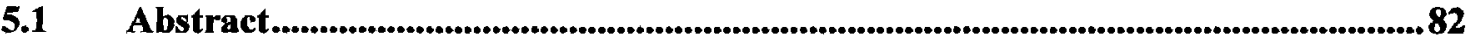

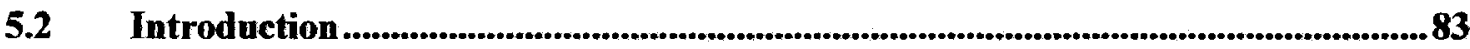

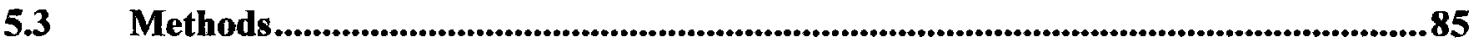

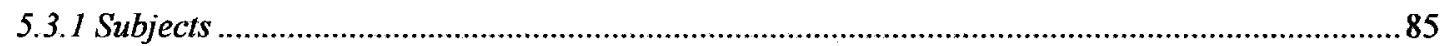

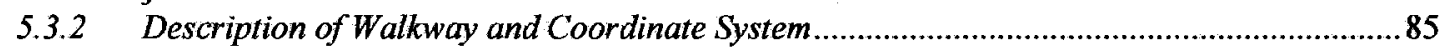

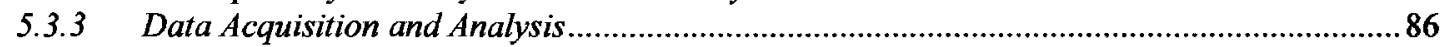

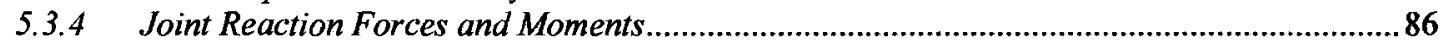

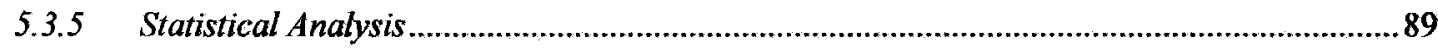

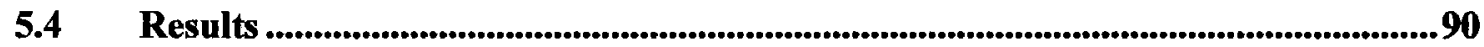

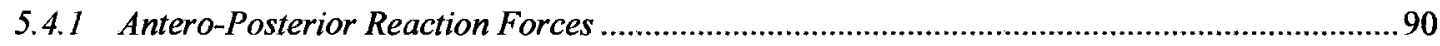

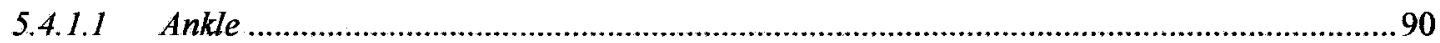

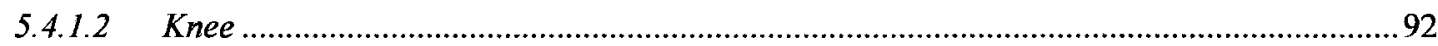

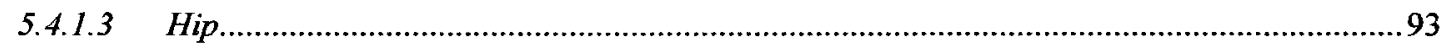

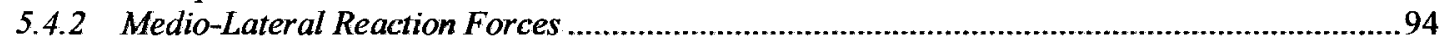

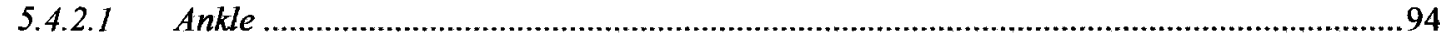

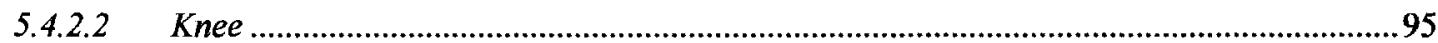

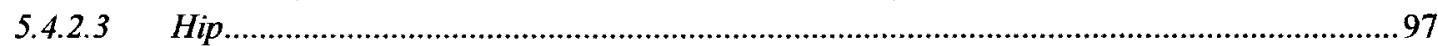

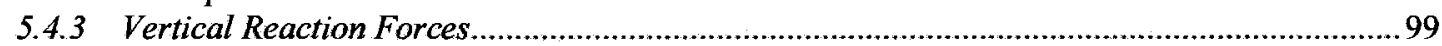

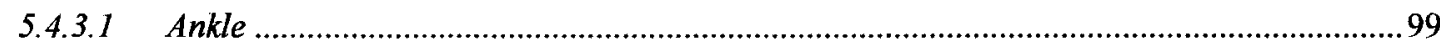

5.4.3.2 Knee

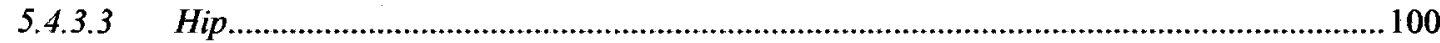

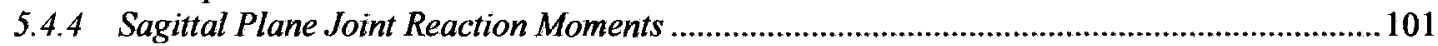

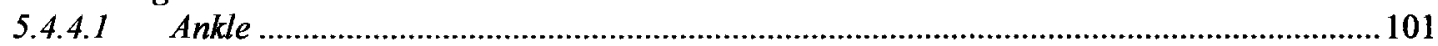

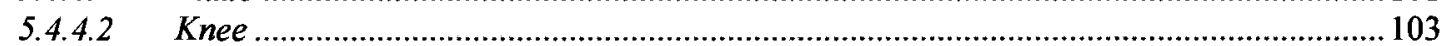

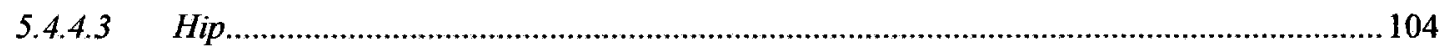

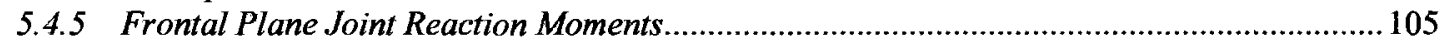

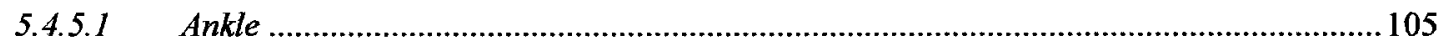

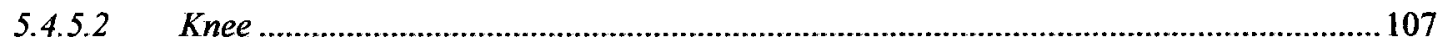

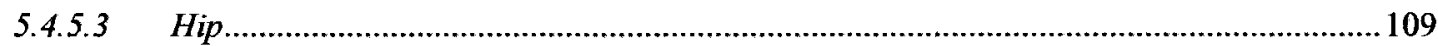

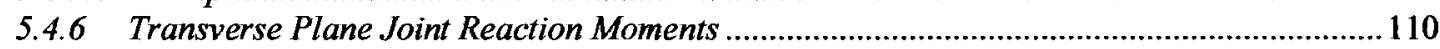

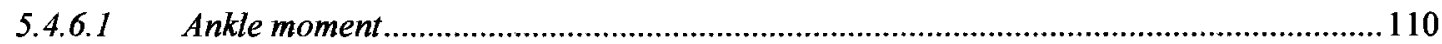

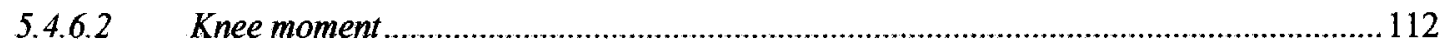

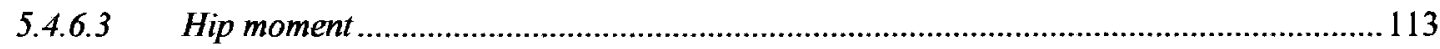

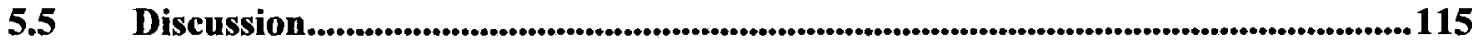

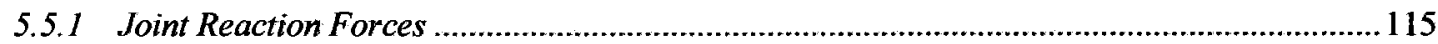

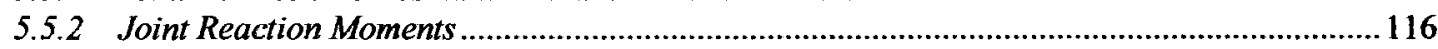

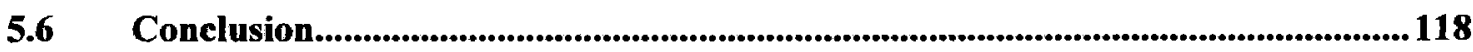

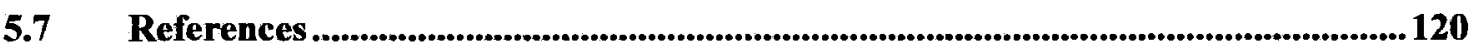

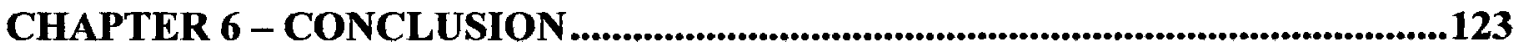

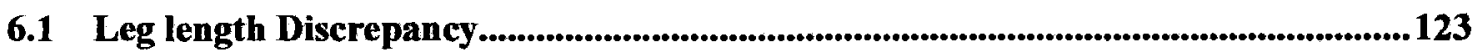

6.2 Avoidance of Down-Slope Slippage .......................................................................................... 124

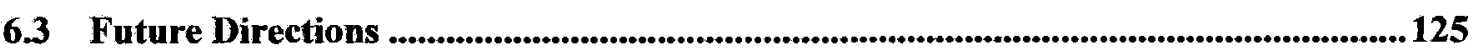

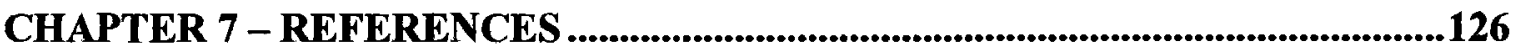

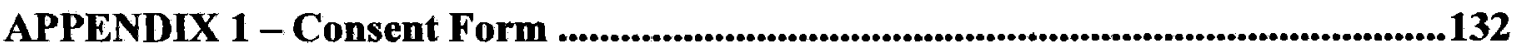

APPENDIX 2 - Ethics Certificate ................................................................................133 


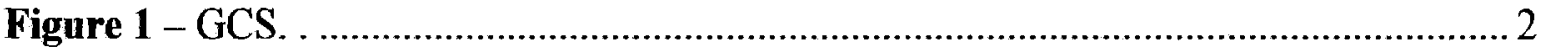

Figure 2 - LCS for each of the lower limb segments.. ……………………………….... 2

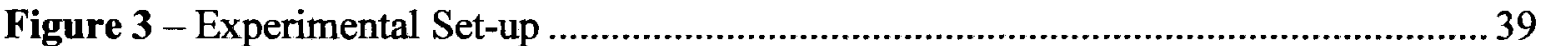

Figure 4 - (a) Average COP data (b) Force Plate.......................................................... 44

Figure 5 - (a) Antero-Posterior GRF (b) Force Vector ..................................................... 44

Figure 6 - (a) Medio-Lateral GRF (b) Force Vector. ……………………………….........46

Figure 7 - (a) Vertical GRF (b) Force Vector ………………...................................... 47

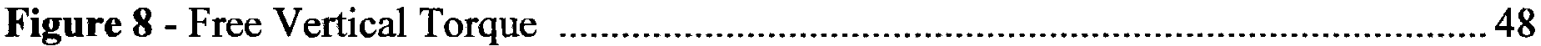

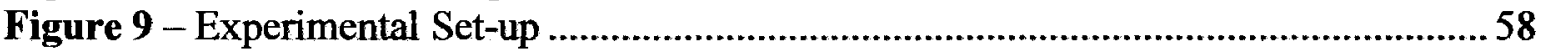

Figure 10 - LCS for each of the lower limb segments .....................................................5 59

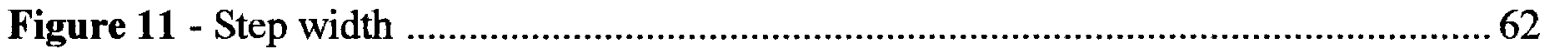

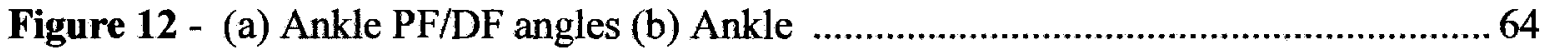

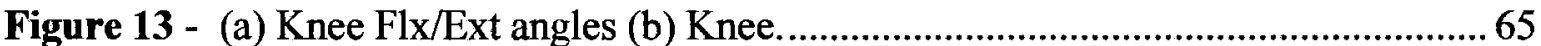

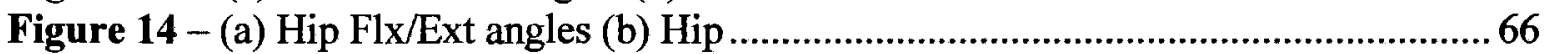

Figure 15 - (a) Ankle Inv/Eve angles (b) Ankle...............................................................68

Figure 16 - (a) Knee Abd/Add angles (b) Knee. .................................................................

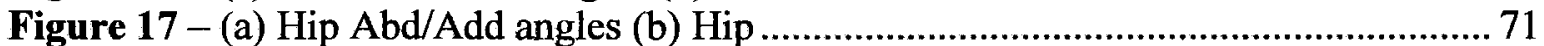

Figure 18 - (a) Ankle IRot/ERot angles (b) Ankle ...................................................... 73

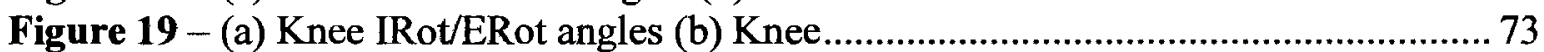

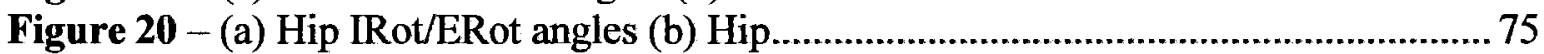

Figure 21 - Experimental Set-up. ………………………………………………..... 86

Figure 22 - LCS for each of the lower-limb segments...................................................87

Figure 23 - (a) Ankle antero-posterior force (b) ForceVector .........................................92

Figure 24 - (a) Knee antero-posterior force (b) ForceVector .............................................. 93

Figure 25 - (a) Hip antero-posterior force (b) ForceVector ................................................ 94

Figure 26 - (a) Ankle medio-lateral force (b) ForceVector .................................................95

Figure 27 - (a) Knee medio-lateral force(b) ForceVector .................................................97

Figure 28 - (a) Hip medio-lateral force (b) ForceVector.....................................................98

Figure 29 - (a) Ankle vertical force (b) ForceVector .......................................................99

Figure 30 -(a) Knee vertical force (b) ForceVector.................................................... 100

Figure 31 -(a)Hip vertical force (b) ForceVector ......................................................... 101

Figure 32 - (a) Ankle sagittal moment (b) Moment Vector ............................................ 102

Figure 33 - (a) Knee sagittal moment (b) Moment Vector................................................ 104

Figure 34 - (a) Hip sagittal moment (b) Moment Vector .................................................. 105

Figure 35 - (a) Ankle frontal moment (b) Moment Vector ............................................... 107

Figure 36 - (a) Knee frontal moment (b) Moment Vector................................................. 108

Figure 37 - (a) Hip frontal moment (b) Moment Vector .................................................. 110

Figure 38 - (a) Ankle transverse moment (b) Moment Vector......................................... 111

Figure 39 - (a) Knee transverse moment (b) Moment Vector ............................................ 113

Figure 40 - (a) Hip transverse moment (b) Moment Vector ............................................. 114 


\section{LIST OF TABLES}

Table 1 - Slope characteristic nomenclature and definitions........................................... 3

Table 2 - Spatio-temporal gait characteristics. ............................................................. 3

Table 3 - Gait cycle terms, event definitions, and associated quantities ............................. 4

Table 4 - The Gait cycle. ............................................................................................ 5

Table 5 - Kinematic abbreviations and sign conventions …………………………….... 5

Table 6 - Joint Force sign conventions ........................................................................ 5

Table 7 - Joint Moment abbreviations and sign conventions ............................................. 6

Table 8 - Summary of variables included in data analysis ............................................ 12

Table 9 - Summary of Subject Anthropometrics .......................................................... 38

Table 10 - Representative gait cycle events used for data analysis.................................40

Table 11 - Total medial-lateral COP ROM ............................................................... 42

Table 12 - Total antero-posterior COP ROM ………………...................................... 43

Table 13 - Medio-lateral GRF values for each side/condition permutation along with associated p-values............................................................................................. 46

Table 14 - Summary of Subject Anthropometrics .......................................................57

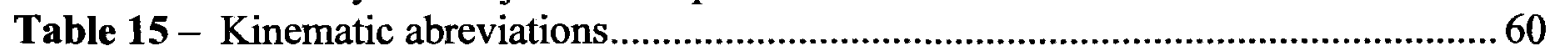

Table 16 - Gait cycle representative event percentages and abbreviations. …………….....60

Table 17 - Kinematic events of the ankle, knee, hip and pelvis in all three planes.............61

Table 18 - Stride properties (stride length, step length and step width) .............................62

Table 19 -Ankle sagittal plane angle values for each side/condition permutation along

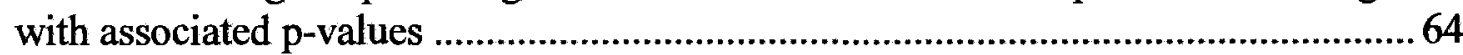

Table 20 - Knee sagittal plane angle values for each side/condition permutation along

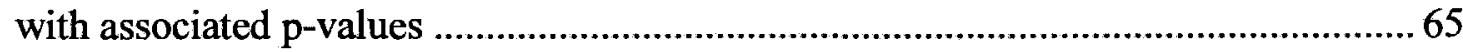

Table 21 - Hip sagittal plane angle values for each side/condition permutation along with associated p-values

Table 22 -Ankle frontal plane angle values for each side/condition permutation along with associated p-values

Table 23 -Knee frontal plane angle values for each side/condition permutation along with

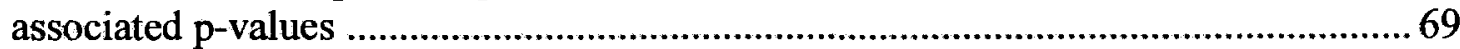

Table 24 -Hip frontal plane angle values for each side/condition permutation along with associated p-values................................................................................................... 71

Table 25 - Ankle transverse plane angle values for each side/condition permutation along with associated $\mathrm{p}$-values ............................................................................. 72

Table 26 -Hip transverse plane angle values for each side/condition permutation along

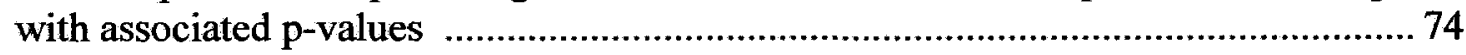

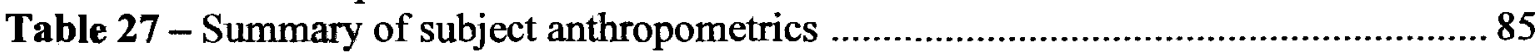

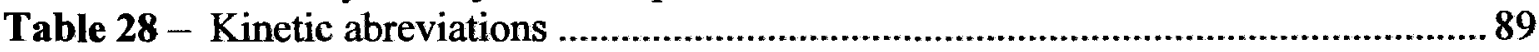

Table 29 - Gait cycle representative event percentages and abbreviations. ........................89

Table 30 - Representative gait cycle events used for data analysis. ................................. 89

Table 31 - Ankle antero-posterior force values for each side/condition permutation along with associated $\mathrm{p}$-values.

Table 31 - Knee antero-posterior force values for each side/condition permutation along with associated p-values

Table 32 - Ankle medio-lateral force values for each side/condition permutation along with associated $\mathrm{p}$-values ....................................................................................... 95 
Table 33 - knee medio-lateral force values for each side/condition permutation along with associated $\mathrm{p}$-values.

Table 34 - Hip medio-lateral force values for each side/condition permutation along with associated p-values......................................................................98

Table 35 - Ankle antero-posterior force values for each side/condition permutation along with associated p-values 100

Table 36 - Hip vertical force values for each side/condition permutation along with associated p-values. 101

Table 37 - Ankle sagittal plane moment values for each side/condition permutation along with associated $\mathrm{p}$-values 102

Table 38 - Knee sagittal moment values for each side/condition permutation along with associated p-values

Table 39 - Hip sagittal moment values for each side/condition permutation along with associated p-values

Table 40 - Ankle frontal plane moment values for each side/condition permutation along with associated $\mathrm{p}$-values 106

Table 41 - knee frontal plane moment values for each side/condition permutation along with associated $\mathrm{p}$-values

Table 42 - Hip frontal plane moments values for each side/condition permutation along with associated p-values

Table 43 - Ankle transverse plane moments values for each side/condition permutation along with associated p-values

Table 44 - Knee transverse plane moments values for each side/condition permutation along with associated p-values.

Table 45 - Hip transverse plane moment values for each side/condition permutation along with associated p-values 


\section{CHAPTER 1 - INTRODUCTION}

\subsection{Thesis Outline}

The following thesis will focus on the dynamics of the lower-limbs while walking on a transversely tilted (cross-slope) surface. GRF, stride characteristics (step width, step length, stride length), kinematics and kinetics (JRF and JRM) will be the main outcomes measures for this study.

Presented in manuscript form, the following thesis comprises seven parts as detailed below. Chapter 1 presents the rationale, purpose and hypotheses of the present study. The delimitations and limitations of the research are also explained, along with a summary of variables under study and the statistical methods used to analyze them. In addition, a nomenclature section summarizes the main terms and definitions used throughout this thesis. Chapter 2 provides an extensive literature review related to the topic of walking, including a review of level and non-level locomotion studies. Mathematical techniques for the computation of kinematics and kinetics will also be covered with a focus on inverse dynamics analysis (IDA) using vectors and Euler angles. Chapters 3, 4, 5 are individual research papers concentrating on GRF, lower-limb kinematics and lower limb kinetics, respectively. Chapter 6 serves as a summary of the main conclusions related to this cross-slope walking study while chapter 7 lists the references used in this thesis. Reference format used throughout is American Psychological association (APA) style. 
The following nomenclature, definitions and abbreviations will be used in this thesis:

1. Coordinate systems: Following the convention set by Vaughan et al. (1999) the Global Coordinate System (GCS) had its origin at the bottom right corner of the first force plate (Fig. 1). For the cross-slope condition, the GCS was rotated about the original $\mathrm{x}$-axis.

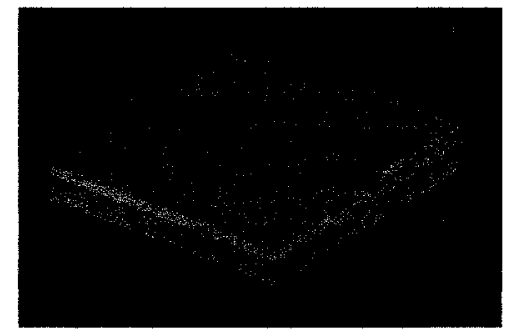

Figure 1 - GCS. $\mathrm{x}$-axis (red) positive in direction of propagation, $\mathrm{y}$-axis (green), $\mathrm{z}$ axis (blue).

The Local Segment Embedded Coordinate System (LCS) used to compute joint angles and Euler angles was also based on those of Vaughan et al. (1999) (Fig. 2):

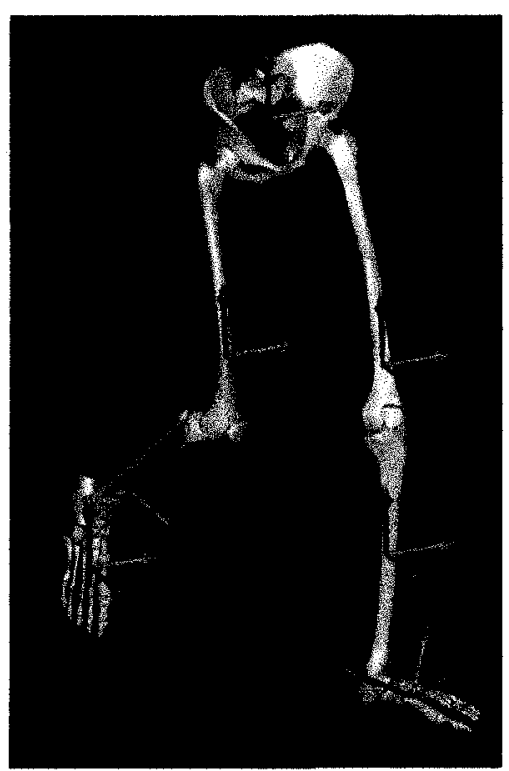

Figure 2 - LCS for each of the lower limb segments. x-axis (blue), y-axis (red) and z-axis (green). 
2. Terrain characteristics: Terrains can be characterized by two possible slope characteristics, cross-slopes and grade (Table 1), occurring separately or in combination. In this study only a cross-slope was used. Slopes can be expressed in $\%$, degrees $\left({ }^{\circ}\right)$, radians or as rise over run. Degrees were chosen for this study.

Table 1 - Slope characteristic nomenclature and definitions used in the present study.

\begin{tabular}{ll}
\hline Slope & Definition \\
\hline Grade: & An incline or decline slope in the direction of propagation. \\
Cross-Slope: & $\begin{array}{l}\text { A transverse slope, perpendicular to the direction of } \\
\text { propagation. }\end{array}$ \\
$\begin{array}{l}\text { Up-Slope (US) } \\
\text { limb: }\end{array}$ & $\begin{array}{l}\text { Limb at a higher elevation while subject is walking on cross-slope. } \\
\text { The right limb throughout this study. }\end{array}$ \\
$\begin{array}{l}\text { Down-Slope } \\
\text { (DS) limb: }\end{array}$ & $\begin{array}{l}\text { Limb at a lower elevation while subject is walking on cross-slope. } \\
\text { The left limb throughout this study. }\end{array}$ \\
\hline
\end{tabular}

3. Spatio-Temporal parameters: Determined using marker and force plate data, these quantities appear in chapter 4 (Table 2).

Table 2 - Spatio-temporal gait characteristics used in the present study.

\begin{tabular}{ll}
\hline Spatio-Temporal parameter & Definition \\
\hline Step Length: & $\begin{array}{l}\text { Leg length normalized antero-posterior distance } \\
\text { between heels at time of heel strike of anterior limb on } \\
\text { the force plate. }\end{array}$ \\
Stride Length: & $\begin{array}{l}\text { Leg length normalized antero-posterior distance } \\
\text { between two successive heel strikes of the same foot. }\end{array}$ \\
Step Width: & $\begin{array}{l}\text { Medio-lateral distance between the heels during double } \\
\text { support phase. }\end{array}$ \\
\hline
\end{tabular}

4. Gait cycle parameters: The usual gait cycle parameters are defined here along with the method of calculation if necessary. Definitions are based on standard definitions (Ounpuu, 1994; Rose and Gamble, 2006) (Table 3) 
Table 3-Gait cycle terms, event definitions, and associated quantities used in the present study.

\begin{tabular}{ll}
\hline Gait term & Description/Calculation \\
\hline The Gait Cycle: & $\begin{array}{l}\text { A full walking stride beginning at initial contact of } \\
\text { one foot and ending at the following initial contact of } \\
\text { the same foot. }\end{array}$ \\
\hline Stance Phase (St): & $\begin{array}{l}\text { Period during which the foot is in contact with the } \\
\text { ground. }\end{array}$ \\
Swing Phase (Sw): & Period during which the foot is in the air. \\
Heel Strike (HS): & $\begin{array}{l}\text { First contact of the ipsilateral foot with the ground } \\
\text { before stance phase, calculated as the instant at which } \\
\text { the magnitude of the ground reaction force exceeds }\end{array}$ \\
60N as the subject steps onto the force plate.
\end{tabular}

Below are representative percentages for portions of the gait cycle defined above for normal adults walking at self-selected walking speeds as presented by Ounpuu (1994) (Table 4). 
Table 4 - The Gait cycle.

\begin{tabular}{|l|l|l|l|}
\hline \multicolumn{2}{|c|}{ Stance Phase (St) 0-60\% } & Swing Phase (Sw): 61-100\% \\
\hline Event & percentage & Event & percentage \\
\hline Early Stance (ESt): & $0-10 \%$ & Early Swing (ESw): & $61-70 \%$ \\
Midstance (MSt): & $11-30 \%$ & Midswing (MSw): & $71-85 \%$ \\
Terminal stance (TSt): & $31-50 \%$ & Terminal Swing (TSw): & $\mathbf{8 6 - 1 0 0 \%}$ \\
Preswing (PSw): & $51-60 \%$ & & \\
\hline
\end{tabular}

5. Kinematics: Kinematics calculated using the Grood and Suntay method (1983) with sign convention of Levangie and Norkin (2005) (Table 5).

Table 5 - Kinematic abbreviations and sign conventions used in the present study.

\begin{tabular}{|c|c|c|c|}
\hline & Sagittal & \begin{tabular}{|l} 
Frontal \\
\end{tabular} & Transverse \\
\hline Ankle & $\begin{array}{l}\text { Plantarflexion (PF): } \\
\text { negative } \\
\text { Dorsiflexion (DF): } \\
\text { positive }\end{array}$ & $\begin{array}{l}\text { Eversion (Eve): } \\
\text { negative } \\
\text { Inversion (Inv): } \\
\text { positive }\end{array}$ & $\begin{array}{l}\text { External rotation (ERot): } \\
\text { negative } \\
\text { Internal rotation (IRot): } \\
\text { positive }\end{array}$ \\
\hline Knee/Hip & $\begin{array}{l}\text { Flexion (Flx): } \\
\text { positive } \\
\text { Extension (Ext): } \\
\text { negative }\end{array}$ & $\begin{array}{l}\text { Abduction (Abd): } \\
\text { negative } \\
\text { Adduction (Add): } \\
\text { positive }\end{array}$ & $\begin{array}{l}\text { External rotation (ERot): } \\
\text { negative } \\
\text { Internal rotation (IRot): } \\
\text { positive }\end{array}$ \\
\hline
\end{tabular}

6. Joint Forces and Moments: All JRF and JRM are net internal moments produced by muscles, supporting tissues, and bones that resist or change the effects of an external load. JRF and JRM were calculated according to a standard IDA method (Vaughan et al, 1999). JRF follow sign convention of Vaughan et al. (1999) (Table 5), while JRM follow sign convention of Winter (1995) (Table 6):

Table 6 - Joint Force sign conventions used in the present study.

\begin{tabular}{|l|l|l|}
\hline Antero-posterior & Medio-lateral & Vertical \\
\hline Anterior: positive & Medial : positive & Proximal: positive \\
Posterior: negative & Lateral : negative & Distal: negative \\
\hline
\end{tabular}


Table 7- Joint Moment abbreviations and sign conventions used in the present study.

\begin{tabular}{|l|l|l|l|}
\hline & Sagittal & Frontal & Transverse \\
\hline Ankle & $\begin{array}{l}\text { DF moment: negative } \\
\text { PF moment: positive }\end{array}$ & $\begin{array}{l}\text { Inv moment : negative } \\
\text { Ever moment : positive }\end{array}$ & $\begin{array}{l}\text { IRot moment: negative } \\
\text { ERot moment: positive }\end{array}$ \\
\hline $\begin{array}{l}\text { Knee/ } \\
\text { Hip }\end{array}$ & $\begin{array}{l}\text { Flx moment: negative } \\
\text { Ext moment: positive }\end{array}$ & $\begin{array}{l}\text { Add moment: negative } \\
\text { Abd moment: positive }\end{array}$ & $\begin{array}{l}\text { IRot moment: negative } \\
\text { ERot moment: positive }\end{array}$ \\
\hline
\end{tabular}

\subsection{Rationale}

The study's underlying goal is to identify how cross-slopes affect gait. Cross-slopes are a regular feature of our physical environment. In the urban setting, it is common practice to tilt sidewalks and roadways to permit water drainage. Canadian national guidelines recommend cross-slope inclination of $0.5-2.3^{\circ}$ for that purpose (National Guide to Sustainable Municipal Infrastructure, 2004). Further, the Ontario Building Code recommends curb ramps, such as driveway entrances, to possess a slope between $5-7^{\circ}$ for motor vehicle passage (Ministry of Municipal Affairs and Housing, 2006). Nonetheless, for a pedestrian, sidewalks with intermittent ramps may impeded gait and/or present an increased risk of falls. For young adults cross-slopes do not necessarily represent a significant challenge, however for elderly and special populations (visually impaired, amputees, wheelchair users, etc) the asymmetrical demands of cross-slope walking may introduce functional muscular-skeletal and balance barriers. In particular, this may precipitate falls, a major cause of injury in elderly populations (Lockhart et al., 2007) with incidences increasing with age (Campbell et al., 1981; Donald and Bulpitt 1999). In addition, the decreased joint flexibility (most notably at the ankles) and strength of older populations (Reeves, et al., 2007) may make cross-slope walking a difficult task to perform. A better knowledge of lower-limb dynamics during non-level walking conditions could also aid in the design of a variety of prostheses and walking aids. 
Very little research has studied the biomechanics involved in cross-slope ambulation. Some running studies involving cross-slopes (Gehlsen et al., 1988; Fujii et al., 1999; Sussman et al., 2001; De Garie 2005) have focused on kinematics of the lower limbs and have found significant differences between the DS and US-limbs. However, few researchers have specifically studied the biomechanics of cross-slope walking (DeGarie et al., 2000; Nicolaou et al., 2002; Urrey, 2002; Pearsall et al., 2007). Therefore, this study aims to quantify the kinematic and kinetic adaptations required for cross-slope walking. This research is relevant to several population segments for whom terrain obstacles can impede walking and increase the risk of falling injuries.

\subsection{Purpose}

This study will quantify the effects of cross-slope on the lower limbs; specifically to determine for each condition and limb-side changes in the:

1. step length, stride length and step width (stride properties)

2. three-dimensional ground reaction forces during stance.

3. free vertical torque during stance

4. COP characteristics

5. ankle, knee, and hip kinematics in all three dimensions during entire gait cycle

6. ankle, knee, and hip forces during stance.

7. ankle, knee, and hip moment during stance.

\subsection{Hypotheses}

\subsubsection{General Hypotheses}

The following hypotheses are made in this study:

H1. Limb Symmetry: It is expected that limb symmetry in all dependent variables will be exhibited between the DS-limb and US-limb on the flat condition. 


\subsubsection{Temporo-Spatial Hypotheses}

H2. Step Length: Step length is expected to remain unchanged between the walking conditions.

H3. Stride Length: Stride length will not be altered by the cross-slope walking condition.

H4. Step Width: Step width will be reduced on the cross-slope condition in order to minimize the distance between limbs and thus the difference in elevation between the lateral sides of the pelvis. Normal step width values range from $5.0-13.0 \mathrm{~cm}$ (Whittle, 2002).

\subsubsection{Centre of Pressure Hypotheses}

H5. COP antero-posterior coordinate: No change is expected in antero-posterior COP range during each step stance phase in accordance with stride property hypotheses $\mathrm{H} 1$ and $\mathrm{H} 2$.

H6. COP medio-lateral coordinate: It is believed that the medio-lateral coordinates of the COP, with respect to the foot, will migrate medially for both limbs for the cross-slope condition in accordance with the reduced step width hypothesized above in $\mathrm{H} 4$.

\subsubsection{Ground Reaction Hypotheses}

H7. Antero-posterior forces: Based on the findings from a previous pilot study (Pearsall et al., 2007), no significant differences are expected between the limb sides and across conditions.

H8. Medio-lateral forces: It is expected that the medio-lateral GRF for both the DS and US-limbs will be significantly greater for the cross-slope condition to avoid 
DS-slippage. More specifically, the US-limb will show greater medial force whereas the DS-limb will show greater lateral force.

H9. Vertical forces: Based on the findings from a previous pilot study (Pearsall et al., 2007), no significant differences are expected between limb sides and across conditions.

\subsubsection{Ground Reaction Torque Hypotheses}

H10. Free vertical torque: It is expected that the free vertical torque not vary significantly across limbs or conditions. The free vertical torque is the sum of the vertical torque along with two horizontal force couples (see equation 3.6), of which the only term expected to change is the medio-lateral GRF component. Since the magnitude of this component is small in comparison to the others this change is not expected to significantly alter the free vertical torque.

\subsubsection{Joint Kinematic Hypotheses}

H11. Sagittal Plane Kinematics: Asymmetrical changes are expected between limbs in the sagittal plane. Based on previous work (Nicoloaou et al., 2002), the US-limb is expected to show increased flexion of all joints. Conversely it is expected that the DS-limb will demonstrate generally less flexion throughout the gait cycle.

H12. Frontal Plane Kinematics: The majority of changes are expected in the frontal plane. Generally, it is believed that the body will shift the body center of mass (BCOM) towards the US-side in an attempt to control DS-slippage. Beginning with the ankles, it is expected that the cross slope will force the DSlimb into a greater Eve while the US-limb will be generally more Inv. No changes are expected at the knees as angular motion is expected to be limited in the frontal plane. The hips are expected to show large differences with the 
DS-hip increasing Abd while the US-hip increases Add on the cross-slope condition.

H13. Transverse Plane Kinematics: Beginning with the ankles, the large Inv of the DS-limb should increase IRot while the US-limb's Eve should increase ERot based on the action of the subtalar joint. Knee rotation is also expected to change on the cross-slope condition. The coupling of the shank and foot will cause increased IRot of the DS-knee and increased ERot of the US-Knee on the cross-slope condition. (Rose and Gamble, 2006). The hips are also expected to follow the same pattern as the knee.

\subsubsection{Joint Forces Hypotheses}

H14. Antero-posterior Joint Force: In keeping with the previous GRF hypotheses (H7), no differences are expected as this force greatly depends on the anteroposterior GRF.

H15. Medio-Lateral Joint Forces: In keeping with the previous GRF hypotheses (H8), large differences are expected at all joints. To balance the medio-lateral GRF, the US-joints are expected to report larger lateral forces whereas the DSjoints will show greater medial force during the cross-slope condition.

H16. Vertical Joint Forces: In keeping with the previous GRF hypotheses (H9), no differences are expected as this force greatly depends on the vertical GRF.

\subsubsection{Joint Moment Hypotheses}

H17. Sagittal Plane Joint Moments: Based on the previous kinematic hypotheses (H11), it is expected that the overly extended DS-limb will produce decreased Ext moments while the overly-flexed US-limb will produce increased Flx moments. 
H18. Frontal Plane Joint Moments: Based on the previous kinematic hypotheses (H12), it is expected that changes will occur at the ankles and hips. The DSankle is expected to sustain an Inv moment while the US-ankle produces an Eve moment to conform to the walking surface. No changes are expected at the knees as minimal rotation occurs at that joint in the frontal plane. The DS-hip will produce an Abd moment while the US-hip produces an Add moment to help lean the body towards the US-side.

H19. Transverse plane Joint Moments: In keeping with the kinematic hypotheses (H13), it is expected that the all three joints produce an IRot moment on the DS-limb and an ERot moment on the US-limb.

\subsection{Limitations}

Limitations of this study include:

1. Short capture area: As a consequence of low camera count $(n=6)$, the number of strides collectable at a high resolution was limited. Temporo-spatial quantities calculated from a short number of strides may not be representative of a subject's more general patterns.

2. Choice of two conditions $\left(0^{\circ}\right.$ and $\left.6^{\circ}\right)$ makes it impossible to predict effects of smaller or greater cross slopes on gait dynamics.

\subsection{Delimitations}

Delimitations of the study include:

1. Subjects walked with right limb as US-limb, regardless of dominant leg side. Asymmetries already present may thus be magnified on the cross-slope.

2. Subjects were all young healthy males.

\subsection{Independent (IV) \& Dependent (DV) Variables}


The variables are classified as independent and dependent with definitions and type summarized below (Table 8). The outcome measures were evaluated at typical events (for example, ESt, MSt) throughout the gait cycle.

Table 8 - Summary of variables included in data analysis

\begin{tabular}{|c|c|c|c|}
\hline \multicolumn{2}{|c|}{ Variables } & \multirow[t]{2}{*}{ Definition } & \multirow[t]{2}{*}{ Scale } \\
\hline Independent & Dependent & & \\
\hline Condition (2) & & $\begin{array}{l}\text { Inclination of walking surface: } \\
\text { 1. } 0^{\circ} \\
2.6^{\circ}\end{array}$ & $\begin{array}{l}\text { Categorical } \\
\text { (dichotomous) }\end{array}$ \\
\hline \multirow[t]{8}{*}{ Body side (2) } & & $\begin{array}{l}\text { Describing relative height of each limb: } \\
\text { 1. DS-limb } \\
\text { 2. US-limb }\end{array}$ & $\begin{array}{l}\text { Categorical } \\
\text { (dichotomous) }\end{array}$ \\
\hline & Spatio-Temporal (3) & $\begin{array}{l}\text { Linear displacement of lower-limbs: } \\
\text { 1. Step Length } \\
\text { 2. Stride Length } \\
\text { 3. Step Width }\end{array}$ & Continuous \\
\hline & Kinematics (18) & $\begin{array}{l}\text { Angular displacement of each joint: } \\
\begin{array}{lll}\text { 1. Ankle } & \text { (US, DS) } \\
\text { 2. knee } & \text { (US, DS) } \\
\text { 3. } & \text { Hip } & \text { (US, DS) }\end{array}\end{array}$ & Continuous \\
\hline & Centre of Pressure (3) & $\begin{array}{l}\text { Linear displacement of stance foot: } \\
\text { 1. Antero-posterior ROM } \\
\text { 2. Medio-lateral ROM } \\
\text { 3. Medio-lateral absolute position }\end{array}$ & Continuous \\
\hline & Time (1) & $\begin{array}{l}\text { Unit of time } \\
\text { 1. Stance Time }\end{array}$ & Continuous \\
\hline & Kinetics (4) & $\begin{array}{l}\text { Ground Reaction Forces: } \\
\text { 1. Vertical } \\
\text { 2. Medio-lateral } \\
\text { 3. Antero-posterior } \\
\text { Ground Reaction Moments: } \\
\text { 1. Free Vertical Moment }\end{array}$ & Continuous \\
\hline & Joint Forces (18) & 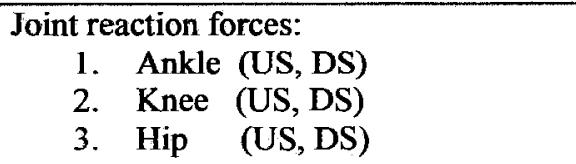 & Continuous \\
\hline & Joint moments (18) & 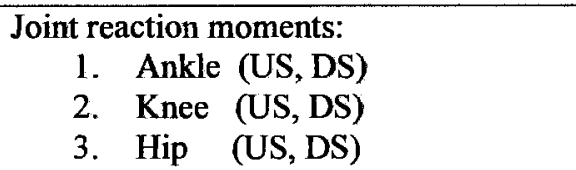 & Continuous \\
\hline
\end{tabular}




\subsection{Statistical Methods and Assumptions}

\subsubsection{Sample Size}

Based on Pearsall et al., (2007), a previous pilot study investigating the effect of cross slope on GRF during walking, a sample size of $n=7$ was sufficient to obtain significant differences between the flat $\left(0^{\circ}\right)$ and cross-slope $\left(6^{\circ}\right)$ condition for the medio-lateral ground reaction forces. In the cross slope condition, the DS-limb experienced mediolateral GRF that were three times greater than that of the flat condition. Based on these findings, it is probable that significantly different findings will be found for all expected outcome measures for the ankle, knee, and hip using a sample size of $n=10$.

\subsubsection{Statistical Methods}

Comparisons of temporo-spatial parameters were made across conditions only and were analyzed using a within subject one-way analysis of variance (ANOVA) for repeated measures with a single factor (condition) having two-levels (Flat and Cross). Significance was set at $\alpha=0.05$ for rejection of the null hypothesis. Analysis of all other outcome measures were made between the level and cross-slope conditions as well as between the DS and US-sides. This was achieved using a within subject analysis of variance $(2 \mathrm{X} 2$ ANOVA) for repeated measures with two factors: condition, having two levels (flat and cross-slope); and side also having two levels (US and DS). Significance level was set at $\alpha=0.05$. Main and interaction effects were computed for each factor, although only the interaction of condition and side was of interest in light of the research questions at hand. 
Post-hoc multiple comparisons among all permutations of the two factors (DS-cross, DSflat, US-cross, US-flat) were conducted via pairwise t-tests only for cases in which significant interaction between the two factors was achieved. This is a rather conservative approach as the post-hoc multiple comparison tests are independent of the overall F-value (Wilcox, 1987). Howell (2002) has suggested this conservative approach be used simply in accordance with general practice within the research community. The p-values resulting from the pairwise t-tests were then corrected using a Bonferroni adjustment, i.e. multiplying the raw p-values by the number of post-hoc comparisons (6).

\subsubsection{Statistical Assumptions}

Normality was assessed using visual inspection of the quantile-quantile plots. All dependent variables were found to not show severe deviations from normality. Sphericity was assessed using Mauchley's test of sphericity. All dependent variables were found not to violate the assumption of sphericity. In fact the design of this experiment cannot lead to any sphericity violations as the covariance matrix of a $2 \times 2$ design constrains the variances to be equal. Skewness was not considered for the post-hoc t-tests as it is not an underlying assumption of paired t-test. 


\section{CHAPTER 2 - REVIEW OF LITERATURE}

\subsection{Human Locomotion}

Human walking has been extensively studied in the past. Even before the advent of computers early scientists such as Giovanni Borelli (1608-1679), Willhelm Weber (18041891), Eduard Weber (1806-1871) and Eadweard Muybridge (1830-1904) made significant contributions towards the understanding of walking (Baker, 2007). In the early $20^{\text {th }}$ century, foundational papers associated with Verne T. Inman (1905-1980) and others

lead to six hypotheses explaining gait known as the "determinants of gait" (Rose and Gamble, 2006). Although some of these so-called determinants have been refuted (Rose and Gamble, 2006), the authors' work is recognized as being paramount to the foundations of gait analysis.

With modern computers and advanced motion capture technology, gait analysis has progressed dramatically from the 1980 s onwards. Work by internationally renowned authors such as D.A. Winter, M.W. Whittle, C.L. Vaughan, S. Ounpuu, P. De Leva, T.P. Andriacchi and many others have lead to a clear understanding of the characteristics of level walking.

Today, much gait research focuses on the study of walking as it deviates from the ideal level walking condition. Perturbations such as slopes (Lay et al., 2006; McIntosh et al., 2006), stairs (Beaulieu et al., 2007; Protopapadaki et al., 2007), obstacles (Lu et al., 
2006; McLellan and Patla, 2006), slippery surfaces (Fong et al., 2005; Lockhart et al., 2007), limited sensory input (McFadyen et al., 2007) and locomotion of special populations (Monaghan et al., 2006; Chaudhari et al., 2008; Goujon-Pillet et al., 2008) are of great interest within the gait analysis community. From the biomechanics perspective parameters commonly analysed include GRF, body segment parameters (BSP), joint kinematics and the estimation of JRF and JRM by means of IDA.

\subsection{Ground Reaction Forces During Level Walking}

GRF act on the body during walking. Each component of the GRF acts to control and stabilize the movement of both the upper and lower body during gait (Cavagna et al., 1977). A force plate capable of recording the GRF is thus of great importance in understanding human locomotion and is essential to conduct a complete IDA using the standard method described in several biomechanics texts (Vaughan et al., 1999; Winter, 2005). Below is a review of the expected behavior of the GRF during level walking based mainly on the Rose and Gamble text (2006).

The GRF vector has three components: the vertical, anterior-posterior, and the mediallateral force. The vertical GRF is the largest component and reaches magnitudes greater than body weight during St (Chao et al., 1983; Ounpuu, 1994; Winter, 2005; Rose and Gamble, 2006). The vertical GRF increases steadily in ESt starting from $0 \mathrm{~N}$ the instant before HS and equaling body weight at the end of the loading phase. During single limb support, vertical GRF increases and reaches a local maximum $\left(\operatorname{MaxF}_{\mathrm{z}} 1\right)$ as the body centre of mass $(\mathrm{BCOM})$ accelerates upwards. A local minimum $\left(\mathrm{MinF}_{\mathrm{z}}\right)$ occurs during 
contralateral toe-off (CTO) at which point the BCOM has reached its highest elevation and begins its descent. A second local maximum $\left(\mathrm{MaxF}_{\mathrm{z}} 2\right)$ occurs as the stance limb controls the downward acceleration of the BCOM and prepares the body for contralateral HS. Finally, the vertical GRF then falls back to $0 \mathrm{~N}$ as the stance foot leaves the ground. The anterior-posterior GRF helps control slippage of the stance limb mainly near HS and TO. At HS, it must provide a posterior force to avoid anterior slippage of the foot. Similarly at TO, an anterior GRF must be provided to avoid backwards slippage and help propel the body in an anterior direction. A continuous medial GRF occurs during St. Near HS, the medial GRF controls the lateral movement of the BCOM; while towards TO, it avoids lateral slippage of the stance limb and provides a lateral force to launch the BCOM towards the contralateral side.

\subsection{Ground Reaction Torques During Level Walking}

Moments or torques occur when a force induces rotation in an object. A torque can be created directly or as a result of a force or force couple acting at a distance from a given point of rotation. Formally, the torque $\tau$ produced by a force $F$ at a distance $r$ from the centre of rotation of an object is defined as the cross product of vectors $r$ and $F$. (Halliday et al., 1993):

$$
\tau=r \times F
$$

During walking, the stance limb applies a vertical torque directly to the ground. Starting at HS, the ERot foot is resisted by ground friction causing an internally rotating vertical 
GRF. Towards the end of double support and the start of single limb support, the foot begins relative IRot resisted by an externally rotating torque. During single limb support, the advancing swing limb causes the stance foot into ERot. An internally rotating torque then increases throughout most of the single support phase reaching a maximum at its latter portion. Towards the end of St, the torque steadily diminishes allowing the stance limb to ERot unconstrained (Rose and Gamble, 2006).

\subsection{Kinematics of Level Walking}

Kinematics is a field of mechanics that deals with the description of motion in terms of linear and angular displacement, velocity and acceleration through space. The implicit knowledge of the forces guiding these motions is not needed in kinematics (Rose and Gamble, 2006). Many investigators (Apkarian, 1989; Ounpuu, 1994; Winter et al.,1994; Rose and Gamble, 2006) have studied level walking kinematics and the intra-subject repeatability of the results has been shown (Kadaba et al., 1989). Conclusions from these studies are summarized below for each plane and each joint.

Throughout the gait cycle the hip, knee and ankle joints must alter their position in an attempt to smooth the walking progression and reduce energetic demands on the body. These movements do not occur in isolation, each joint functions in interdependence as part of a complete locomotor system. Joint motion is controlled by both external and internal forces. A complete description of each joint's motion in all three planes, without regard to the forces that caused them, will be described below. 


\subsubsection{Sagittal Plane}

Sagittal plane kinematics have been the most extensively studied, as motions are relatively large and are easily computable. Characteristic and repeatable angular movements occur at ankle, knee, and hip joints.

\subsubsection{Ankle}

In the sagittal plane, the ankle begins the St in a relatively neutral position, but quickly goes into PF as the foot makes ground contact. DF begins as the BCOM passes over the stance limb reaching a maximum towards the end of St before heel rise. Beginning at heel rise, the ankle DF angle decreases bringing the ankle into maximum PF at TO. In Sw, PF decreases reaching a slight DF to a near neutral position to prepare for HS.

\subsubsection{Knee}

Two flexion peaks characterize knee Flx/Ext angles during gait. The first and largest peak occurs during St absorbing loading impact. Ext then begins reaching a maximum at TO. During Sw, knee Flx begins allowing foot clearance resulting in a second, larger, Flx peak. The knee completes the cycle by going into Ext in preparation for HS.

\subsubsection{Hip}

Hip motion in the sagittal plane follows a near sinusoidal motion. At HS, the stance limb is in full Flx and begins Ext as the BCOM moves anteriorly over the stance limb reaching maximal Ext at the end of St. Beginning in TSt and continuing throughout Sw, the hip begins Flx to move the swing limb forward. 


\subsubsection{Frontal Plane}

Frontal plane joint angles, although much smaller than the sagittal plane angles, reveal important information about the characteristics of the lower-limbs during walking. Relatively, greater inter-subject variability exists.

\subsubsection{Ankle}

Beginning at HS in slight Inv, ground contact quickly forces the ankle into Eve during the loading phase. Towards the end of St as the ankle begins PF in the sagittal plane, the joint also begins Inv reaching a maximum at TO. During Sw, the ankle reduces its Inv in anticipation of the next HS.

\subsubsection{Knee}

The knee remains in a relatively neutral angle during loading but then begins Abd as TO nears. Abd increases in ESw and then decreases to a near neutral angle at the end of Sw.

\subsubsection{Hip}

The hip begins the St phase in a neutral position. The hip then begins Add during weight acceptance as the BCOM shifts laterally over the stance limb. At the end of loading the BCOM begins to shift towards the contralateral limb in preparation for HS causing a decrease in Add angle. Near TO, the hip enters Abd and then during Sw begins Add until it returns to its neutral position in preparation for HS. 


\subsubsection{Transverse Plane}

Relatively small motions occur in the transverse plane. These motions are important as they can help explain torsional forces occurring in the body during walking.

\subsubsection{Ankle}

The ankle begins in slight IRot and quickly becomes ERot during loading. Afterwards, the ankle begins IRot reaching a maximum near TO. During Sw, the ankle remains in slight IRot, but oscillates slightly before it prepares for HS. The transverse motion described here follows the Grood and Suntay (1983) method and as such relates the relative motion of the foot with the respect to the shank. The foot progression angle described in certain texts (Rose and Gamble, 2006) relates the motion of the foot with respect to the line of progression during walking showing ankle ERot throughout.

\subsubsection{Knee}

In general there is very little motion in the transverse plane for the knee as it remains in slight IRot throughout most of St and Sw. However, near HS (in preparation for and shortly afterwards) the knee remains in ERot.

\subsubsection{Hip}

The hip remains in ERot throughout the gait cycle reaching a maximum during MSw and a minimum near HS. 


\subsection{Joint Reaction Forces During Level Walking}

JRF can be determined directly using telemetric devices implanted in vivo or using mathematical models such as IDA (Komistek et al., 2005). Telemetric methods are usually reserved for studies using prosthetic device. In this study, mathematical methods are used to determine JRF. Expected JRF during level walking have been presented by Vaughan et al. (1999). JRF at the ankle, knee, and hip, as determined via the NewtonEuler equations (section 2.11), are very similar in shape to the GRF previously described.

\subsection{Joint Reaction Moments During Level Walking}

Expected JRM may be viewed in Eng and Winter (1995). Characteristic curves for the ankle, knee, and hip in all three dimensions are summarized below. From IDA, typically, forces are calculated from the distal (ankle) to proximal (hip) joints.

\subsubsection{Sagittal Plane}

Sagittal plane moments are generally larger than in other planes and play an important role in allowing forward progression during walking.

\subsubsection{Ankle}

At the ankle, a DF moment is seen shortly after HS as plantarflexors eccentrically control the descent of the foot. As foot flat is achieved towards MSt, a PF moment controls the forward progression of the stance limb over the foot. In TSt, the PF moment finally overcomes ankle DF and generates a large power output to initiate TO and begin the Sw. 


\subsubsection{Knee}

At the knee, a TSw knee Flx moment prepares the stance limb to absorb loading impact. Knee Flx is then controlled eccentrically by knee extensors resulting in an Ext moment phase during loading. In MSt, a Flx moment is produced in preparation for CTO. In TSt and beginning of PSW, knee extensors eccentrically contract to control knee Flx ending in a maximal knee Ext moment before TO.

\subsubsection{Hip}

At the hip, large Ext moments during loading act to stabilize the trunk and avoid collapse of the stance limb. The hip extensors concentrically contract to raise the BCOM. During TSt and PSw, a Flx moment decelerates the rapidly extending hip. At the end of PSw, the hip flexors generate power to advance the swing limb and help in foot-clearance.

\subsubsection{Frontal Plane}

\subsubsection{Ankle}

At the ankle, an Eve moment after HS controls the Inv of the ankle during weight acceptance. Ankle frontal plane moments were highly variable as small errors in COP could easily reverse the direction of the moments. Furthermore, anatomical differences between subjects could produce these different gait strategies (Eng and Winter, 1995).

\subsubsection{Knee}

At the knee, St Abd moments overcome the Add moment produced by the medial oriented BCOM. It is noted that this moment is not provided by muscular activity, but by passive structures of the knee (Winter, 2005). 


\subsubsection{Hip}

At the hip, St Abd moments once again overcome the Add moments produced by the medially oriented BCOM. Functionally, the hip controls excessive dropping of the contralateral pelvis during St.

\subsubsection{Transverse Plane}

\subsubsection{Ankle}

At the ankle, ERot moments are seen throughout St, first as the swing limb advances and then as TO of the stance limb begins.

\subsubsection{Knee}

At the knee, an ERot moment is seen during loading as the pelvis rotates towards the stance limb. During TSt, an IRot moment is produced as the pelvis begins to rotate in the opposite direction in preparation for Sw.

\subsubsection{Hip}

At the hip, external rotators decelerate the forward rotation of the contralateral pelvis producing an ERot moment. During TSt and PSw, an IRot moment occurs in preparation for Sw. 


\subsection{Kinematics of Cross-Slope Walking}

The kinematics of cross-slope walking have not been studied by many authors in the past (DeGarie et al., 2000; Nicolaou et al., 2002). DeGarie et al. examined cross-slope walking using an electromagnetic real time motion analysis system (Ultratrak® Polhemus Inc, Burlington, VT, USA) sampling at $120 \mathrm{~Hz}$. Using a small sample size $(\mathrm{n}=3)$, the study revealed significant asymmetries between US and DS-limb using cross-slopes of $20 \%$ $\left(11.3^{\circ}\right)$ and $40 \%\left(21.8^{\circ}\right)$. It was seen that for the $20 \%$ slope, the DS-knee had greater ROM during St and TO compared to the US-knee; whereas during Sw the US-knee showed greater ROM as compared to the DS-knee. On the $40 \%$ slope, Flx was greater for the US-knee throughout the gait cycle. This study concluded that asymmetrical changes at the knee were produced during the cross-slope walking condition.

Nicolaou et al. (2002) measured gait adaptations of the lower body on cross-slopes of 5\% $\left(2.9^{\circ}\right)$ and $10 \%\left(5.7^{\circ}\right)$ also using the Ultratrak ${ }^{\circledR}$ system. Data from five subjects $(\mathrm{n}=5)$ were collected at $60 \mathrm{~Hz}$ and filtered using a low pass filter with a cutoff frequency of 12 Hz. They reported trends of increasing DF of US-ankle and increasing PF of the DSankle over the entire gait cycle on the $5 \%$ and $10 \%$ slope condition. Differences between conditions were only found to be significant during loading and MSt. Knee kinematics revealed an increase in Flx of US-knee on the 10\% slope. Greater Ext was seen to be significant for both slope conditions for the DS-knee. Hip kinematics revealed differences in both the sagittal and frontal planes. In the sagittal plane, the DS-hip exhibited greater Ext under both slope conditions. In the frontal plane, the US-hip presented greater Add on the $10 \%$ slope during each phase of gait cycle measured, whereas significance was only 
found during the loading response for the 5\% slope. The DS-hip showed greater Abd under both slopes throughout loading and MSt. Temporo-spatial parameters were also examined. A trend of decreasing stride width was found to exist, however only the $10 \%$ grade showed a significantly smaller stride width. No other temporo-spatial parameters showed significant changes under the cross-slope condition. Nicolaou et al. concluded that the kinematic changes observed result from a cross-slope induced leg length discrepancy (LLD), where the DS-limb is functionally lengthened while the US-limb is shortened.

\section{$2.8 \quad$ Kinematics of Cross-Slope Running}

Gehlsen et al. (1988) studied the effects of cross slopes $\left(-10^{\circ},-5^{\circ}, 0^{\circ}, 5^{\circ}, 10^{\circ}\right)$ on knee kinematics while running on a treadmill using young male and female subjects $(\mathrm{n}=15)$. Triaxial electrogoniometers measured DS and US-knee ROM in all three planes. Many significant differences were found. In the sagittal plane, the US-limb had greater mean ROM than the DS-knee on the $10^{\circ}$ cross-slope during Sw. During St, the US-knee mean ROM was less than that of the DS-knee. On the $10^{\circ}$ cross-slope, both US and DS-knees had smaller mean ROM than during the flat condition throughout the gait cycle. In the transverse plane, the US-knee mean ROM was greater than the DS-knee ROM for the $5^{\circ}$ and $10^{\circ}$ condition during Sw. During St, the DS-knee mean ROM was greater than the US-knee for the $10^{\circ}$ cross-slope. In the frontal plane, the US-knee had greater mean ROM than the DS-knee during Sw for the $10^{\circ}$ cross slope. During St, the US-knee mean ROM was smaller than the DS-knee for the $10^{\circ}$ cross slope. The findings above lead the authors to conclude that knee kinematics are significantly altered during cross-slope running. 
Runners reduce the US-limb step length, increased knee Flx at HS and reduce knee Ext at TO to maintain a vertical upper body position.

Fujii (1999) studied lower limb kinematics during slow jogging on cross-slope surfaces inclined at $15 \%\left(8.5^{\circ}\right)(\mathrm{n}=3)$. Consistent with results from walking studies presented above, it was found that the DS-knee showed a greater amount of Ext as compared to USknee. However, contrary to the walking studies reviewed, US-ankle showed greater PF. Fujii concluded that the US and DS-limbs' asymmetrical kinematic changes are due to their differing roles in controlling the vertical movement of the BCOM.

Finally, Sussman et al., (2001) studied cross-slope running at $6 \mathrm{mph}(9.7 \mathrm{~km} / \mathrm{h})$ and 7 $\mathrm{mph}(11.3 \mathrm{~km} / \mathrm{h})$ on a treadmill inclined at $2.5^{\circ}$ and $5^{\circ}$ using recreational runners $(\mathrm{n}=5)$. They reported asymmetrical responses across limbs with increased knee Flx at HS and TO for the US-limb. Moreover, increased knee Ext for the DS-limb under all slope and velocity combinations were also found.

\section{$2.9 \quad$ Kinematics of Incline Walking}

Incline walking studies have shown that there are changes in kinematic patterns between level and incline walking. McIntosh et al. (2006) investigated walking dynamics on inclined and declined surfaces $\left(0^{\circ}, \pm 5^{\circ}, \pm 8^{\circ} \pm 10^{\circ}\right)$ using a Vicon ${ }^{\mathrm{TM}}$ (system 370 , Oxford Metrics, Oxford, UK) $(\mathrm{n}=9)$. Marker coordinates, force plate and EMG data were collected. Marker data were collected at $50 \mathrm{~Hz}$ and force plate data at $1000 \mathrm{~Hz}$. Data were analyzed using Vicon clinical manager (Oxford Metrics, version 1.34). 
Trends of decreasing cadence with increasing angle (from $-10^{\circ}$ to $10^{\circ}$ ) were found, though significance was only found from $-10^{\circ}$ to $0^{\circ}$. Stride length decreased as decline angle decreased from $-10^{\circ}$ to $0^{\circ}$. Walking speed increased as incline angle increased from $0^{\circ}$ to $10^{\circ}$.

The authors also reported several differences for lower limb kinematics. The ankle joint remained in greater DF during loading, became more $\mathrm{PF}$ in $\mathrm{TSt}$ and returned to greater $\mathrm{DF}$ during $\mathrm{Sw}$ as incline angle increased from $0^{\circ}$ to $10^{\circ}$. For increasing negative grades, PF decreased. Major adaptations were seen at the knee. Maximum knee Flx at HS and during loading were seen to increase with increasing positive grade, but remained similar for negative grades. However, maximum knee Flx in Sw was seen to increase with increasing negative slope. At the hip, sagittal differences were only seen at HS. It was found that hip Flx increased from $25^{\circ}$ to $58^{\circ}$ as grade increased from $-10^{\circ}$ to $10^{\circ}$. Finally at the pelvis it was seen that anterior pelvic tilt increased from $8^{\circ}$ to $13^{\circ}$ as incline angle increased from $0^{\circ}$ to $10^{\circ}$, however frontal and transverse pelvic kinematics remained similar under all conditions. The perturbation of grade impacted both the temporo-spatial and kinematics of walking.

\subsection{Kinetics of Incline Walking}

In the same study by McIntosh et al. (2006), GRF data and lower-limb kinetics were also reported. Beginning with the GRF data, the first peak of vertical GRF was seen to increase as grade increased from $-8^{\circ}$ to $-10^{\circ}$ and from $8^{\circ}$ to $10^{\circ}$. The second peak of 
vertical GRF increased significantly only between the $5^{\circ}$ and $8^{\circ}$ incline. Antero-posterior GRF increases between $0^{\circ}$ and $\pm 5^{\circ}$ grades.

The JRM also showed many differences. Ankle sagittal plane moments showed different kinetic patterns for different slope conditions. Positive inclines, including $0^{\circ}$ showed a single peak in PF moment towards TSt, whereas declines revealed a binary peak pattern with a first peak during MSt and another towards TSt. Ankle moment were significantly different across all inclines. Knee Flx moment at HS increased as decline angle increased, knee Ext moment during loading increased with increasing positive slope. Hip Abd moments were generally found to be significantly decreased on the $\pm 10^{\circ}$ conditions. Peak hip Flx and Ext moments were found to be greater for the uphill conditions as compared to flat and downhill. The perturbation of grade greatly changed both the GRF patterns and the JRM during walking.

\subsection{Inverse Dynamics}

\subsubsection{The Inverse Dynamic Approach}

There are a number of possible methods to be used in determining joint kinetics (forces and moments). The most direct way of measuring these quantities is to surgically implant transducers into a muscle or tendon (Winter, 2005). This invasive method poses ethical concerns and is generally not used to measure walking kinetics in healthy humans. Alternately, it is also possible to use forward dynamic methods to indirectly solve joint dynamic problems. However, forward dynamic solutions tend to be difficult to implement 
due to the large number of constraints that must be taken into account (Winter, 2005). IDA methods are frequently used in gait analysis (Apkarian et al., 1989; Davis III et al., 1991; Eng and Winter, 1995; McIntosh et al., 2006) when anthropometric, kinematic and force plate data are available. An advantage of the IDA solutions over the forward solutions is that the IDA computations for each frame of data are independent of the next (Huiskes and Mow, 2005). A survey of the literature reveals four main methods of IDA: vector and Euler angles, homogeneous matrices, wrenches and quaternions, and generalized coordinates (Dumas and Chèze, 2007). This study uses an approach based on vectors and Euler angles and the Newton-Euler equations of motion as outlined by Vaughan et al. (1999). It must be kept in mind when comparing kinetic results derived from IDA methods, especially for the knee and hip, that the method used has a nonnegligible influence on the results (Dumas et al., 2007).

\subsubsection{Inverse Dynamic Assumptions}

The following assumptions are made during the IDA process: All segments are assumed to act as rigid bodies with constant length and mass in which the distance between any two points, the center of mass location, and the moment of inertia in the body remain invariant. It is also assumed that all joints act as ball and socket joints. Movement of the rigid segments is governed by Newton's laws for both linear and angular displacement. Newton's second law in linear form states that the summation of external forces acting on a segment is equal to the rate of change of the linear momentum of the segment:

$$
\sum \vec{F}_{e x t}=\frac{d \vec{p}}{d t}
$$


The angular form of Newton's second law states that the summation of external moments acting on a segment about its center of gravity is equal to the rate of change of the angular momentum of the segment:

$$
\sum \vec{M}_{e x t}=\frac{d \vec{L}}{d t}
$$

Applying these laws to the segments can generate joint angular kinematics and kinetics. It is general practice to divide the lower-limbs into six rigid segments: left foot, right foot, left shank, right shank, left thigh and right thigh (Apkarian et al., 1989; Vaughan et al., 1999; Eng and Winter, 1995; Winter 2005).

\subsubsection{Required Quantities}

In order to solve the IDA problem using a standard Newtonian method, body segment parameters (length, mass and moment of inertia), linear kinematics (joint center position, COM position and acceleration, segment embedded axes coordinates), angular kinematics (segment angular velocity and acceleration and Euler angles) and force plate data (forces and moments at point of application) must be integrated into Newton's linear and angular laws described above (Vaughan et al., 1999).

\subsubsection{Sensitivity of the Inverse Dynamic Model}

As seen in section 2.11.3 various quantities must be calculated or estimated in order to solve the IDA problem. Uncertainties in these quantities impact the precision of the 
calculated JRF and JRM. This section will explore the effect of uncertainties in marker reconstruction, BSP, GRF point of application, and different coordinate systems.

\subsubsection{Digitization Errors}

A digitization error of a certain anatomical point only perturbs the segment in which it resides and does not propagate to other segments (Silva and Ambrosio, 2004). In addition, using the IDA methods in the current study, a digitizing error would only affect a single data point and would be smoothed out via the filtering process. However, it must be kept in mind that marker inaccuracies due to skin motion have non-negligible effect on segment angle computation (Riemer et al., 2007).

\subsubsection{Estimation of Body Segment Parameters}

There are many methods to determine BSP. The researcher is faced with the choice of directly measuring the BSP for each subject or to use pre-existing models. Direct measurement may involve using mass scanning techniques for each subject (Dumas et al., 2004; Ganley and Powers, 2004), though for simple gait analysis the potential harmful effects of exposing subjects to radiation usually outweighs the advantages of this approach. In choosing a pre-existing model, the researcher must make an appropriate

choice from the large selection found in the literature (Pearsall and Costigan, 1999). A simple geometric approach, in combination with regression equations, requiring segment circumference and lengths has been proposed by Vaughan (1999), but has not gained widespread use. In general, there are three main methods of estimating BSP: Cadaver estimates, based on work by Demspter (1955) and Chandler et al. (1975), geometric 
calculations based on (Hanavan, 1964) or mass scanning methods (Zatsiorsky et al., 1983). Importantly, these various methods have been shown to produce statistically different results in calculated joint kinetics (Rao et al., 2006), highlighting the importance of choosing an appropriate model. Of particular importance to this study, it was found that variations in BSP, though having a negligible effect on most kinetic outcome measures, could lead to differences of up to $1 \mathrm{~N} / \mathrm{kg}$ in hip proximal-distal force (Pearsall and Costigan, 1999). Particularly, Rao et al. recommend using the Zatsiorsky model (Zatsiorsky, 1983) for gait analysis of young healthy subjects. Within this study the Zatsiorsky model with adjustments suggested by De Leva (De Leva, 1996) were used.

\subsubsection{Centre of Pressure}

Errors or inaccuracies in determining the point of application (COP) of the GRF can severely impact the subsequent IDA solution. (Silva and Ambrosio, 2004). COP data were visually found to be extremely variable when the magnitude of the resultant GRF vector was small. Therefore, joint kinetics were only calculated for the interval in which the magnitude of the GRF vector was greater than $60 \mathrm{~N}$.

\subsubsection{Reference frames}

It addition the choice of coordinate system and reference frames used to express the joint kinetics must also be taken into account when comparing kinetic results from separate studies. Walking kinetic results expressed in a GCS have been shown to differ significantly from those expressed in a LCS (Liu and Lockhart, 2006; Schache et al., 2007). In a detailed study using three orthogonal and one non-orthogonal reference 
frame, it was found that JRM were significantly different based on reference frame use alone (Schache and Baker, 2007). As suggested by other authors (Gagnon et al., 2001; Schache and Baker, 2007) this current study uses the same non-orthogonal local joint reference frames to express both the joint kinetics and the joint kinematics. Using this method, the moment results represent torques about the axes of rotation of the joints and are thus more representative of the actual moments.

\subsubsection{Limitations of the Model}

It is important to note that IDA solutions can only yield net JRF and JRM, muscular cocontractions or friction within the joint cannot be separated from these values. Solving for the various forces present at the joint (bone, ligament and muscle force) is not possible as the problem presents more unknowns then there are possible equations (Vaughan et al., 1982; Komistek et al., 2005). However at low velocities, such as those present in walking, values obtained through IDA may differ by only a few percent with direct measurement techniques (Winter, 2005). 


\section{CHAPTER 3 - GROUND REACTION FORCES AND FREE VERTICAL TORQUE DURING LEVEL AND CROSS-SLOPE WALKING IN HEATHY INDIVIDUALS}

\subsection{Abstract}

Ground reaction forces (GRF) and moments (GRM) play a vital role in human locomotion, propelling the body forward while avoiding slippage on the walking surface. This investigation focused on the GRF and GRM exerted on the body while walking on a transversely tilted surface (cross-slope). The goal of this investigation was to quantify the GRF and GRM during flat $\left(0^{\circ}\right)$ and cross-slope $\left(6^{\circ}\right)$ walking. In addition centre of pressure (COP) data were also measured. Ten healthy young adult males performed flat and cross-slope walking at a self-selected walking pace. Two force plates within a walking platform measured forces and moments in all three dimensions. Data were analysed at representative gait events and it was found that there were significant differences in medio-lateral GRF between the two walking conditions. The medio-lateral GRF changed directions for the up-slope (US) limb and increased threefold for the downslope (DS) limb. In addition, the antero-posterior range of motion (ROM) of the COP of the DS-limb increased while on the cross-slope. No significant changes in GRM were measured during this investigation. This modest cross-slope walking condition induced important asymmetrical changes in the lower-limb GRF patterns and may well represent a substantial physical obstacle to populations with restricted mobility. 


\subsection{Introduction}

The underlying purpose of the study is to identify how cross-slopes affect gait. Crossslopes are a regular feature of our physical environment. In the urban setting, it is common practice to tilt sidewalks and roadways to permit water drainage. Canadian national guidelines recommend a cross-slope inclination of $0.5-2.3^{\circ}$ for that purpose (National Guide to Sustainable Municipal Infrastructure, 2004). Further, the Ontario Building Code recommends curb ramps, such as driveway entrances, to possess a slope between $5-7^{\circ}$ for motor vehicle passage (Ministry of Municipal Affairs and Housing, 2006). Nonetheless, for a pedestrian, sidewalks with intermittent ramps may impede gait and/or present an increased risk of falls. For young adults cross-slopes do not represent a significant challenge, however for elderly and special populations (visually impaired, amputees, wheelchair users, etc) the asymmetrical demands of cross-slope walking may introduce functional muscular-skeletal and balance barriers. In particular, this may precipitate falls, a major cause of injury in elderly populations (Lockhart et al., 2007) with incidences increasing with age (Campbell et al., 1981; Donald and Bulpitt 1999). In addition, the decreased joint flexibility (most notably at the ankles) and strength of older populations (Reeves, et al., 2007) may make cross-slope walking a difficult task to perform. Furthermore, a better understanding of GRF and GRM during non-level walking conditions could aid in the design of a variety of prostheses and walking aids.

GRF and GRM during walking, along with gravity, are the main external forces that drive the human locomotor system (Rose and Gamble, 2006). GRF during flat walking have been extensively studied in the past (Chao et al., 1983; Eng and Winter, 1995). GRF 
during slope walking (up and down inclines) has also received considerable attention (Leroux et al., 2002; Lay et al., 2006; McIntosh et al., 2006), but studies dealing with GRF on cross-sloped surfaces have been fewer (Pearsall et al., 2007). Pearsall et al.'s pilot study $(\mathrm{n}=3)$ demonstrated that medio-lateral forces between the flat and cross-slope condition were significantly different; however no change was seen in the anteroposterior or vertical forces. It was found that the main role of the GRF in cross-slope walking was to control and resist downward slippage of the limbs during the stance (St) phase. Previous studies of cross-slope walking exploring kinematics (DeGarie et al., 2000; Nicolaou et al., 2002) have found asymmetric responses between the DS and USlimbs. Further, a study involving foot pressure showed significant pressure redistributions on the cross-slope condition (Urrey, 2002). Based on these cross-slope studies, differences in GRF and GRM are expected.

The aim of this study was therefore to measure GRF and GRM as well as COP in relation to limb side and slope condition. The data reported in this study will be combined with kinematic data collected simultaneously and will be presented in a forthcoming study.

\subsection{Methods}

\subsubsection{Subjects}

A sample of ten young healthy adult males, with no history of gait abnormalities, were recruited among the McGill University student population. Excluded were any subjects with a leg length discrepancy (LLD) greater than $2.0 \mathrm{~cm}$. Leg length was measured as the distance between the greater trochanter and the lateral malleoli. This study was approved by the McGill University Research Ethics Board Office (Appendix 2) and all subjects 
signed a consent form before participating in this study (Appendix 1). Subjects wore nonobstructing clothing and walked barefoot along a wooden walkway. A summary of relevant anthropometric data is presented (Table 9).

Table 9 - Summary of Subject Anthropometrics $(n=10)$

\begin{tabular}{lcccccc} 
& $\begin{array}{c}\text { Age } \\
\text { (years) }\end{array}$ & $\begin{array}{c}\text { Height } \\
(\mathbf{c m})\end{array}$ & $\begin{array}{c}\text { Body mass } \\
(\mathbf{k g})\end{array}$ & $\begin{array}{c}\text { Right leg length } \\
(\mathbf{c m})\end{array}$ & $\begin{array}{c}\text { Left leg length } \\
(\mathbf{c m})\end{array}$ \\
\hline Mean & 22.6 & 181.7 & 76.8 & 96.0 & 95.8 \\
\hline S.D. & $(3.1)$ & $(6.5)$ & $(8.2)$ & $(3.8)$ & $(3.9)$ \\
\hline
\end{tabular}

\subsubsection{Description of Walkway and Coordinate System}

A walkway was used of length $6.91 \mathrm{~m}$ and width $1.21 \mathrm{~m}$ containing two force plates (AMTI $^{\mathrm{TM}}$, model 0R6-7-1000, Watertown, MA, USA) within its surface (Fig. 3). The force plates were positioned such that two consecutive steps during a stride were captured while each subject walked along the platform. Force plates were isolated from the platform's surface by means of small gaps $(0.5 \mathrm{~cm})$ and stabilized by several sub-platform braces within the walkway both when flat and inclined. To avoid slippage, seven parallel strips of tactile tape were placed along the direction of progression. Following conventions set by Vaughan et al. (1999), the Global Coordinate System (GCS) had its origin at the bottom right corner of the first force plate for both conditions. 


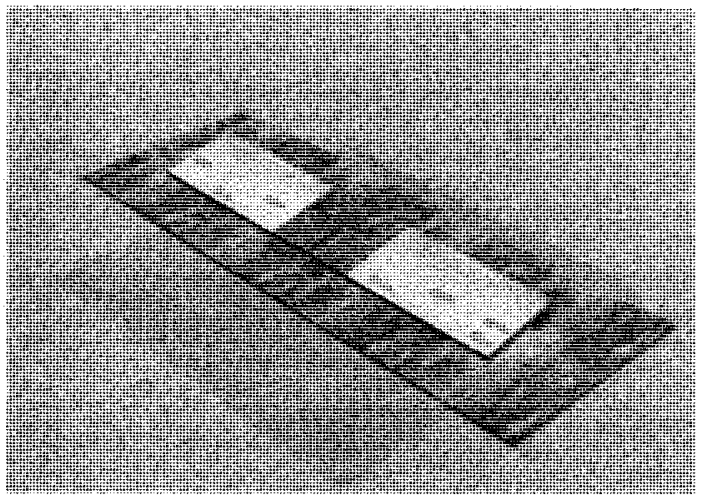

(a)

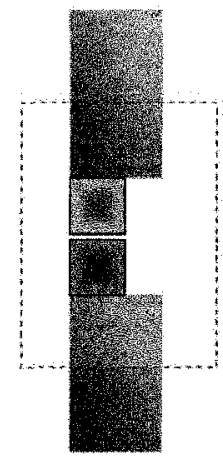

(b)

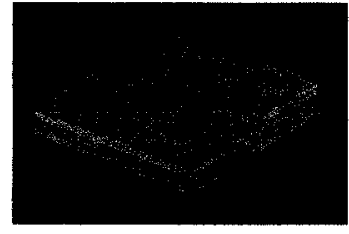

(c)

Figure 3 - Experimental Set-up: (a) Cross-slope tilted walking platform with embedded force plates. Footprints show direction of locomotion. (b) Top view of walking platform with dotted outline showing approximate capture area. (c) Coordinate system with origin in bottom right corner of force plate 1 . $x$-axis (red), y-axis (green), $\mathrm{z}$-axis (blue).

\subsubsection{Data Acquisition and Analysis}

After familiarization to both the flat and cross-slope walking conditions, subjects performed barefoot walking trials at their self-selected comfortable pace beginning with the flat condition. Trials were rejected if either foot did not land fully on the force plate during their respective step. In post-processing, five trials per condition for each subject were retained for analysis.

\subsubsection{Force Plate Data}

Force plate data were acquired at $960 \mathrm{~Hz}$ and filtered using a $4^{\text {th }}$ order low-pass Butterworth filter with a $20 \mathrm{~Hz}$ cut-off frequency. Three force and moment components measured about the centre of the force plate were synchronized with kinematic data to be used in a future study via Vicon ${ }^{\mathrm{TM}}$ (Vicon, Los Angeles, USA) software. COP and the free vertical torque were calculated from the force plate output (see sections 3.4.3.2 and 
3.4.3.3). Between heel strike (HS) and toe-off (TO), calculated as the first and last frame at which the magnitude of the GRF was nearest to $60 \mathrm{~N}, \mathrm{GRF}$ and GRM data were evaluated at three major events based on the typical vertical GRF force curve (Rose and Gamble, 2006) (Table 10) using custom MatLabß (v2006b, The Mathworks Inc., Natwick, MA, USA) routines. Additional events based on curve characteristics, as noted on the individual figures, were also evaluated for certain curves.

Table 10 - Representative gait cycle events used for data analysis with description and method of calculation.

\begin{tabular}{ll}
\hline Gait Cycle events & Description/Calculation \\
\hline Early Stance (ESt): & $\begin{array}{l}\text { Last contact of the contralateral foot with the ground during ipsilateral St } \\
\left.\text { phase, calculated as the first peak in vertical GRF (MaxF } \mathrm{M}_{\mathrm{z}}\right) .\end{array}$ \\
Midstance (MSt): & $\begin{array}{l}\text { The minimum vertical GRF value during single support } \\
\left(\mathrm{MinF}_{\mathrm{z}}\right) .\end{array}$ \\
Terminal Stance (TSt): & $\begin{array}{l}\text { The second peak in vertical GRF as single support ends and double support } \\
\text { begins }\left(\mathrm{MaxF}_{\mathrm{z}} 2\right) .\end{array}$ \\
\hline
\end{tabular}

\subsubsection{Centre of Pressure}

To calculate the COP during gait, the coordinates of the true centre of the force plate are required (Kwon, 1998). These coordinates were found within the force plate specification sheets available from the manufacturer. With respect to the current study, let $x_{0}, y_{0}, z_{0}$ represent the coordinates of the true centre and $x, y, z$ be the coordinates of the point of application of the GRF vector (COP). Using the variables defined above, the moment about the COP for the $\mathrm{x}$ and $\mathrm{y}$-axis can be defined as:

$$
M_{x}=\left(y-y_{o}\right) \times F_{z}-\left(z-z_{o}\right) \times F_{y}
$$




$$
M_{y}=-\left(x-x_{o}\right) \times F_{z}+\left(z-z_{o}\right) \times F_{x}
$$

As the z-coordinate of the COP is constant (always on the surface of the plate), we can allow $\mathrm{z}=0$ in (3.1) and (3.2). Solving (3.1) and (3.2) for $\mathrm{y}$ and $\mathrm{x}$ respectively yields the COP coordinates:

$$
\begin{aligned}
& y=\frac{M_{x}-z_{o} F_{y}}{F_{z}}+y_{o} \\
& x=-\left(\frac{M_{y}+z_{o} F_{x}}{F_{z}}\right)+x_{o}
\end{aligned}
$$

\subsubsection{Ground Reaction Moments}

The moment about the $\mathrm{z}$-axis $\left(\mathrm{M}_{\mathrm{z}}\right)$ measured by the force plate is referenced to the centre of the plate. It is the sum of the torques created by $F_{x}$ and $F_{y}$ acting at the COP and the torque applied by the stance foot also acting at the COP. Including this last quantity, called the free vertical torque $\left(T_{z}\right)$, the equation for $M_{z}$ becomes:

$$
M_{z}=\left(x-x_{o}\right) \times F_{y}-\left(y-y_{o}\right) \times F_{x}+T_{z}
$$

The free vertical torque is the torque of interest during walking as it is independent of foot placement on the force plate and represents the true torque applied by the stance limb. Substituting the coordinates of the COP found in (3.3) and (3.4) and solving for $T_{z}$ in (3.5) gives the following:

$$
T_{z}=M_{z}-\left(x-x_{o}\right) F_{y}+\left(y-y_{o}\right) F_{x}
$$




\subsubsection{Statistical Analysis}

Analysis of GRF and $T_{z}$ (at representative gait events) as well as COP coordinates and ROM values were conducted. Analysis of variance (2X2 ANOVA) were made between the flat and cross-slope conditions as well as between the DS and US-sides using a within subject design for repeated measures. Significance level was set at $\alpha=0.05$. Post-hoc multiple comparisons with a Bonferonni correction were conducted for cases in which significant interaction between condition and side was achieved. Significance level was set at $\alpha=0.05$ (after Bonferonni adjustment). SPSS ${ }^{\mathrm{TM}}$ (SPSS for Windows, version 15.0) was used for statistical analysis.

\subsection{Results}

\subsubsection{Centre of Pressure}

\subsubsection{Medio-Lateral COP}

The average COP coordinates are shown (Fig. 4). No significant differences were found between the positions of the medio-lateral coordinate of the COP at all events measured. In addition the total ROM from HS to TO in the medio-1ateral direction did not change across sides or conditions (Table 11).

Table 11 - Total medial-lateral COP ROM $(\mathrm{cm})$ values averaged across all trials and subjects for each side/condition permutation.

\begin{tabular}{|c|c|c|c|c|}
\hline $\mathrm{COP}_{\mathbf{y}}$ & $\begin{array}{l}\text { DS/ } \\
\text { Cross }\end{array}$ & $\begin{array}{l}\text { DS/ } \\
\text { Flat }\end{array}$ & $\begin{array}{l}\text { US/ } \\
\text { Cross }\end{array}$ & $\begin{array}{l}\text { US/ } \\
\text { Flat }\end{array}$ \\
\hline ROM & $\begin{array}{c}5.01 \\
(1.00)\end{array}$ & $\begin{array}{r}3.83 \\
(0.55)\end{array}$ & $\begin{array}{c}3.86 \\
(0.91)\end{array}$ & $\begin{array}{c}3.75 \\
(0.72)\end{array}$ \\
\hline
\end{tabular}

Group means and standard deviations (SD) 


\subsubsection{Antero-Posterior COP}

The total ROM from HS to TO in the antero-posterior direction of the COP (Fig. 4) showed significant differences across sides and conditions $(\mathrm{p}=0.008)$. For the flat condition, there were no significant differences between sides indicating symmetry between the limbs.

Post-hoc pairwise comparisons revealed differences between conditions for the DS-limb $(\mathrm{p}=0.040)$ with a mean $\mathrm{ROM}$ value $2.18 \mathrm{~cm}$ greater on the cross-slope than on the flat condition (Table 12). In addition the amount of time spent in St (calculated as the interval of time between HS and TO) was found not to differ across side and conditions $(\mathrm{p}=0.661)$. Not surprisingly all pairwise comparisons were also non-significant $(\mathrm{p}=$ 1.000).

Table 12 - Total antero-posterior COP ROM $(\mathrm{cm})$ values and time (s) averaged across all trials and subjects for each side/condition permutation. Associated p-values for each relevant pairwise comparison are also presented.

\begin{tabular}{|c|c|c|c|c|c|c|c|c|}
\hline $\mathrm{COP}_{\mathrm{x}}$ & $\begin{array}{l}\text { DS/ } \\
\text { Cross }\end{array}$ & $\begin{array}{l}\text { DS/ } \\
\text { Flat }\end{array}$ & $\begin{array}{l}\text { US/ } \\
\text { Cross }\end{array}$ & $\begin{array}{l}\text { US/ } \\
\text { Flat }\end{array}$ & $\begin{array}{c}\text { DS/ } \\
\text { Flat } \\
- \\
\text { US/ } \\
\text { Flat }\end{array}$ & $\begin{array}{c}\text { DS/ } \\
\text { Cross } \\
- \\
\text { DS/ } \\
\text { Flat }\end{array}$ & $\begin{array}{c}\text { DS/ } \\
\text { Cross } \\
- \\
\text { US/ } \\
\text { Cross }\end{array}$ & $\begin{array}{c}\text { US/ } \\
\text { Cross } \\
- \\
\text { US/ } \\
\text { Flat }\end{array}$ \\
\hline ROM & $\begin{array}{l}24.55 \\
(4.08)\end{array}$ & $\begin{array}{l}22.37 \\
(2.37)\end{array}$ & $\begin{array}{l}22.39 \\
(2.90)\end{array}$ & $\begin{array}{l}22.52 \\
(2.36)\end{array}$ & 1.000 & $0.040^{*}$ & 0.129 & 1.000 \\
\hline Time & $\begin{array}{c}0.64 \\
(0.03)\end{array}$ & $\begin{array}{c}0.65 \\
(0.04)\end{array}$ & $\begin{array}{c}0.65 \\
(0.03)\end{array}$ & $\begin{array}{c}0.66 \\
(0.03)\end{array}$ & 1.000 & 1.000 & 1.000 & 1.000 \\
\hline
\end{tabular}

Group means and standard deviations (SD)

* Indicates significant difference at $\alpha<0.05$ for the post-hoc Bonferonni analysis. 


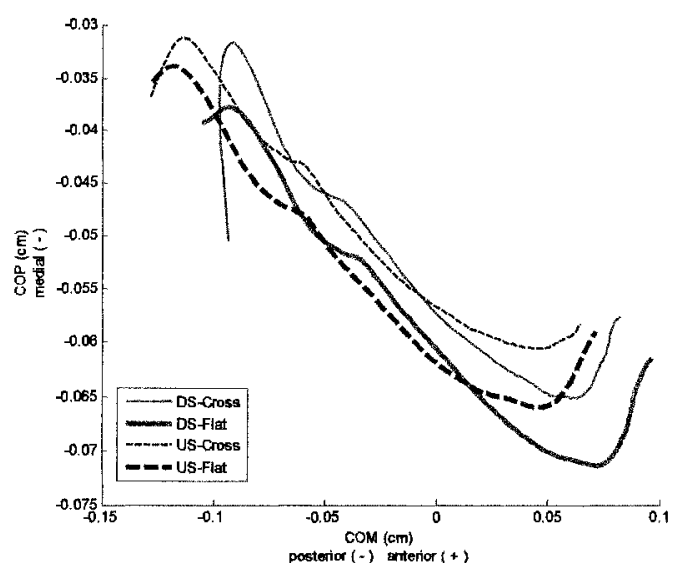

(a)

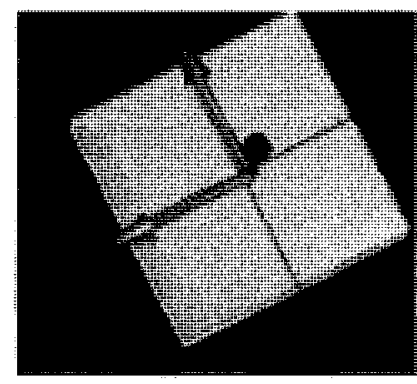

(b)

Figure 4 - (a) Average COP data for the US and DS-limbs under the flat and cross-slope conditions. Coordinates presented are referenced to the centre of the force plate. (b) Bird's eye view of force plate with force plate local coordinate system shown. Thus, a negative value for the $y$-axis (green) indicates foot placement to the right of the centre of the force plate. A negative $\mathrm{x}$-value (red) represents foot placement posterior to the centre of the force plate. Coordinate system for the DS-limb was reversed in the mediolateral direction for graphical representation and statistical analysis.

\subsubsection{Ground Reaction Forces}

\subsubsection{Antero-Posterior Force}

The antero-posterior forces (Fig. 5) did not differ significantly between the US and DS-

limbs across the flat and cross-slope conditions at all events studied.

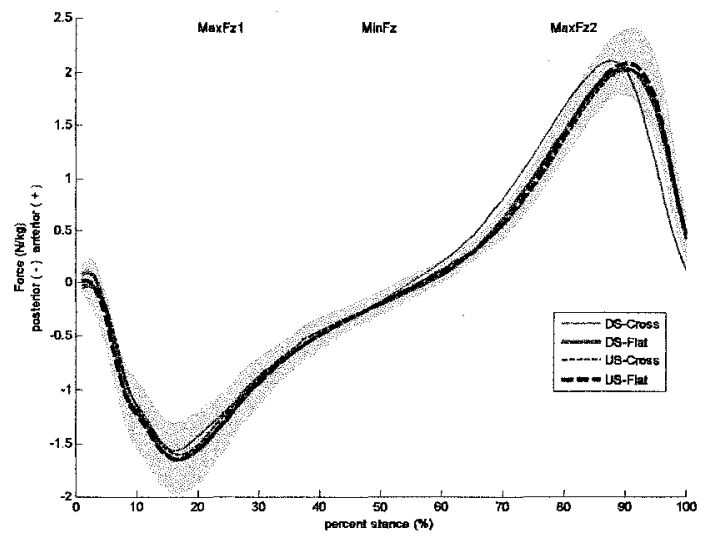

(a)

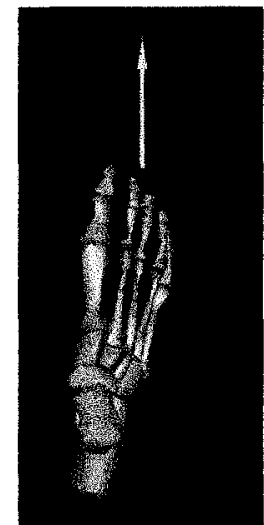

(b)

Figure 5 - (a) Antero-Posterior GRF (N/kg) averaged across all subjects and all trials for each side/condition permutation. Anterior (positive), Posterior (negative). Grey region is the standard deviation of the US-flat condition. (b) An anterior force vector. 


\subsubsection{Medio-lateral Force}

The greatest changes in GRF were in the medio-lateral direction (Fig. 6). The mediolateral force showed highly significant differences $(p<0.001)$ between sides and condition at all events under study. For the flat condition, there were no significant differences between sides at $\mathrm{MinF}_{\mathrm{z}}$ indicating symmetry between the limbs at this event.

However asymmetries between sides on the flat condition were seen at $\mathrm{MaxF}_{\mathrm{z}} 1$ and $\operatorname{MaxF}_{\mathrm{z}} 2(\mathrm{p}=0.027, \mathrm{p}=0.004$ respectively). These differences are very small as compared to those induced by the cross-slope. For $\operatorname{MaxF}_{\mathrm{z}} 1$, there is a $0.15 \mathrm{~N} / \mathrm{kg}$ differences between sides on the flat condition, but approximately $1.20 \mathrm{~N} / \mathrm{kg}$ difference across conditions.

Pairwise comparisons revealed highly significant differences $(p<0.001)$ across conditions for both limbs as well as across limbs for the cross-slope condition (Table 13). At $\mathrm{MinF}_{\mathrm{y}} 1$, the US-limb increased its lateral force $(-0.51 \mathrm{~N} / \mathrm{kg}$ to $-1.06 \mathrm{~N} / \mathrm{kg})$ while the DS-limb reduced its lateral force $(-0.46 \mathrm{~N} / \mathrm{kg}$ to $-0.11 \mathrm{~N} / \mathrm{kg})$ on the cross-slope. At $\operatorname{MaxF}_{\mathrm{z}} 1, \operatorname{MinF}_{\mathrm{z}}$, and $\mathrm{MaxF}_{\mathrm{z}} 2$ the US-limb experienced a change in the direction of force from a medial force $\left(0.27 \mathrm{~N} / \mathrm{kg}, 0.23 \mathrm{~N} / \mathrm{kg}\right.$ and $0.41 \mathrm{~N} / \mathrm{kg}$ for $\operatorname{MaxF}_{\mathrm{z}} 1, \operatorname{MinF}_{\mathrm{z}}$, and $\operatorname{MaxF}_{\mathrm{z}} 2$ respectively), to a lateral force $(-1.00 \mathrm{~N} / \mathrm{kg},-0.58 \mathrm{~N} / \mathrm{kg}$ and $-0.85 \mathrm{~N} / \mathrm{kg}$ for $\operatorname{MaxF}_{\mathrm{z}} 1, \mathrm{MinF}_{\mathrm{z}}$, and $\mathrm{MaxF}_{\mathrm{z}} 2$ respectively) for the cross-slope condition. The DS-limb maintained a medial force, but produced dramatically increased magnitudes (from 0.42 $\mathrm{N} / \mathrm{kg}$ to $1.54 \mathrm{~N} / \mathrm{kg}, 0.31 \mathrm{~N} / \mathrm{kg}$ to $1.07 \mathrm{~N} / \mathrm{kg}$ and from $0.57 \mathrm{~N} / \mathrm{kg}$ to $1.60 \mathrm{~N} / \mathrm{kg}$ at $\mathrm{MaxF}_{\mathrm{z}} 1$, $\operatorname{MinF}_{\mathrm{z}}$, and $\mathrm{MaxF}_{\mathrm{z}} 2$ respectively). 
Table 13 - Medio-lateral GRF (N/kg) evaluated at representative gait cycle events and averaged across all trials and subjects for each side/condition permutation. Associated p-values for each relevant pairwise comparison are also presented.

\begin{tabular}{|c|c|c|c|c|c|c|c|c|}
\hline$F_{y}$ & $\begin{array}{l}\text { DS/ } \\
\text { Cross }\end{array}$ & $\begin{array}{l}\text { DS/ } \\
\text { Flat }\end{array}$ & $\begin{array}{l}\text { US/ } \\
\text { Cross }\end{array}$ & $\begin{array}{l}\text { US/ } \\
\text { Flat }\end{array}$ & $\begin{array}{l}\text { DS/ } \\
\text { Flat } \\
- \\
\text { US/ } \\
\text { Flat }\end{array}$ & $\begin{array}{c}\text { DS/ } \\
\text { Cross } \\
- \\
\text { DS/ } \\
\text { Flat }\end{array}$ & $\begin{array}{c}\text { DS/ } \\
\text { Cross } \\
- \\
\text { US/ } \\
\text { Cross }\end{array}$ & $\begin{array}{c}\text { US/ } \\
\text { Cross } \\
- \\
\text { US/ } \\
\text { Flat }\end{array}$ \\
\hline $\operatorname{MinF}_{\mathbf{y}} 1$ & $\begin{array}{c}-0.11 \\
(0.11)\end{array}$ & $\begin{array}{l}-0.46 \\
(0.15)\end{array}$ & $\begin{array}{l}-1.06 \\
(0.26)\end{array}$ & $\begin{array}{l}-0.51 \\
(0.17)\end{array}$ & 1.000 & $<0.001 *$ & $<0.001^{*}$ & $<0.001$ * \\
\hline $\operatorname{MaxF}_{2} 1^{\dagger}$ & $\begin{array}{c}1.54 \\
(0.20)\end{array}$ & $\begin{array}{c}0.42 \\
(0.14)\end{array}$ & $\begin{array}{l}-1.00 \\
(0.29)\end{array}$ & $\begin{array}{c}0.27 \\
(0.09)\end{array}$ & $0.027^{*}$ & $<0.001^{*}$ & $<0.001^{*}$ & $<0.001$ * \\
\hline $\mathbf{M i n F}_{\mathbf{z}}$ & $\begin{array}{c}1.07 \\
(0.18)\end{array}$ & $\begin{array}{c}0.31 \\
(0.09)\end{array}$ & $\begin{array}{c}-0.58 \\
(0.14)\end{array}$ & $\begin{array}{c}0.23 \\
(0.05)\end{array}$ & 0.069 & $<0.001^{*}$ & $<0.001^{*}$ & $<0.001$ * \\
\hline $\operatorname{MaxF}_{z} 2^{+}$ & $\begin{array}{c}1.69 \\
(0.26)\end{array}$ & $\begin{array}{c}0.57 \\
(0.17)\end{array}$ & $\begin{array}{c}-0.85 \\
(0.25)\end{array}$ & $\begin{array}{c}0.41 \\
(0.14)\end{array}$ & $0.004^{*}$ & $<0.001^{*}$ & $<0.001^{*}$ & $<0.001$ * \\
\hline
\end{tabular}

Group means and standard deviations (SD)

* Indicates significant difference at $\alpha<0.05$ for the post-hoc Bonferonni analysis.

${ }^{\dagger}$ Represents an asymmetry between limbs on the flat condition at this event.

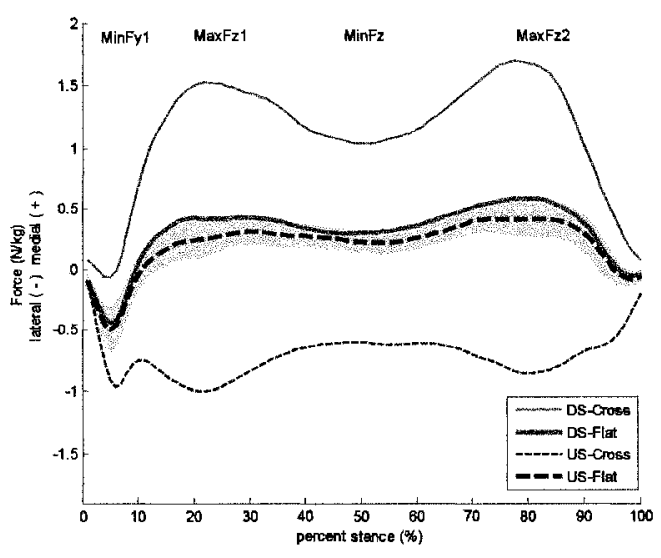

(a)

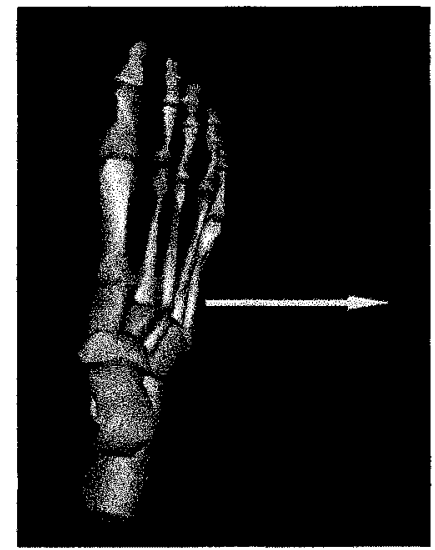

(b)

Figure 6 - (a) Medio-Lateral GRF (N/kg) averaged across all subjects and all trials for each side/condition permutation. Coordinate system for the DS-limb was modified to allow a medially oriented force to be positive and a lateral force to be negative for both limbs. Grey region is the standard deviation of the USflat condition. (b) A lateral force vector. 


\subsubsection{Vertical Force}

The vertical GRF showed no differences between the DS and US-limbs across conditions at all events (Fig. 7)

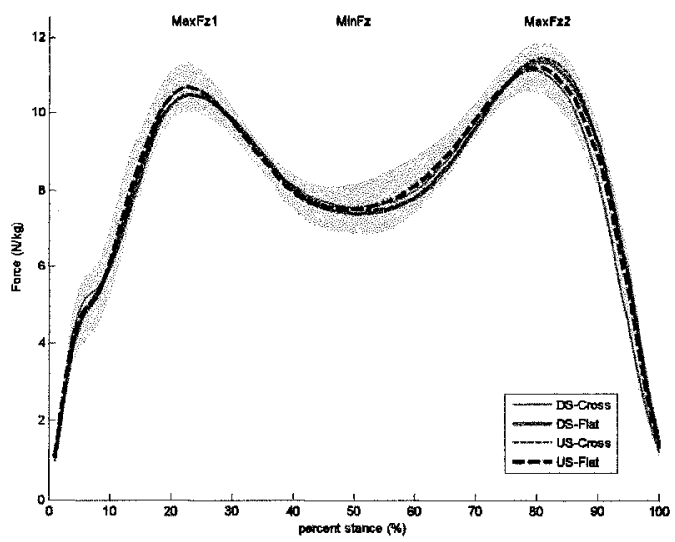

(a)

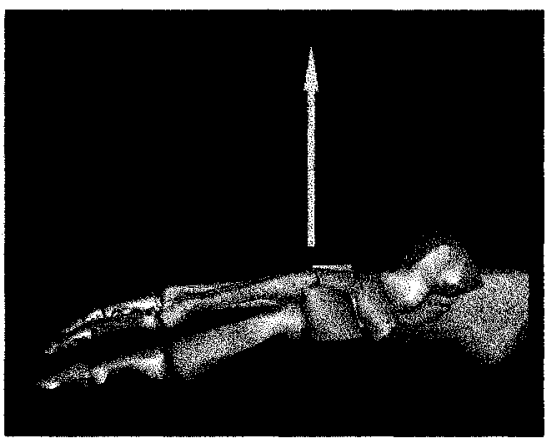

(b)

Figure 7 - (a) Vertical GRF (N/kg) averaged across all subjects and all trials for each side/condition permutation. Grey region is the standard deviation of the US-flat condition. (b) A vertical force vector.

\subsubsection{Free Vertical torque}

The free vertical torque did not differ significantly between the DS and US-limbs across the flat and cross-slope conditions at all events studied (Fig, 8). 


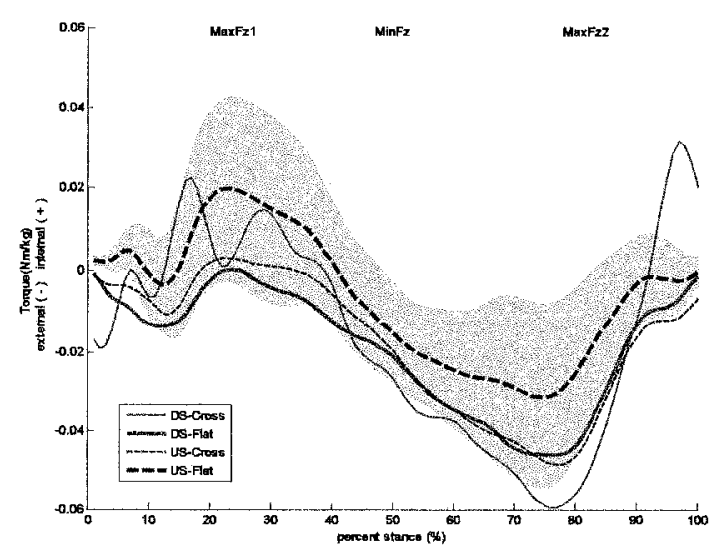

(a)

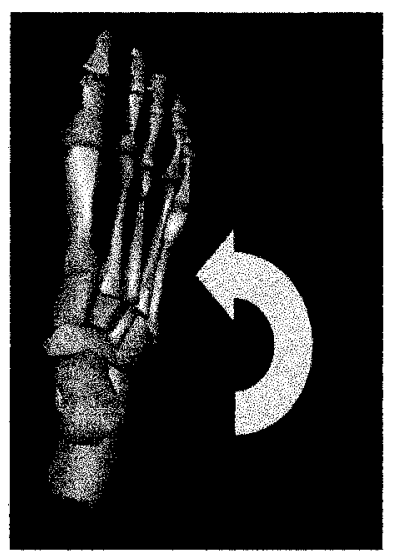

(b)

Figure 8 - Free Vertical Torque $(\mathrm{Nm} / \mathrm{kg})$ averaged across all subjects and all trials for each side/condition permutation. IRot (positive), ERot (negative). Grey region is the standard deviation of the US-flat condition. (b) An internally rotating torque.

\subsection{Discussion}

\subsubsection{Centre of Pressure}

A medially oriented progression of COP in ESt followed by a rapid lateral movement near TO was seen for both limbs throughout the two conditions. This is typical to findings reported by other authors (Rose and Gamble, 2006). The increase in anterior-posterior range of the DS-limb during the cross-slope condition may be associated with changing kinematic patterns in the sagittal plane. More specifically, an increased rocker phase in St may be occurring, however time spent in St was found to be similar for both sides.

\subsubsection{Ground Reaction Forces}

On the flat condition typical GRF patterns were exhibited in all three directions (Rose and Gamble, 2006; Riley et al., 2007). The medio-lateral GRF is greatest during ESt and TSt 
while the body actively controls the body center of mass (BCOM) acceleration, consequently these two events warrant further discussion. During ESt, the body attempts to stem the lateral progression of the BCOM, resulting in a medially oriented force for the flat condition. During TSt, the body actively steers the BCOM to the next intended foot strike location requiring a medial force to avoid lateral slippage of the stance limb. This is seen for both limbs during the flat condition. On the cross-slope condition, the US-limb experienced laterally directed forces at these same events, the reverse of that seen on the flat condition. The body's need to control the movement of the BCOM is overshadowed by the need to avoid DS-slippage, but not to the extent that COP migration towards next foot strike position is halted. On the cross-slope, the DS-limb experienced a medial force approximately three times greater, as compared to the flat condition, as the body tries to avoid DS-slippage. These findings are in agreement with a pilot study $(n=3)$ by Pearsall et al. (2007) who found the same directionality change for the US-limb and a similar threefold increase for the DS-limb during the cross-slope condition.

\subsubsection{Free Vertical Torque}

Few studies have reported findings on free vertical torque ( $\mathrm{Li}$ et al., 2001; Dalleau et al., 2007). Though there are large variations in the reported values, the general pattern and mean values reported here for the flat condition are similar to those of $\mathrm{Li}$ et al. Rose and Gamble (2006) reported findings of ground reaction torque for one adult female subject. Though it is unclear whether the torque reported was measured about the COP or about the centre of the force plate, results are generally consistent with those reported here. Perhaps due to the large inter and intra-subject variability in free vertical torque no 
changes were seen across sides or conditions. It is speculated however that subtle changes may be occurring across sides and further investigation using steeper cross-slopes may produce significant pattern changes.

\subsection{Conclusion}

Cross-slope walking was seen to produce significantly different and asymmetrical GRF patterns in the medio-lateral direction. The GRF reported are a reflection of the body's attempt to control DS-slippage while maintaining locomotor needs. The cross-slope walking scenario in some ways mimics LLD wherein other researchers have found that the vertical GRF increased for the longer limb during the push-off phase (Bhave et al., 1999; Perttunen et al., 2004). However, this over reliance on the US-limb for support was not reflected in the GRF and GRM reported in the present study, presumably as the modest cross-slope induced too subtle a limping effect.

This study indicates that the body uses non-symmetric propulsion strategies to navigate across the cross-slope condition. Although visual cues have been found to be the main factor in obstacle avoidance type tasks (Deshpande and Patla, 2005; McFadyen et al., 2007), it is unclear to what extent vestibular or somatic feedback provides cues during the cross-slope walking condition. However complex the locomotor and balance task of cross-slope walking, it is evident that an asymmetrical response is produced. Further studies considering a range of cross-slope inclinations, among normal and special populations, are needed to gain a greater understanding of cross-slope walking. 


\subsection{References}

Bhave, A., Paley, D., Herzenberg, J.E. (1999). Improvement in gait parameters after lengthening for the treatment of limb-length discrepancy. Journal of Bone and Joint Surgery, 81-A, 529-534.

Campbell, A.J., Reinken, J., Allen, B.C., Martinez, G.S. (1981). Falls in old age: a frequency and related factors. Age and Ageing, 10, 264-70.

Chao, E.Y., Laughman, R.K., Schneider, E., Stauffer, R.N. (1983). Normative data of knee joint motion and ground reaction forces in adult level walking. Journal of Biomechanics, 16(3), 219-233.

Dalleau, G., Allard, M.S., Beaulieu, M., Rivard, C., Allard, P. (2007). Free moment contribution to quiet standing in able-bodied and scoliotic girls. European Spine Journal, 16, 1593-1599.

DeGarie, L., \& Pearsall, D.J. (2000, August). Gait analysis on a transversely tilted platform. Paper presented at the XIth Congress of the Canadian Society for Biomechanics, Montreal, $Q C$.

Deshpande, N., \& Patla, A.E. (2005). Dynamic visual-vestibular integration during goal directed human locomotion. Experimental Brain Research, 166(2), 237-47.

Donald, I.P., \& Bulpitt, C.J. (1999). The prognosis of falls in elderly people living at home. Age and Ageing, 28, 121-5.

Eng, J.J., \& Winter, D.A. (1995). Kinetic analysis of the lower limb during walking: What information can be gained from a three-dimensional model. Journal of Biomechanics, 28(6), 753-758.

Kwon, Y.H. (2000, December). Centre of Pressure. Retrieved Nov 13, 2007, from http://www.kwon3d.com/theory/grf/cop.html

Lay, A.N., Hass, C.J., Gregor, R.J. (2006). The effects of sloped surfaces on locomotion: A kinematics and kinetic analysis. Journal of Biomechanics, 39, 1621-1628.

Leroux, A., Fung, J., Barbeau, H. (2002). Postural adaptations to walking on inclined surfaces: I. Normal strategies. Gait \& Posture, 15(1), 64-74.

Li, Y., Wang, W., Crompton, R.H., Gunther, M.M. (2001). Free vertical moments and transverse forces in human walking and their role in relation to arm-swing. Journal of Experimental Biology, 204, 47-58.

Lockhart, T.E., Spaulding, J.M., Park, S.H. (2007). Age-related slip avoidance strategy while walking over known slippery floor surface. Gait \& Posture, 26, 142-149. 
McFadyen, B.J., Bouyer, L., Bent, L.R., Inglis, J.T. (2007). Visual-vestibular influences on locomotor adjustments for stepping over an obstacle. Experimental Brain Research, 179(2), 235-43.

McIntosh, A.S., Beatty, K.T., Dwan, L.N., Vickers, D.R. (2006). Gait dynamics on an inclined walkway. Journal of Biomechanics, 39, 2491-2502.

Ministry of municipal affairs and housing (Ontario), Building and development branch. (2006). Building Code Compendium, Ontario. Vol I ( $\sec 3.8 .3 .2)$. Toronto: Publications Ontario.

National Guide to Sustainable Municipal Infrastructure. (2004, July). Sidewalk Design, Construction and Maintenance. Retrieved Sept 24, 2007, from http://sustainablecommunities.fcm.ca/files/Infraguide/Roads_and_Sidewalks/side walk_design_constr_maintenance.pdf

Nicolaou, M., Pearsall, D.J, Loh, J. (2002, August). Gait adaptation to transverse slopes. Paper presented at the IVth World Congress for Biomechanics, Calgary, AB.

Pearsall, D.J., Ouckama, R., Loh, J., Bouchard, C.E. (2007, July). Effects of cross slope on gait ground reaction forces. Paper presented at the International Society for Posture \& Gait Research, Burlington, VT.

Perttunen, J.R., Anttila, E., Sodergard, J., Merikanto, J., Komi, P.V. (2004). Gait asymmetry in patients with limb length discrepancy. Scandinavian Journal of Medicine \& Science in Sports, 14, 49-56.

Reeves, N.D., Spanjaard, M., Mohagheghi, A.A., Baltzopoulos, V., Maganaris, C.N. (2007). Older adults employ alternative strategies to operate within their maximum capabilities when ascending stairs. Journal of Electromyography \& Kinesiology, doi: 10.1016/j.jelekin.2007.09.009.

Riley, O.P., Paolini, G., Della Croce, U., Paylo, K.W., Kerrigan, D.C. (2007). A kinematic and kinetic comparison of overground and treadmill walking in healthy subjects. Gait \& Posture, 26, 17-24.

Rose, J., \& Gamble, J.G. (Eds.) (2006). Human Walking ( $3^{\text {rd }}$ ed) (pp. 44-57). Philadelphia: Lippincott Williams \&Wilkins.

Urrey, S.R. (2002). Redistribution of foot pressure in healthy adults during sideslope walking. Foot \& Ankle International, 23(12), 1112-8.

Vaughan, C.L., Davis, B.L., \& O'Connor, J.C. (1999). Dynamics of human gait $\left(2^{\text {nd }} \mathrm{ed}.\right)$. (pp. 15-43, 83-106). Cape Town, South Africa: Kiboho. 


\section{CHAPTER 4 - LOWER-LIMB KINEMATICS DURING FLAT AND CROSS- SLOPE WALKING IN HEALTHY INDIVIDUALS}

\subsection{Abstract}

The kinematics of the lower-limbs during walking have been identified as important gait parameters. This investigation focused on a three-dimensional kinematic analysis of the ankles, knees, and hips during flat $\left(0^{\circ}\right)$ walking versus walking on a transversely tilted surface (cross-slope of $6^{\circ}$ ). Passive optical markers placed on each subject were tracked using six Vicon ${ }^{\mathrm{TM}}$ (Vicon, Los Angeles, USA) cameras to compute joint kinematics according to the Grood and Suntay method. In addition step width, step length and stride length were measured. Ten healthy young adult males performed flat and cross-slope walking trials at their self-selected walking speed. The main kinematic changes occurred in the sagittal and frontal planes. The up-slope (US) limb generally exhibited increased flexion (Flx), while the down-slope (DS) limb had greater extension (Ext) thereby creating a functional leg length discrepancy (LLD) effect. In the frontal plane, the hips responded to the cross-slope by leaning the body US and thus migrating the body centre of mass (BCOM) towards the US-side to presumably maintain balance. In addition, step width was reduced on the cross-slope surface, potentially to reduce the LLD induced by the cross-slope. This modest cross-slope walking condition induced important asymmetrical changes in the lower-limb locomotor patterns and may well represent a substantial physical obstacle to populations with restricted mobility. 


\subsection{Introduction}

The study's underlying purpose is to identify how cross-slopes affect gait. Cross-slopes are a regular feature of our physical environment. In the urban setting, it is common practice to tilt sidewalks and roadways to permit water drainage. Canadian national guidelines recommend a cross-slope inclination of $0.5-2.3^{\circ}$ for that purpose (National Guide to Sustainable Municipal Infrastructure, 2004). Further, the Ontario Building Code recommends curb ramps, such as driveway entrances, to possess a slope between $5-7^{\circ}$ for motor vehicle passage (Ministry of Municipal Affairs and Housing, 2006). Nonetheless, for a pedestrian, sidewalks with intermittent ramps may impede gait and/or present an increased risk of falls. For young adults cross-slopes do not represent a significant challenge, however for elderly and special populations (visually impaired, amputees, wheelchair users, etc) the asymmetrical demands of cross-slope walking may introduce functional muscular-skeletal and balance barriers. In particular, this may precipitate falls, a major cause of injury in elderly populations (Lockhart et al., 2007) with incidences increasing with age (Campbell et al., 1981; Donald and Bulpitt 1999). In addition, the decreased joint flexibility (most notably at the ankles) and strength of older populations (Reeves, et al., 2007) may make cross-slope walking a difficult task to perform. Furthermore, a better understanding of lower-limb kinematics during non-level walking conditions may aid in the design of a variety of prostheses and walking aids.

Kinematics is the study of motion without knowledge of the underlying forces causing the observed motion (Rose and Gamble, 2006). A kinematic analysis of gait can reveal the general characteristics of an individual's walking pattern and, in a clinical setting, 
locomotor abnormalities can often be detected and even rectified (Levangie and Norkin, 2005). Repeatable lower-limb kinematic patterns in flat walking have been shown (Kadaba et al., 1989) and observed through numerous studies reporting three-dimensional analyses (Apkarian et al., 1989; Ounpuu, 1994; Winter et al., 1994; Nester et al., 2003; Riley et al., 2007).

To the knowledge of the authors, two studies to date have explored the kinematics of cross-slope walking (De Garie and Pearsall, 2000; Nicolaou et al., 2002). De Garie and Pearsall found differences in knee Flx/Ext range of motion (ROM) between sides with the DS-limb showing greater ROM during Stance (St) and toe-off (TO) and a reduced ROM during Swing ( $\mathrm{Sw}$ ) on a $20 \%\left(11.5^{\circ}\right)$ cross-slope. At $40 \%\left(23.6^{\circ}\right)$, US-limb knee Flx was greater throughout the entire gait cycle. Nicolaou et al. (2002) measured gait adaptations of the lower body on cross-slopes of $5 \%\left(2.9^{\circ}\right)$ and $10 \%\left(5.7^{\circ}\right)$. The authors reported trends of increasing dorsiflexion (DF) of the US-ankle and increasing plantarflexion (PF) of the DS-ankle over the entire gait cycle, but with significant differences during loading and midstance (MSt), on the 5\% and 10\% slope condition. Knee kinematics revealed increased Flx of the US-knee on the 10\% slope. Greater Ext was significant for both slope conditions for the DS-knee. Hip kinematics revealed differences in both the sagittal and frontal planes. In the sagittal plane, the DS-hip exhibited greater Ext under both slope conditions. In the frontal plane, the US-hip presented trends of greater adduction (Add) on the $10 \%$ slope during each phase of gait cycle measured, becoming significant $(\mathrm{p}<$ 0.05 ) only found during the loading phase for the $5 \%$ slope. The DS-hip showed greater abduction (Abd) under both slopes throughout loading and MSt. In addition, temporo- 
spatial parameters were also examined revealing a trend of decreasing stride width on the cross-slope condition becoming significant only for the $10 \%$ slope. Related studies involving the analysis of ground reaction forces (GRF) during cross-slope walking (Pearsall et al., 2007, chapter 3) have shown significant differences to occur in the mediolateral direction. Further, a study involving foot pressure showed significant pressure redistributions on the cross-slope condition (Urrey, 2002). Based on the findings of these studies, asymmetrical differences in three-dimensional lower limb kinematics are expected during cross-slope walking.

Therefore, the aim of this study was to quantify ankle, knee, and hip kinematics of both limbs in all three anatomical planes during cross-slope walking. In addition stride width, step length and step width were also analysed. GRF data simultaneously collected with the kinematic data presented here will be used to calculate joint kinetics using an inverse dynamic analysis approach in a forthcoming study.

\subsection{Methods}

\subsubsection{Subjects}

A sample of ten young healthy adult males, with no history of gait abnormalities, were recruited among the McGill University student population. Excluded were any subjects with a leg length discrepancy (LLD) greater than $2.0 \mathrm{~cm}$. Leg length was measured as the distance between the greater trochanter and the lateral malleoli. This study was approved by the McGill University Research Ethics Board Office (Appendix 2) and all subjects

signed a consent form before participating in this study (Appendix 1). Subjects wore non- 
obstructing clothing and walked barefoot along a wooden walkway. A summary of relevant anthropometric data is presented (Table 14).

Table 14 - Summary of Subject Anthropometrics $(n=10)$

\begin{tabular}{lcccccc} 
& $\begin{array}{c}\text { Age } \\
(\text { years })\end{array}$ & $\begin{array}{c}\text { Height } \\
(\mathrm{cm})\end{array}$ & $\begin{array}{c}\text { Body mass } \\
(\mathbf{k g})\end{array}$ & $\begin{array}{c}\text { Right leg length } \\
(\mathrm{cm})\end{array}$ & $\begin{array}{c}\text { Left leg length } \\
(\mathbf{c m})\end{array}$ \\
\hline Mean & 22.6 & 181.7 & 76.8 & 96.0 & 95.8 \\
\hline S.D. & $(3.1)$ & $(6.5)$ & $(8.2)$ & $(3.8)$ & & $(3.9)$ \\
\hline
\end{tabular}

\subsubsection{Description of Walkway and Coordinate System}

A walkway was used of length $6.91 \mathrm{~m}$ and width $1.21 \mathrm{~m}$ containing two force plates (AMTI $^{\mathrm{TM}}$, model 0R6-7-1000, Watertown, MA, USA) within its surface (Fig. 9). The force plates were positioned such that two consecutive steps during a stride were captured while each subject walked along the platform. Force plates were isolated from the platform's surface by means of small gaps $(0.5 \mathrm{~cm})$ and stabilized by several sub-platform braces within the walkway both when flat and inclined. To avoid slippage, seven parallel strips of tactile tape were placed along the direction of progression. Following the conventions set by Vaughan et al. (1999), the Global Coordinate System (GCS) had its origin at the bottom right corner of the first force plate for both conditions. 


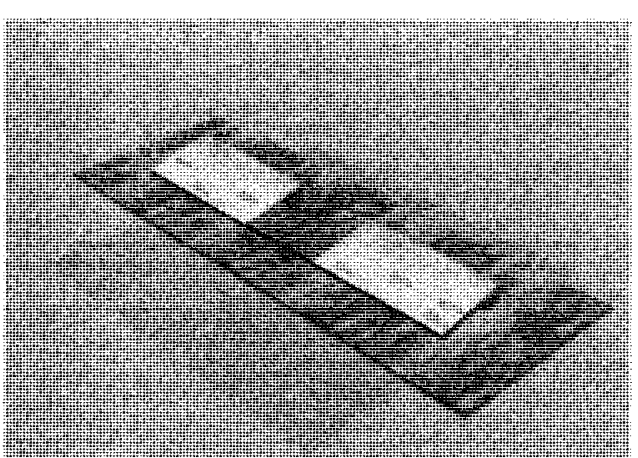

(a)

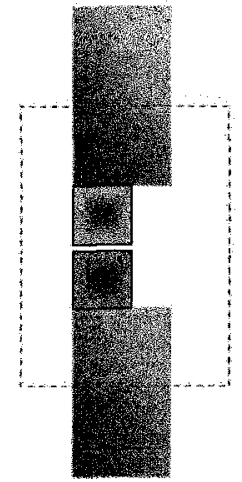

(b)

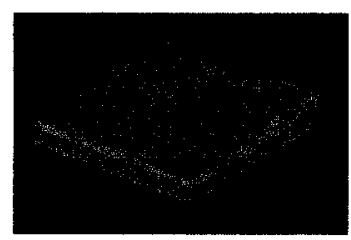

(c)

Figure 9 - Experimental Set-up: (a) Cross-slope tilted walking platform with embedded force plates. Footprints show direction of locomotion. (b) Top view of walking platform with dotted outline showing approximate capture area. (c) Coordinate system with origin in bottom right corner of force plate 1 . $x$-axis (red), y-axis(green), z-axis (blue).

\subsubsection{Data Acquisition and Analysis}

After familiarization to both the flat and cross-slope walking conditions, subjects performed barefoot walking trials at their self-selected comfortable pace beginning with the flat condition. Trials were rejected if either foot did not land fully on the force plate during their respective step. In post-processing, five trials per condition for each subject were retained for analysis. Anatomical position static-standing trials on the flat surface to be used in post-processing were also collected for each subject.

\subsubsection{Joint Angles}

Data from passive optical markers placed according to the Vicon ${ }^{\mathrm{TM}}$ (Vicon, Los Angeles, USA) Plug-in Gait ${ }^{\mathrm{TM}}$ model were collected at $240 \mathrm{~Hz}$ using a six camera Vicon ${ }^{\mathrm{TM}}$ (Vicon, Los Angeles, USA) system. Data were collected, labeled and filtered using a Woltring filter, similar in characteristics to the Butterworth filter (Stokes et al. 1995), with a $10 \mathrm{~Hz}$ cut-off frequency within the Vicon ${ }^{\mathrm{TM}}$ (Vicon, Los Angeles, USA) software 
environment. Lower-limb segment orientations (Fig. 10) defined by the local coordinate systems (LCS) as well as joint centre coordinates were then exported into MatLabß (v2006b, The Mathworks Inc., Natwick, MA, USA) where custom routines calculated joint angles according to the Grood and Suntay method (Grood and Suntay, 1983).

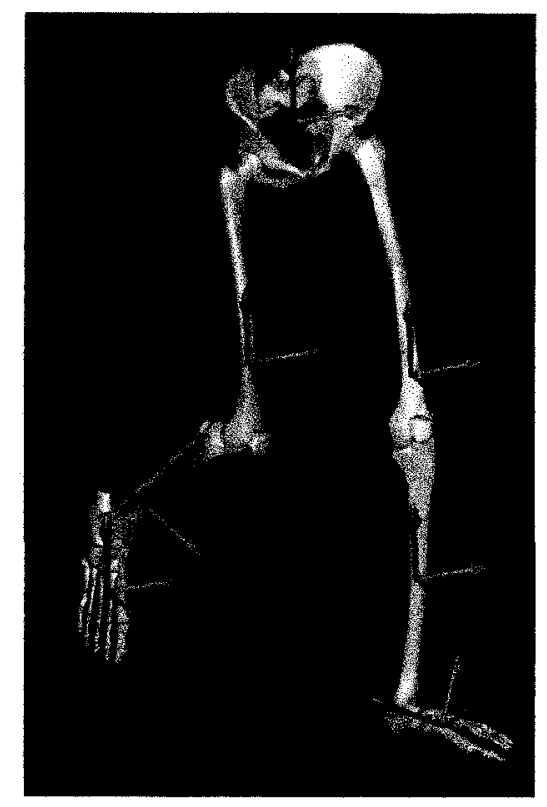

Figure 10 - LCS for each of the lower limb segments. $x$-axis (blue), $y$-axis (red) and z-axis (green).

The Grood and Suntay method describes joint angles as the relative motion of the distal segment with respect to the proximal segment. Specifically, ankle angles refer to the angle between the shank and foot segments; knee angles, the shank and the thigh; hip angles, the thigh and the pelvis. The raw Grood and Suntay angles for each trial were then adjusted using the anatomical position static-trial angles as follows:

$$
J_{i}=J_{i} r a w \pm J_{i} a n a t
$$

$$
\begin{aligned}
\text { where } \mathrm{J}_{\mathrm{i}} & : \text { angles for joint } J \text { and plane } i \\
\mathrm{~J}_{\mathrm{j}} \text { raw } & : \text { raw angles for joint } J \text {, plane } i \\
\mathrm{~J}_{\mathrm{i} \text { anat }} & : \text { anatomical angles for joint } J, \text { plane } i
\end{aligned}
$$


Important features (events) revealed through visual inspection of data and guided by past research (Ounpuu, 1994; Winter et al.,1994; Rose and Gamble, 2006) in joint kinematics have been selected for analysis. In addition to heel strike (HS) and toe-off (TO), calculated as the first and last frame respectively at which the magnitude of the GRF was nearest to $60 \mathrm{~N}$, kinematics were evaluated at the events outlined below (Table 17) with kinematic abbreviations noted in Table 15. Representative gait cycle percentages based on Ounpuu (1994) and related abbreviations are presented in Table 16. Sign conventions are based on Eng and Winter (1994). Naming conventions were inspired by those of McIntosh et al. (2006) with each event having three alpha-numeric characters: The first representing the joint, the second the plane and the third the event number. A maximum of four events based on prominent features in the graphs were used (two for the stance phase (St), two for the swing phase (Sw)). For example, $A_{x} 2$ is the $2^{\text {nd }}$ ankle sagittal plane angle in St.

Table 15 - Kinematic abbreviations

\begin{tabular}{|l|l|l|l|}
\hline & \multicolumn{1}{|c|}{ Sagittal (x) } & \multicolumn{1}{c|}{ Frontal (y) } & \multicolumn{1}{c|}{ Transverse (z) } \\
\hline Ankle & $\begin{array}{l}\text { Plantarflexion (PF) } \\
\text { Dorsiflexion (DF) }\end{array}$ & $\begin{array}{l}\text { Inversion (Inv) } \\
\text { Eversion (Eve) }\end{array}$ & $\begin{array}{l}\text { External rotation (ERot) } \\
\text { Internal rotation (IRot) }\end{array}$ \\
\hline $\begin{array}{l}\text { Knee }+ \\
\text { Hip }\end{array}$ & $\begin{array}{l}\text { Flexion (Flx) } \\
\text { Extension (Ext) }\end{array}$ & $\begin{array}{l}\text { Abduction (Abd) } \\
\text { Adduction (Add) }\end{array}$ & $\begin{array}{l}\text { External rotation (ERot) } \\
\text { Internal rotation (IRot) }\end{array}$ \\
\hline
\end{tabular}

Table 16 - Gait cycle representative event percentages and abbreviations.

\begin{tabular}{|l|l|l|l|}
\hline Stance Phase (St) 0-60\% & \multicolumn{2}{|l|}{ Swing Phase (Sw): 61-100\% } \\
\hline & Percentage & Event & Percentage \\
\hline Event & $0-10 \%$ & Early Swing (ESw): & $61-70 \%$ \\
Midstance (MSt): & $11-30 \%$ & Midswing (MSw): & $71-85 \%$ \\
Terminal stance (TSt): & $31-50 \%$ & Terminal Swing (TSw): & $86-100 \%$ \\
Preswing (PSw): & $51-60 \%$ & & \\
\hline
\end{tabular}


Table 17 - Kinematic events of the ankle, knee, hip and pelvis in all three planes

\begin{tabular}{|c|c|c|c|}
\hline & Sagittal (x) & Frontal (y) & Transverse (z) \\
\hline Ankle & $\begin{array}{l}\text { PF }(-) / D F(+) \\
A_{x} 1: \text { maximum PF ESt } \\
A_{x} 2 \text { maximum DF St } \\
A_{x} 3 \text { maximum } P F S w \\
A_{x} 4: \text { maximum DS Sw }\end{array}$ & $\begin{array}{l}\text { Inv }(+) / \text { Eve }(-) \\
A_{y} 1: \text { maximum Eve } S t \\
A_{y} 3: \text { maximum Inv ESw } \\
A_{y} 4: \text { maximum Inv TSw }\end{array}$ & $\begin{array}{l}\text { IRot }(+) / \text { ERot }(-) \\
\mathrm{A}_{\mathbf{z}} 1: \text { maximum ERot } \mathrm{St} \\
\mathrm{A}_{\mathbf{z}} 3: \text { maximum IRot } \mathrm{MSw} \\
\mathrm{A}_{\mathrm{z}} 4: \text { maximum IRot } \mathrm{TSw}\end{array}$ \\
\hline Knee & $\begin{array}{l}\text { Flex }(+) / \text { Ext }(-) \\
\mathrm{K}_{\mathrm{x}} 1: \text { maximum Flx } \mathrm{St} \\
\mathrm{K}_{\mathrm{x}} 2: \text { minimum Flx } \mathrm{St} \\
\\
\mathrm{K}_{\mathrm{x}} 3: \text { maximum Flx Sw } \\
\mathrm{K}_{\mathrm{x}} 4: \text { minimum Flx Sw }\end{array}$ & $\begin{array}{l}\text { Abd }(-) / \text { Add }(+) \\
\mathrm{K}_{\mathrm{y}} 1: \text { maximum Abd ESt } \\
\mathrm{K}_{\mathrm{y}} 2: \text { maximum Add } \mathrm{MSt} \\
\mathrm{K}_{\mathrm{y}} 3: \text { maximum Abd } \mathrm{Sw} \\
\mathrm{K}_{\mathrm{y}} 4: \text { maximum Add TSw }\end{array}$ & $\begin{array}{l}\text { IRot }(+) / \text { ERot }(-) \\
K_{z} 1: \text { Knee rotation at } A_{y} 1 \\
K_{z} 3: \text { Knee rotation at } A_{y} 3 \\
K_{z} 4: \text { Knee rotation at } A_{y} 4\end{array}$ \\
\hline Hip & $\begin{array}{l}\text { Flex }(+) / \text { Ext }(-) \\
\mathrm{H}_{\mathbf{x}} 1: \text { maximum Flx } \mathrm{St} \\
\mathrm{H}_{\mathrm{x}} 2: \text { maximum Ext } \mathrm{St} \\
\mathrm{H}_{\mathrm{x}} 4: \text { maximum Flx Sw }\end{array}$ & $\begin{array}{l}\text { Abd }(-) / \text { Add }(+) \\
H_{y} 1: \text { maximum Add ESt } \\
\mathrm{H}_{\mathrm{y}} 3 \text { maximum Abd } \mathrm{Sw} \\
\mathrm{H}_{\mathrm{y}} 4 \text { maximum } \mathrm{Add} \mathrm{MSw}\end{array}$ & $\begin{array}{l}\text { IRot }(+) / \text { ERot }(-) \\
\mathrm{H}_{z} 2 \text {; maximum ERot } T S t \\
\mathrm{H}_{\mathrm{z}} 3 \text { maximum ERot } \mathrm{MSw} \\
\mathrm{H}_{2} 4 \text { maximum IRot } \mathrm{TSw}\end{array}$ \\
\hline
\end{tabular}

\subsubsection{Statistical Analysis}

Temporo-spatial parameters were compared solely across conditions (flat and crossslope) and were analyzed using a within subject one-way analysis of variance (1X2 ANOVA) for repeated measures at an $\alpha=0.05$ significance level. Analysis of joint kinematics at important gait events were made between conditions and between the DS and US-limbs using a within subject analysis of variance (2X2 ANOVA) for repeated measures at an $\alpha=0.05$ level. Post-hoc analyses using a Bonferonni correction were computed for each multiple comparison in cases where significant interaction between condition and side were achieved. Significance level was set at $\alpha=0.05$ (after Bonferonni adjustment). SPSS ${ }^{\mathrm{TM}}$ (SPSS for Windows, version 15.0) was used for statistical analysis. 


\subsection{Results}

\subsubsection{Temporo-Spatial Properties}

Step and stride length (normalized to leg length) showed no significant differences $(\mathrm{p}=$ $0.246, p=0.460$ respectively) across conditions. Mean step width results were significantly different across conditions $(\mathrm{p}=0.024)$ with the flat condition showing a 1.2 cm greater step width (Fig. 11). All stride property values are summarized in Table 18.

Table 18 - Stride properties (stride length normalized to leg length, step length normalized to leg length and step width) averaged across all trials and subjects for the flat and cross-slope conditions.

\begin{tabular}{lcc} 
& Flat (0\%) & Cross-Slope (6\%) \\
\hline Step length (cm/cm) & 83.3 & 82.1 \\
& $(5.6)$ & $(4.0)$ \\
& 168.2 & 169.2 \\
Stride & $(10.9)$ & $(9.4)$ \\
length(cm/cm) & & \\
Step Width (cm) & 9.3 & 8.1 \\
& $(2.7)$ & $(2.6)$ \\
\hline
\end{tabular}

Group means and standard deviations presented (SD)

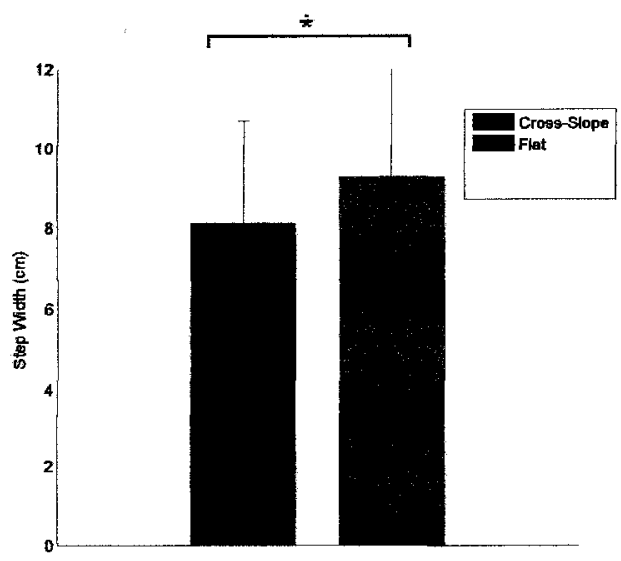

Figure 11 - Step width $(\mathrm{cm})$ averaged across all subjects and trials for the flat and cross-slope conditions 


\subsubsection{Sagittal Plane Kinematics}

\subsubsection{Ankle}

The ankle sagittal plane angles showed significant differences $(\mathrm{p}<0.021)$ between sides and condition at all events under study, though relevant post-hoc comparisons were seen only at $A_{x} 1, A_{x} 2$, TO and $A_{x} 4$ (Fig. 12). For the flat condition, there were no significant differences between sides indicating symmetry between the ankles.

Pairwise comparisons revealed significant differences across conditions for the US and DS-ankles (Table 19). At $A_{x} 1$, the maximum PF in ESt, differences were seen between conditions for the US-ankle $(p=0.004)$ with the cross-slope condition revealing diminished PF $\left(-8.0^{\circ}\right.$ to $\left.-6.3^{\circ}\right)$. At $\mathrm{A}_{\mathrm{x}} 2$, the maximum DF during St, differences occurred between conditions for the DS-ankle $(p=0.008)$ as well as between conditions for the US-ankle $(\mathrm{p}=0.046)$. The DS-ankle saw a reduction of DF $\left(14.9^{\circ}\right.$ to $\left.12.6^{\circ}\right)$ while the USankle increased DF $\left(14.2^{\circ}\right.$ to $\left.15.4^{\circ}\right)$ under the cross-slope condition. At TO, differences occurred between conditions for the DS-ankle $(\mathrm{p}=0.026)$ with the cross-slope condition showing a much greater amount of $\mathrm{PF}\left(-12.7^{\circ}\right.$ vs. $\left.-7.8^{\circ}\right)$. At $\mathrm{A}_{\mathrm{x}} 4$ differences were seen between conditions for both ankles $(\mathrm{p}=0.036$ and $\mathrm{p}=0.001$ for the DS and US-ankles respectively). The maximum DF in Sw decreased for the DS-ankle $\left(5.8^{\circ}\right.$ to $\left.4.4^{\circ}\right)$ while increasing for the US-ankle $\left(3.9^{\circ}\right.$ to $\left.6.6^{\circ}\right)$ under the cross-slope condition. 
Table 19 -Ankle sagittal plane angle values (degrees) evaluated at representative gait cycle events and averaged across all trials and subjects for each side/condition permutation. Associated p-values for each relevant pairwise comparison are also presented.

\begin{tabular}{|c|c|c|c|c|c|c|c|c|}
\hline $\mathbf{A}_{\mathbf{x}}$ & $\begin{array}{l}\text { DS/ } \\
\text { Cross }\end{array}$ & $\begin{array}{l}\text { DS/ } \\
\text { Flat }\end{array}$ & $\begin{array}{l}\text { US/ } \\
\text { Cross }\end{array}$ & $\begin{array}{l}\text { US/ } \\
\text { Flat }\end{array}$ & $\begin{array}{c}\text { DS/ } \\
\text { Flat } \\
- \\
\text { US/ } \\
\text { Flat }\end{array}$ & $\begin{array}{c}\text { DS/ } \\
\text { Flat } \\
- \\
\text { DS/ } \\
\text { Cross }\end{array}$ & $\begin{array}{c}\text { DS/ } \\
\text { Cross } \\
- \\
\text { US/ } \\
\text { Cross }\end{array}$ & $\begin{array}{c}\text { US/ } \\
\text { Flat } \\
- \\
\text { US/ } \\
\text { Cross }\end{array}$ \\
\hline $\mathbf{A}_{\mathbf{x}} 1$ & $\begin{array}{l}-5.1 \\
(4.8)\end{array}$ & $\begin{array}{c}-5.3 \\
(4.2)\end{array}$ & $\begin{array}{l}-6.3 \\
(5.5)\end{array}$ & $\begin{array}{c}-8.0 \\
(5.3)\end{array}$ & 0.294 & 1.000 & 1.000 & $0.004^{*}$ \\
\hline $\mathbf{A}_{\mathbf{x}} 2$ & $\begin{array}{l}12.6 \\
(3.8)\end{array}$ & $\begin{array}{l}14.9 \\
(2.8)\end{array}$ & $\begin{array}{l}15.4 \\
(4.1)\end{array}$ & $\begin{array}{l}14.2 \\
(4.1)\end{array}$ & 1.000 & $0.008^{*}$ & 0.549 & $0.046^{*}$ \\
\hline TO & $\begin{array}{c}-12.7 \\
(7.9)\end{array}$ & $\begin{array}{l}-7.8 \\
(5.3)\end{array}$ & $\begin{array}{l}-8.0 \\
(3.3)\end{array}$ & $\begin{array}{c}-10.8 \\
(5.6)\end{array}$ & 0.149 & $0.026^{*}$ & 0.127 & 0.133 \\
\hline$A_{x} 4$ & $\begin{array}{c}4.4 \\
(4.1)\end{array}$ & $\begin{array}{c}5.8 \\
(4.4)\end{array}$ & $\begin{array}{c}6.6 \\
(3.0)\end{array}$ & $\begin{array}{c}3.9 \\
(3.8)\end{array}$ & 0.440 & $0.036^{*}$ & 0.060 & $0.001^{*}$ \\
\hline
\end{tabular}

Group means and standard deviations presented (SD)

* Indicates significant difference at $\alpha<0.05$ for the post-hoc Bonferonni analysis.

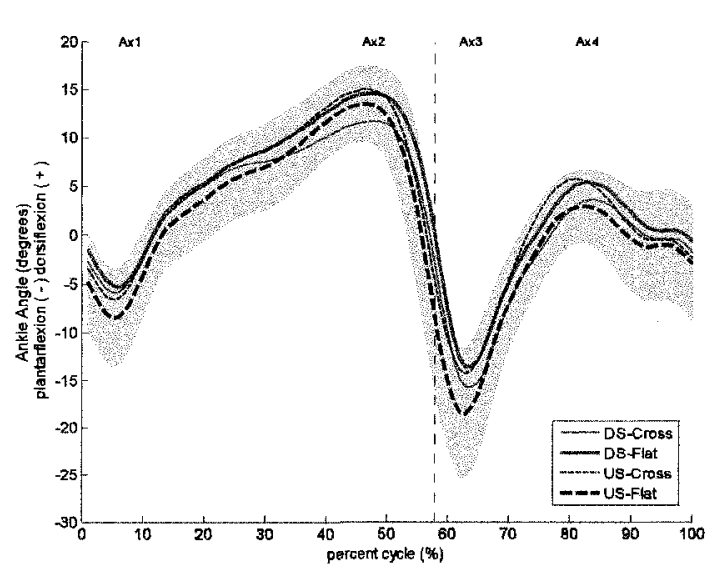

(a)

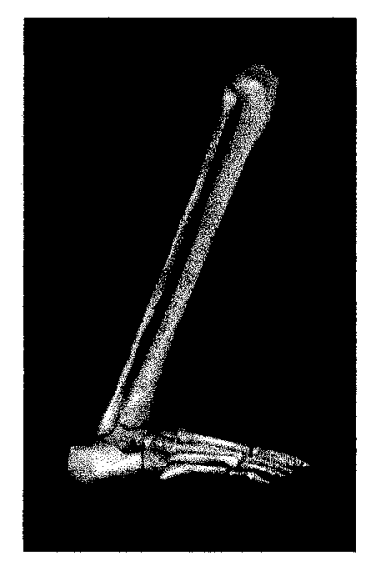

(b)

Figure 12 - (a) Ankle PF/DF angles (degrees) averaged across all subjects and all trials for the DS and USankles under the flat and cross-slope conditions. Vertical line indicates approximate position of TO. PF (negative), DF (positive). Grey region is the standard deviation of the US-flat condition. (b) Maximum DF during St near $\mathrm{A}_{\mathrm{x}} 2$. 


\subsubsection{Knee}

The knee sagittal angles showed significant differences at HS $(p=0.008)$ (Fig. 13). There were no significant differences between sides for the flat condition indicating symmetry between the knees. Pairwise comparisons revealed significant differences ( $\mathrm{p}<0.001)$ between conditions for the US-knee with Flx increasing $\left(2.9^{\circ}\right.$ to $\left.4.6^{\circ}\right)$ on the cross-slope (Table 20).

Table 20 - Knee sagittal plane angle values (degrees) evaluated at representative gait cycle events and averaged across all trials and subjects for each side/condition permutation. Associated $p$-values for each relevant pairwise comparison are also presented.

\begin{tabular}{|c|c|c|c|c|c|c|c|c|}
\hline $\mathbf{K}_{\mathbf{x}}$ & $\begin{array}{l}\text { DS/ } \\
\text { Cross }\end{array}$ & $\begin{array}{l}\text { DS/ } \\
\text { Flat }\end{array}$ & $\begin{array}{l}\text { US/ } \\
\text { Cross }\end{array}$ & $\begin{array}{l}\text { US/ } \\
\text { Flat }\end{array}$ & $\begin{array}{c}\text { DS/ } \\
\text { Flat } \\
- \\
\text { US/ } \\
\text { Flat }\end{array}$ & $\begin{array}{c}\text { DS/ } \\
\text { Flat } \\
- \\
\text { DS/ } \\
\text { Cross }\end{array}$ & $\begin{array}{c}\text { DS/ } \\
\text { Cross } \\
- \\
\text { US/ } \\
\text { Cross }\end{array}$ & $\begin{array}{c}\text { US/ } \\
\text { Flat } \\
- \\
\text { US/ } \\
\text { Cross }\end{array}$ \\
\hline HS & $\begin{array}{c}4.9 \\
(5.8)\end{array}$ & $\begin{array}{c}4.7 \\
(5.0)\end{array}$ & $\begin{array}{c}4.6 \\
(8.5)\end{array}$ & $\begin{array}{c}2.9 \\
(8.0)\end{array}$ & 1.000 & 1.000 & 1.000 & $<0.001$ * \\
\hline
\end{tabular}

Group means and standard deviations (SD)

* Indicates significant difference at $\alpha<0.05$ for the post-hoc Bonferonni analysis.

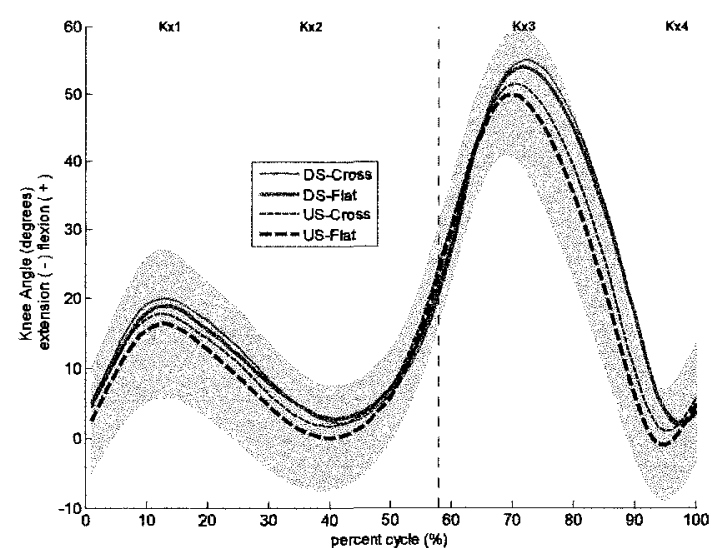

(a)

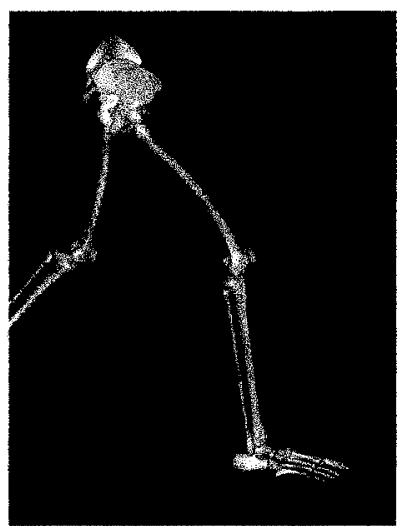

(b)

Figure 13 - (a) Knee Flx/Ext angles (degrees) averaged across all subjects and all trials for the DS and USknees under the flat and cross-slope conditions. Vertical line indicates approximate position of TO. Ext (negative), Flx (positive). Grey region is the standard deviation of the US-flat condition. (b) Maximum Flx during St near $\mathrm{K}_{\mathbf{x}} 1$. 


\subsubsection{Hip}

The hip sagittal plane angles were significantly different $(p<0.007)$ at $\mathrm{H}_{x} 4$ (Fig. 14). Flat walking symmetry was maintained across sides for the flat condition.

At $\mathrm{H}_{\mathrm{x}} 4$, pairwise comparisons disclosed differences between conditions for the US-hip ( $p$ $<0.001$ respectively) (Table 21$)$. The maximum Flx in Sw increased $\left(24.3^{\circ}\right.$ to $\left.27.4^{\circ}\right)$ on the cross-slope condition.

Table 21 - Hip sagittal plane angle values (degrees) evaluated at representative gait cycle events and averaged across all trials and subjects for each side/condition permutation. Associated p-values for each relevant pairwise comparison are also presented.

\begin{tabular}{|c|c|c|c|c|c|c|c|c|}
\hline $\mathbf{H}_{\mathbf{x}}$ & $\begin{array}{l}\text { DS/ } \\
\text { Cross }\end{array}$ & $\begin{array}{l}\text { DS/ } \\
\text { Flat }\end{array}$ & $\begin{array}{l}\text { US/ } \\
\text { Cross }\end{array}$ & $\begin{array}{l}\text { US/ } \\
\text { Flat }\end{array}$ & $\begin{array}{c}\text { DS/ } \\
\text { Flat } \\
- \\
\text { US/ } \\
\text { Flat }\end{array}$ & $\begin{array}{c}\text { DS/ } \\
\text { Flat } \\
- \\
\text { DS/ } \\
\text { Cross }\end{array}$ & $\begin{array}{c}\text { DS/ } \\
\text { Cross } \\
- \\
\text { US/ } \\
\text { Cross }\end{array}$ & $\begin{array}{c}\text { US/ } \\
\text { Flat } \\
- \\
\text { US/ } \\
\text { Cross }\end{array}$ \\
\hline $\mathbf{H}_{\mathbf{x}} \mathbf{4}$ & $\begin{array}{l}25.5 \\
(5.5)\end{array}$ & $\begin{array}{c}24.9 \\
(5.7)\end{array}$ & $\begin{array}{l}27.4 \\
(6.5)\end{array}$ & $\begin{array}{c}24.3 \\
(6.0)\end{array}$ & 1.000 & 0.735 & 1.000 & $<0.001^{*}$ \\
\hline
\end{tabular}

Group means and standard deviations (SD)

* Indicates significant difference at $\alpha<0.05$ for the post-hoc Bonferonni analysis.

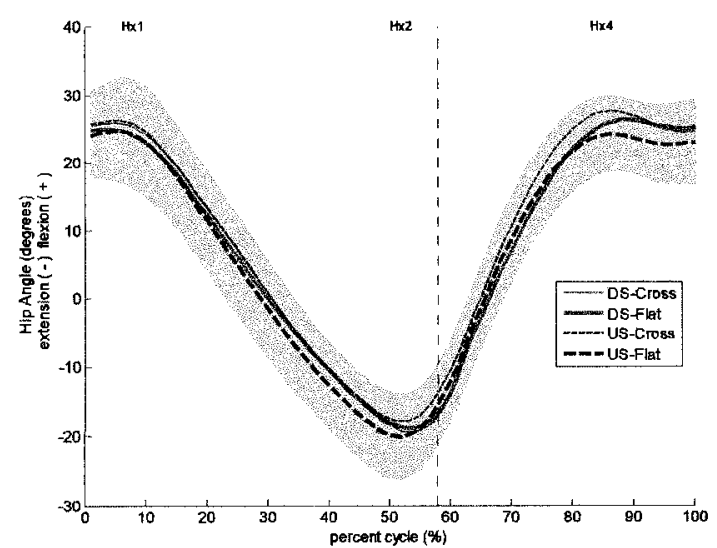

(a)

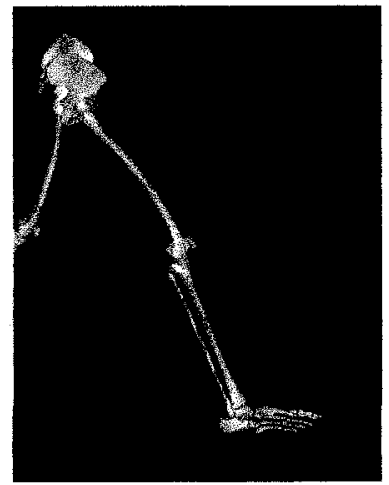

(b)

Figure 14 - (a) Hip Flx/Ext angles (degrees) averaged across all subjects and all trials for the DS and UShips under the flat and cross-slope conditions. Vertical line indicates approximate position of TO. Ext (negative), Flx(positive). Grey region is the standard deviation of the US-flat condition. (b) Maximum Flx near $\mathrm{H}_{\mathbf{x}} 1$. 


\subsubsection{Frontal Plane Kinematics}

\subsubsection{Ankle}

The ankle frontal plane angles were significantly different across side and condition at all events $(p<0.011)$ (Fig. 15), though during post-hoc comparisons relevant differences were only seen at HS and TO (Table 22). Symmetry was satisfied across sides on the flat condition.

At HS, pairwise comparisons revealed differences to lie across conditions for the DS and US-ankles ( $p=0.027$ and $p<0.001$ respectively). The DS-ankle showed an increased Inv (from $2.6^{\circ}$ to $4.0^{\circ}$ ) while the US-ankle decreased Inv $\left(4.1^{\circ}\right.$ to $\left.3.1^{\circ}\right)$ on the cross-slope condition. At TO differences lay across conditions for the US-ankle only $(p=0.030)$. The US-ankle decreased Inv $\left(6.3^{\circ}\right.$ to $\left.5.0^{\circ}\right)$ on the cross-slope condition.

Table 22 -Ankle frontal plane angle values (degrees) evaluated at representative gait cycle events and averaged across all trials and subjects for each side/condition permutation. Associated p-values for each relevant pairwise comparison are also presented.

\begin{tabular}{|c|c|c|c|c|c|c|c|c|}
\hline $\mathbf{A}_{\mathbf{y}}$ & $\begin{array}{l}\text { DS/ } \\
\text { Cross }\end{array}$ & $\begin{array}{l}\text { DS/ } \\
\text { Flat }\end{array}$ & $\begin{array}{l}\text { US/ } \\
\text { Cross }\end{array}$ & $\begin{array}{l}\text { US/ } \\
\text { Flat }\end{array}$ & $\begin{array}{c}\text { DS/ } \\
\text { Flat } \\
- \\
\text { US/ } \\
\text { Flat }\end{array}$ & $\begin{array}{c}\text { DS/ } \\
\text { Flat } \\
- \\
\text { DS/ } \\
\text { Cross }\end{array}$ & $\begin{array}{c}\text { DS/ } \\
\text { Cross } \\
- \\
\text { US/ } \\
\text { Cross }\end{array}$ & $\begin{array}{c}\text { US/ } \\
\text { Flat } \\
- \\
\text { US/ } \\
\text { Cross }\end{array}$ \\
\hline HS & $\begin{array}{c}4.0 \\
(4.3)\end{array}$ & $\begin{array}{c}2.6 \\
(3.8)\end{array}$ & $\begin{array}{c}3.1 \\
(4.9)\end{array}$ & $\begin{array}{c}4.1 \\
(4.8)\end{array}$ & 1.000 & $0.027^{*}$ & 1.000 & $<0.001 *$ \\
\hline TO & $\begin{array}{c}6.8 \\
(5.0)\end{array}$ & $\begin{array}{c}5.7 \\
(4.1)\end{array}$ & $\begin{array}{c}5.0 \\
(4.8)\end{array}$ & $\begin{array}{c}6.3 \\
(5.3)\end{array}$ & 1.000 & 0.237 & 0.817 & $0.030^{*}$ \\
\hline
\end{tabular}

Group means and standard deviations (SD)

* Indicates significant difference at $\alpha<0.05$ for the post-hoc Bonferonni analysis. 


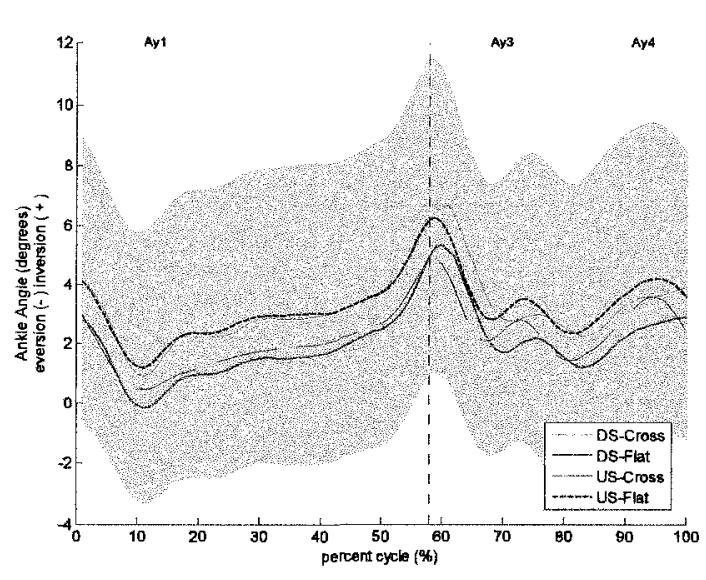

(a)

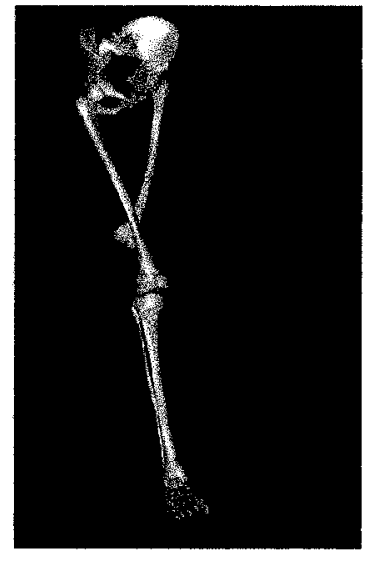

(b)

Figure 15 - (a) Ankle Inv/Eve angles (degrees) averaged across all subjects and all trials for the DS and US-ankles under the flat and cross-slope conditions. Vertical line indicates approximate position of TO. Eve (negative), Inv(positive). Grey region is the standard deviation of the US-flat condition. (b) Ankle Inv near HS.

\subsubsection{Knee}

For the knee frontal plane angles, all events saw significant $(p<0.033)$ interaction across sides and condition (Fig. 16). Symmetry was maintained across sides for all events during the flat walking trials.

Only $\mathrm{K}_{\mathrm{y}} 3$, the maximal Abd during $\mathrm{Sw}$, revealed relevant significant pairwise differences in post-hoc testing (Table 23). Differences occurred across conditions for the DS-knee $(p=0.006)$ with the Abd angle decreasing on the cross-slope condition $\left(-15.6^{\circ}\right.$ to $\left.-13.5^{\circ}\right)$. 
Table 23 -Knee frontal plane angle values (degrees) evaluated at representative gait cycle events and averaged across all trials and subjects for each side/condition permutation. Associated p-values for each relevant pairwise comparison are also presented.

\begin{tabular}{|c|c|c|c|c|c|c|c|c|}
\hline $\mathbf{K}_{\mathbf{y}}$ & $\begin{array}{l}\text { DS/ } \\
\text { Cross }\end{array}$ & $\begin{array}{l}\text { DS/ } \\
\text { Flat }\end{array}$ & $\begin{array}{l}\text { US/ } \\
\text { Cross }\end{array}$ & $\begin{array}{l}\text { US/ } \\
\text { Flat }\end{array}$ & $\begin{array}{c}\text { DS/ } \\
\text { Flat } \\
- \\
\text { US/ } \\
\text { Flat }\end{array}$ & $\begin{array}{c}\text { DS/ } \\
\text { Flat } \\
- \\
\text { DS/ } \\
\text { Cross }\end{array}$ & $\begin{array}{c}\text { DS/ } \\
\text { Cross } \\
- \\
\text { US/ } \\
\text { Cross }\end{array}$ & $\begin{array}{c}\text { US/ } \\
\text { Flat } \\
- \\
\text { US/ } \\
\text { Cross }\end{array}$ \\
\hline$K_{y} \mathbf{3}$ & $\begin{array}{l}-13.5 \\
(7.6)\end{array}$ & $\begin{array}{c}-15.6 \\
(8.3)\end{array}$ & $\begin{array}{c}-18.1 \\
(13.0)\end{array}$ & $\begin{array}{l}-16.6 \\
(12.2)\end{array}$ & 1.000 & $0.006^{*}$ & 1.000 & 0.135 \\
\hline
\end{tabular}

Group means and standard deviations (SD)

* Indicates significant difference at $\alpha<0.05$ for the post-hoc Bonferonni analysis.

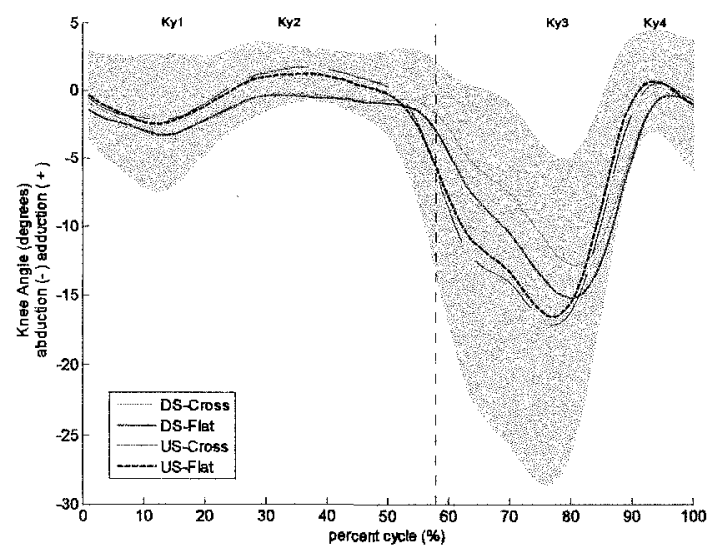

(a)

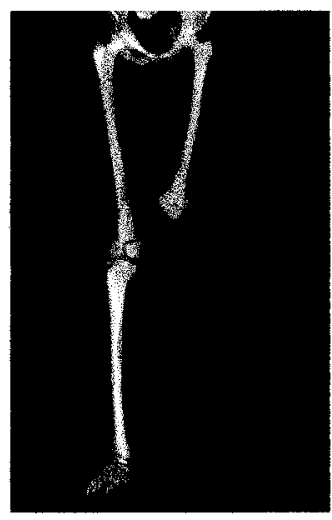

(b)

Figure 16 - (a) Knee Abd/Add angles (degrees) averaged across all subjects and all trials for the DS and US-knees under the flat and cross-slope conditions. Vertical line indicates approximate position of TO. Abd (negative), Add (positive). Grey region is the standard deviation of the US-flat condition. (b) Knee Abd near $\mathrm{K}_{\mathrm{y}} 3$.

\subsubsection{Hip}

Hip frontal plane angles showed significant interaction across sides and conditions $(\mathrm{p}<$ 0.005 ) at all events (Fig. 17). An asymmetry was seen across the DS and US-hips during flat walking at $T O(p=0.007)$. However substantially larger differences were seen across conditions for the DS and US-hips ( $\mathrm{p}=0.004$ and $\mathrm{p}<0.001$ respectively). 
Pairwise comparisons revealed differences at all events under study (Table 24). At HS, differences were seen across conditions for the DS-hip. A slight decrease in Add from $1.9^{\circ}$ to $1.1^{\circ}$ was seen for the cross-slope condition. At $\mathrm{H}_{\mathrm{y}} 1$ differences were seen across conditions for the DS and US-hips ( $p=0.007$ and $p=0.004$ respectively) as well as across sides for the cross-slope condition $(p=0.027)$. The DS-hip reduced Add on the crossslope condition $\left(8.4^{\circ}\right.$ to $\left.6.9^{\circ}\right)$. The US-hip increased its Add on the cross-slope $\left(10.7^{\circ}\right.$ to $\left.12.4^{\circ}\right)$. At TO, differences were seen across conditions for the DS and US-hips as well as across sides for the cross-slope condition. The DS-hip increased Abd $\left(-3.1^{\circ}\right.$ to $\left.-4.6^{\circ}\right)$, while the US-hip increased Add $\left(1.0^{\circ}\right.$ to $\left.3.4^{\circ}\right)$ on the cross-slope. At $\mathrm{H}_{\mathrm{y}} 3$, differences across conditions for the US-hip $(\mathrm{p}=0.001)$ as well as across sides for the cross-slope condition $(p=0.003)$ were revealed. The US-hip was slightly Abd $\left(-0.9^{\circ}\right)$ on the flat condition, becoming slightly Add $\left(1.1^{\circ}\right)$ on the cross slope. On the cross-slope, the DS-hip reveals a large maximal Abd angle $\left(-5.4^{\circ}\right)$ while the US-hip showed Add $\left(1.1^{\circ}\right) . \mathrm{H}_{\mathrm{y}} 4$ saw a difference in conditions for the US-hip $(p=0.002)$ with Add increasing $\left(3.6^{\circ}\right.$ to $\left.5.7^{\circ}\right)$ on the cross-slope condition. 
Table 24 -Hip frontal plane angle values (degrees) evaluated at representative gait cycle events and averaged across all trials and subjects for each side/condition permutation. Associated p-values for each relevant pairwise comparison are also presented.

\begin{tabular}{|c|c|c|c|c|c|c|c|c|}
\hline $\mathbf{H}_{\mathbf{y}}$ & $\begin{array}{l}\text { DS/ } \\
\text { Cross }\end{array}$ & $\begin{array}{l}\text { DS/ } \\
\text { Flat }\end{array}$ & $\begin{array}{l}\text { US/ } \\
\text { Cross }\end{array}$ & $\begin{array}{l}\text { US/ } \\
\text { Flat }\end{array}$ & $\begin{array}{c}\text { DS/ } \\
\text { Flat } \\
- \\
\text { US/ } \\
\text { Flat }\end{array}$ & $\begin{array}{c}\text { DS/ } \\
\text { Flat } \\
\text { DS/ } \\
\text { Cross }\end{array}$ & $\begin{array}{c}\text { DS/ } \\
\text { Cross } \\
- \\
\text { US/ } \\
\text { Cross }\end{array}$ & $\begin{array}{c}\text { US/ } \\
\text { Flat } \\
- \\
\text { US/ } \\
\text { Cross }\end{array}$ \\
\hline HS & $\begin{array}{c}1.1 \\
(2.6)\end{array}$ & $\begin{array}{c}1.9 \\
(2.5)\end{array}$ & $\begin{array}{c}5.2 \\
(5.0)\end{array}$ & $\begin{array}{c}3.4 \\
(4.0)\end{array}$ & 1.000 & $0.023^{*}$ & 0.198 & 0.088 \\
\hline $\mathbf{H}_{\mathbf{y}} \mathbf{1}$ & $\begin{array}{c}6.9 \\
(2.0)\end{array}$ & $\begin{array}{c}8.4 \\
(1.3)\end{array}$ & $\begin{array}{r}12.4 \\
(4.3)\end{array}$ & $\begin{array}{l}10.7 \\
(3.8)\end{array}$ & 0.442 & $0.007 *$ & $0.027^{*}$ & $0.004^{*}$ \\
\hline $\mathbf{T O}^{+}$ & $\begin{array}{c}-4.6 \\
(1.8)\end{array}$ & $\begin{array}{l}-3.1 \\
(2.1)\end{array}$ & $\begin{array}{c}3.4 \\
(4.6)\end{array}$ & $\begin{array}{c}1.0 \\
(3.9)\end{array}$ & $0.007^{*}$ & $0.004^{*}$ & $<0.001^{*}$ & $<0.001^{*}$ \\
\hline $\mathbf{H}_{\mathbf{y}} \mathbf{3}$ & $\begin{array}{c}-5.4 \\
(1.2)\end{array}$ & $\begin{array}{l}-4.1 \\
(2.1)\end{array}$ & $\begin{array}{c}1.1 \\
(4.1)\end{array}$ & $\begin{array}{c}-0.9 \\
(3.6)\end{array}$ & 0.087 & 0.154 & $0.003^{*}$ & $0.001^{*}$ \\
\hline $\mathbf{H}_{\mathrm{y}} 4$ & $\begin{array}{c}0.7 \\
(2.4)\end{array}$ & $\begin{array}{c}1.6 \\
(2.4)\end{array}$ & $\begin{array}{c}5.7 \\
(4.4)\end{array}$ & $\begin{array}{c}3.6 \\
(3.9)\end{array}$ & 0.898 & 0.122 & 0.062 & $0.002^{*}$ \\
\hline
\end{tabular}

Group means and standard deviations (SD)

* Indicates significant difference at $\alpha<0.05$ for the post-hoc Bonferonni analysis.

${ }^{\dagger}$ Represents an asymmetry between limbs on the flat condition at this event.

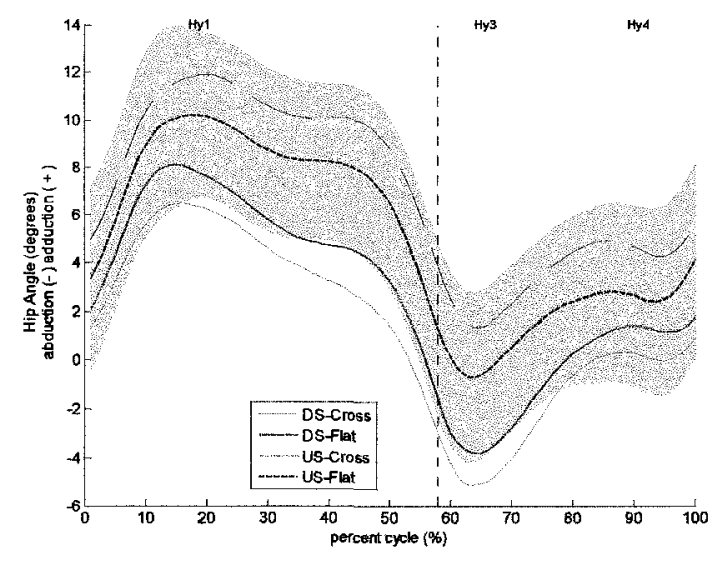

(a)

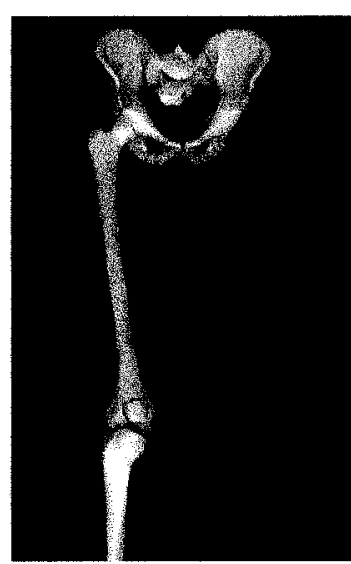

(b)

Figure 17 - (a) Hip Abd/Add angles (degrees) averaged across all subjects and all trials for the DS and UShips under the flat and cross-slope conditions. Vertical line indicates approximate position of TO. Abd (negative), Add (positive). Grey region is the standard deviation of the US-flat condition. (b) Hip Add near $\mathrm{H}_{\mathrm{y}} 1$. 


\subsubsection{Transverse Plane Kinematics}

\subsubsection{Ankle}

Ankle transverse plane angles showed significant differences between side and slope ( $p$ $<0.019$ ) at all events (Fig. 18), but relevant comparisons occurred only at HS, $\mathrm{A}_{\mathrm{z}} 1$, and TO in post-hoc analysis (Table 26). Symmetry was exhibited across sides for the flat condition $(\mathrm{p}>0.791)$.

At HS, differences were seen across conditions for the US and DS-ankles. The slightly IRot $\left(0.6^{\circ}\right)$ US-ankle became ERot $\left(-2.2^{\circ}\right)$ on the cross-slope $(p<0.001)$. The ERot angle $\left(-3.0^{\circ}\right)$ of the DS-ankle became slightly IRot $\left(0.7^{\circ}\right)$ on the cross-slope $(p=0.011)$. At $A_{z} 1$ differences occurred across conditions for the DS-ankle $(p=0.041)$ with ERot decreasing (from $-11.9^{\circ}$ to $-8.6^{\circ}$ ) on the cross-slope. At TO, US-ankle IRot angle decreased (from $6.9^{\circ}$ to $\left.3.3^{\circ}\right)$ on the cross-slope $(p=0.014)$.

Table 25 - Ankle transverse plane angle values (degrees) evaluated at representative gait cycle events and averaged across all trials and subjects for each side/condition permutation. Associated p-values for each relevant pairwise comparison are also presented.

\begin{tabular}{|c|c|c|c|c|c|c|c|c|}
\hline $\mathbf{A}_{\mathbf{z}}$ & $\begin{array}{l}\text { DS/ } \\
\text { Cross }\end{array}$ & $\begin{array}{l}\text { DS/ } \\
\text { Flat }\end{array}$ & $\begin{array}{l}\text { US/ } \\
\text { Cross }\end{array}$ & $\begin{array}{l}\text { US/ } \\
\text { Flat }\end{array}$ & $\begin{array}{c}\text { DS/ } \\
\text { Flat } \\
- \\
\text { US/ } \\
\text { Flat }\end{array}$ & $\begin{array}{c}\text { DS/ } \\
\text { Flat } \\
- \\
\text { DS/ } \\
\text { Cross }\end{array}$ & $\begin{array}{c}\text { DS/ } \\
\text { Cross } \\
- \\
\text { US/ } \\
\text { Cross }\end{array}$ & $\begin{array}{c}\text { US/ } \\
\text { Flat } \\
- \\
\text { US/ } \\
\text { Cross }\end{array}$ \\
\hline HS & $\begin{array}{c}0.7 \\
(5.0)\end{array}$ & $\begin{array}{c}-3.0 \\
(5.6)\end{array}$ & $\begin{array}{c}-2.2 \\
(11.8)\end{array}$ & $\begin{array}{c}0.6 \\
(11.9)\end{array}$ & 1.000 & $0.011^{*}$ & 1.000 & $<0.001^{*}$ \\
\hline $\mathbf{A}_{\mathbf{x}} \mathbf{1}$ & $\begin{array}{c}-8.6 \\
(5.8)\end{array}$ & $\begin{array}{l}-11.9 \\
(5.7)\end{array}$ & $\begin{array}{c}-9.7 \\
(11.0)\end{array}$ & $\begin{array}{c}-8.1 \\
(11.2)\end{array}$ & 0.791 & $0.041^{*}$ & 1.000 & 0.131 \\
\hline TO & $\begin{array}{c}8.4 \\
(8.7)\end{array}$ & $\begin{array}{c}5.5 \\
(5.8)\end{array}$ & $\begin{array}{c}3.3 \\
(11.4)\end{array}$ & $\begin{array}{c}6.9 \\
(11.8)\end{array}$ & 1.000 & 0.267 & 0.396 & $0.014^{*}$ \\
\hline
\end{tabular}

Group means and standard deviations (SD)

* Indicates significant difference at $\alpha<0.05$ for the post-hoc Bonferonni analysis. 


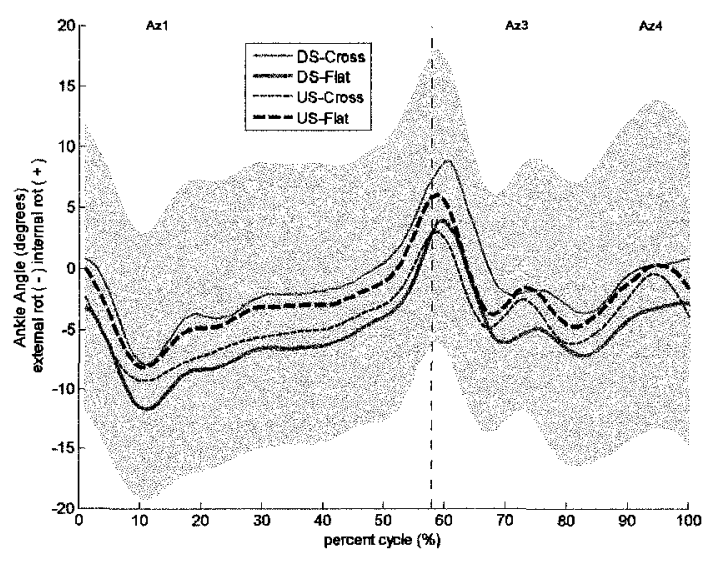

(a)

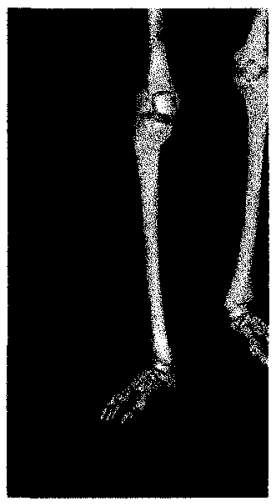

(b)

Figure 18 - (a) Ankle IRot/ERot angles (degrees) averaged across all subjects and all trials for the DS and US-ankles under the flat and cross-slope conditions. Vertical line indicates approximate position of TO. ERot (negative), IRot (positive). Grey region is the standard deviation of the US-flat condition. (b) Ankle ERot during Sw.

\subsubsection{Knee}

No differences in knee transverse angles occurred at all events investigated (Fig. 19).

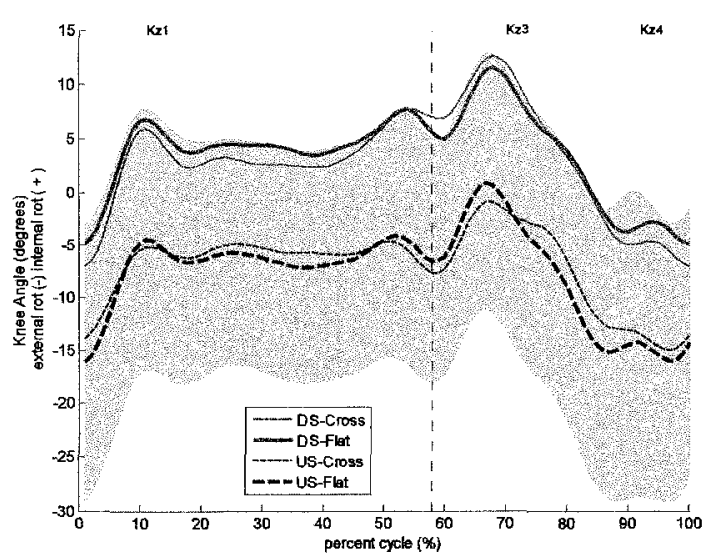

(a)

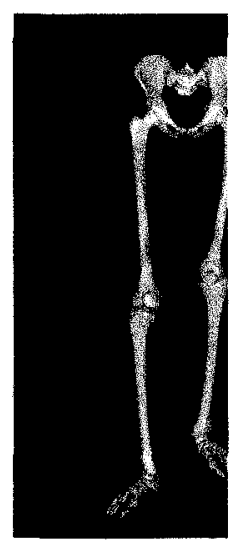

(b)

Figure 19 - (a) Knee IRot/ERot angles (degrees) averaged across all subjects and all trials for the DS and US-knees under the flat and cross-slope conditions. Vertical line indicates approximate position of TO. ERot (negative), IRot (positive). Grey region is the standard deviation of the US-flat condition. (b)Knee in ERot during Sw. 


\subsubsection{Hip}

For the hip transverse plane angles (Fig. 20), interaction differences were significant at all events studied $(\mathrm{p}<0.037)$. Symmetry between the hips was maintained in the transverse plane.

Pairwise comparisons revealed relevant differences to lie only across conditions for the US-hip ( $\mathrm{p}=0.034, \mathrm{p}=0.031$ ) at TO and $\mathrm{H}_{\mathrm{z}} 4$ respectively (Table 26). At TO, ERot increased (from $-4.5^{\circ}$ to $-6.6^{\circ}$ ) on the cross-slope condition. At $\mathrm{H}_{\mathrm{z}} 4$, hip rotation changed from a slightly neutral angle $\left(1.0^{\circ}\right)$ to an ERot $\left(-3.1^{\circ}\right)$ angle on the cross-slope.

Table 26 -Hip transverse plane angle values (degrees) evaluated at representative gait cycle events and averaged across all trials and subjects for each side/condition permutation. Associated p-values for each relevant pairwise comparison are also presented.

\begin{tabular}{|c|c|c|c|c|c|c|c|c|}
\hline $\mathbf{H}_{\mathbf{z}}$ & $\begin{array}{l}\text { DS/ } \\
\text { Cross }\end{array}$ & $\begin{array}{l}\text { DS/ } \\
\text { Flat }\end{array}$ & $\begin{array}{l}\text { US/ } \\
\text { Cross }\end{array}$ & $\begin{array}{l}\text { US/ } \\
\text { Flat }\end{array}$ & $\begin{array}{c}\text { DS/ } \\
\text { Flat } \\
- \\
\text { US/ } \\
\text { Flat }\end{array}$ & $\begin{array}{c}\text { DS/ } \\
\text { Flat } \\
- \\
\text { DS/ } \\
\text { Cross }\end{array}$ & $\begin{array}{c}\text { DS/ } \\
\text { Cross } \\
- \\
\text { US/ } \\
\text { Cross }\end{array}$ & $\begin{array}{c}\text { US/ } \\
\text { Flat } \\
- \\
\text { US/ } \\
\text { Cross }\end{array}$ \\
\hline TO & $\begin{array}{c}0.7 \\
(6.0)\end{array}$ & $\begin{array}{c}-0.1 \\
(6.6)\end{array}$ & $\begin{array}{c}-6.6 \\
(15.3)\end{array}$ & $\begin{array}{c}-4.5 \\
(15.2)\end{array}$ & 1.000 & 0.835 & 1.000 & $0.034^{*}$ \\
\hline $\mathrm{H}_{\mathbf{2}} 4$ & $\begin{array}{c}0.8 \\
(7.3)\end{array}$ & $\begin{array}{c}-0.7 \\
(6.2)\end{array}$ & $\begin{array}{c}-3.1 \\
(18.0)\end{array}$ & $\begin{array}{c}1.0 \\
(18.0)\end{array}$ & 1.000 & 0.423 & 1.000 & $0.031^{*}$ \\
\hline
\end{tabular}

Group means and standard deviations (SD)

* Indicates significant difference at $\alpha<0.05$ for the post-hoc Bonferonni analysis. 


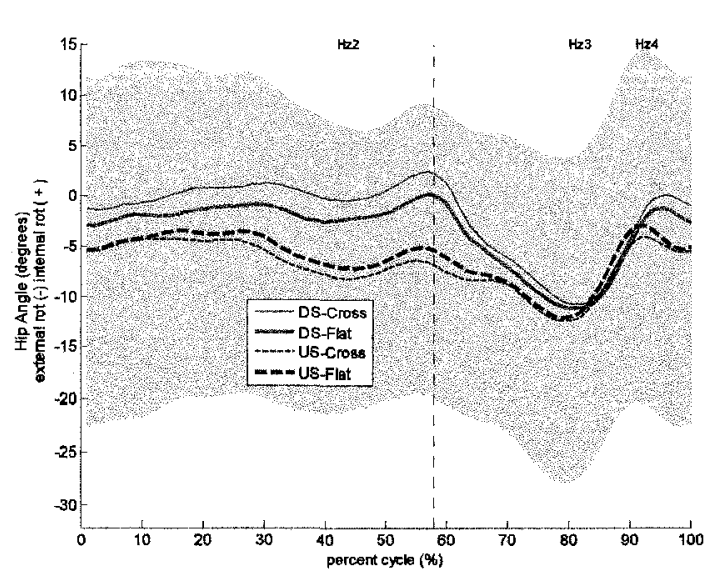

(a)

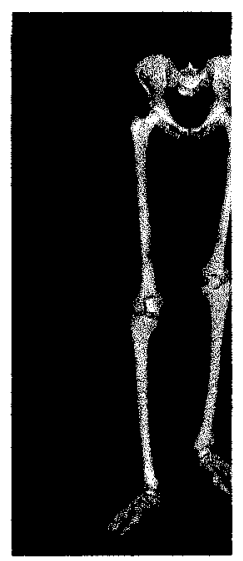

(b)

Figure 20 - (a) Hip IRot/ERot angles (degrees) averaged across all subjects and all trials for the DS and US-hips under the flat and cross-slope conditions. Vertical line indicates approximate position of TO. ERot (negative), IRot (positive). Grey region is the standard deviation of the US-flat condition. (b) Hip in ERot during Sw.

\subsection{Discussion}

\subsubsection{Stride Properties}

On the flat walking condition an average step width of $9.3 \pm 2.7 \mathrm{~cm}$ was reported. This value lies within the range found by other investigators (Whittle, 2002; Owings et al., 2004). Whittle reported normative values ranging from $5.0-13.0 \mathrm{~cm}$, while Owings reported values of $9.5 \pm 1.8 \mathrm{~cm}$ for young adults walking on a treadmill. Lay (Lay et al., 2006) reported values of $1.5 \pm 1.6 \mathrm{~cm}$ for normalized stride length, values from the present study of $168.2 \pm 10.9 \mathrm{~cm}$ are thus slightly greater than Lay’s.

To the knowledge of the investigators a single study has explored the temporo-spatial parameters during cross-slope walking (Nicolaou et al., 2002). The reduction of step width on the cross-slope found here is in agreement with Nicolaou et al. It is believed 
that the reduction in step width on this condition may be a motor control strategy employed by the subjects of this study to help maintain balance. This strategy may help optimize both balance and locomotion needs while on the cross-slope surface. The average decrease of $1.21 \mathrm{~cm}$ reported in this study lead to a $13 \%$ reduction in LLD. Though small, this reduction may allow for easier foot clearance of the US-limb in ESw and reduce the chance of tripping. Studies involving toe-clearance have reported average toe-clearance distances in young adults to range from $1.29 \mathrm{~cm}$ (Winter, 1992) to $1.56 \mathrm{~cm}$ (Begg et al., 2007), thus a small perturbation in toe-clearance height has functional consequences.

\subsubsection{Kinematics}

Flat walking kinematics have been extensively studied in normal populations (Apkarian, 1989; Ounpuu, 1994; Winter et al.,1994; Rose and Gamble, 2006). These studies will form the basis of comparison to the present study's flat walking condition results with Winter's paper taking precedence as the joint angles in all three planes have been reported for all three joints.

\subsubsection{Sagittal Plane kinematics}

On the flat walking condition, sagittal plane kinematics for all three joints showed expected characteristic gait curves with peaks occurring within the range reported by other researchers (Ounpuu, 1994; Winter et al., 1994; Rose and Gamble, 2006). On the cross-slope condition differences from flat were seen in all three joints. The ankle reported the most changes across conditions and sides with the US-ankle reducing PF and increasing DF, while the DS-ankle increased PF and reduced DF. To the knowledge of 
the investigators, cross-slope kinematic data are not available for the ankle and hip. However knee kinematic data are available with DeGarie and Pearsall (2000) revealing increased Flx throughout the entire gait cycle for the US-knee while on a $40 \%\left(23.6^{\circ}\right)$ cross-slope. The results of this study are consistent with DeGarie and Pearsall, showing increased US-knee Flx.

Inspecting the behavior of all three joints in the sagittal plane, it is reasonable to speculate that the different adaptations of the US and DS-limbs in the sagittal plane are the result of the cross-slope inducing a LLD. The DS-limb must remain generally more extended and acts as a functionally shorter limb that must be lengthened. The US-limb must increase Flx due to the cross-slope and acts as a functionally longer limb that must be shortened and thus flexed. The results of the stride property section also support this claim: it is possible that the body reduces step width on the cross-slope condition as an attempt to minimize differences in functional leg length. However, it seems that the sagittal kinematics must also change to fully resolve the locomotor problem of cross-slope walking. Additionally, increased Flx of the US-limb may also help foot clearance as the cross-slope is perceived as an obstacle liable to cause tripping.

\subsubsection{Frontal Plane Kinematics}

For the flat walking condition, frontal plane kinematics agreed well with those presented by Winter et al. (1994). Average kinematic joint patterns used in Apkarian's study (1989) $(n=3)$ fall within the standard deviation of the results presented here, but the individual patterns were slightly different. Rose and Gamble (2006) and Ounpuu (1994) only 
presented hip angles for the frontal plane which were in agreement with the results of the present study.

The main lower-limb adaptations were seen in the frontal plane for the cross-slope condition. Beginning at the ankles, it is clear that the foot must conform to the walking surface to maintain adequate ground contact. However, the body must also realign the body centre of mass (BCOM) by leaning towards the US-side to avoid DS-slippage. This body lean is expressed in the ankle and hip kinematic adaptations seen in this study. The DS-ankle must increase Inv while the US-ankle increases Eve. The DS-hip increases Abd while the Us-hip increasing Add. Pelvis adaptations are not known, but the ankle and hip adaptations may result in a frontal plane drop in pelvis on the DS-side to maintain an upright upper body.

\subsubsection{Transverse Plane Kinematics}

For the flat walking condition, transverse plane kinematics were in general agreement with those of other investigators (Apkarian, 1989; Winter et al., 1994). The data presented by Rose and Gamble (2006) and Ounpuu (1992) reported mean hip IRot angles throughout a large percentage of the gait, although this pattern was not seen in the current data, the data is in agreement taking the standard deviation values into account.

The cross-slope ankle kinematic changes in the transverse plane can be explained by the coupled motion of the subtalar joint in the frontal and transverse planes. As the DS-ankle joint is forced into Inv, obligatory IRot is expected; conversely Eve of the US-ankle brings ERot (Rose and Gamble, 2006). 


\subsection{Conclusion}

Investigation of lower-limb joint kinematics revealed two major adaptations to the crossslope walking condition. In the sagittal plane, the body increases Flx of the US-limb while increasing Ext of the DS-limb in order to reduce the effects on a LLD. The increased Flx of the US-limb also allows for easier foot clearance and the avoidance of tripping. In the frontal plane, the body leans towards the US-limb thus laterally moving the $\mathrm{BCOM}$ in this direction to avoid DS-slippage and bringing asymmetrical responses in the ankle and hip frontal plane angles. Future studies should address the pelvis kinematics as well as the relation between reduced step width and body lean in the frontal plane.

The asymmetrical changes presented here occur on a very modest cross-slope, with the greater slopes appearing in the natural environment being a possible threat to safety in special populations. As older adults have limited ROM of the joints, especially at the ankle (Reeves et al., 2007) it is unknown how well the pathological foot could conform to the demands of the cross-slope surface and how this mis-adaptation could lead to further kinematic changes at the knee and hip. Further studies involving special populations are also needed. 


\subsection{References}

Apkarian, J., Naumann, S., Cairns, B. (1989). A three dimensional kinematic and dynamic model of the lower limb. Journal of Biomechanics, 22(2), 143-155.

Begg, R., Best, R., Dell'Oro, L., Taylor, S. (2007). Minimum foot clearance during walking: Strategies for the minimization of trip-related falls. Gait \& Posture, 25, 191-198.

Campbell, A.J., Reinken, J., Allan, B.C., Martinez, G.S. (1981). Falls in old age: a frequency and related factors. Age and Ageing. 10, 264-70.

DeGarie, L., \& Pearsall, D.J. (2000, August). Gait analysis on a transversely tilted platform. Paper presented at the XIth Congress of the Canadian Society for Biomechanics, Montreal, $Q C$.

Donald, I.P., \& Bulpitt, C.J., (1999). The prognosis of falls in elderly people living at home. Age and Ageing, 28, 121-5.

Grood, E., \& Suntay, W. (1983). A joint coordinate system for the clinical description of three-dimensional motion. Applications to the knee. Journal of Biomechanical Engineering, 105, 136-143.

Kadaba, M.P., Ramakrishnan, H.K., Wooten, M.E., Gainey, J., Gorton, G., Cochran, G.V. (1989). Repeatability of kinematic, kinetic, and electromyographic data in normal adult gait. Journal of Orthopaedic Research, 8(6), 849-860.

Lay, A.N., Hass, C.J., Gregor, R.J. (2006). The effects of sloped surfaces on locomotion: A kinematics and kinetic analysis. Journal of Biomechanics, 39, 1621-1628.

Levangie, P.K., \& Norkin, C.C. (Eds.) (2005). Joint Structure \& Function: A comprehensiveAnalysis ( $4^{\text {th }}$ ed.) (pp 524-527). Philadelphia: F.A. Davis Company.

Lockhart, T.E., Spaulding, J.M., Park, S.H. (2007). Age-related slip avoidance while walking over a known slippery floor surface. Gait \& Posture, 26, 142-149.

Ministry of municipal affairs and housing (Ontario), Building and development branch. (2006). Building Code Compendium, Ontario. Vol I (sec 3.8.3.2). Toronto: Publications Ontario.

McIntosh, A.S., Beatty, K.T., Dwan, L.N., Vickers, D.R. (2006). Gait dynamics on an inclined walkway. Journal of Biomechanics, 39, 2491-2502.

National Guide to Sustainable Municipal Infrastructure. (2004, July). Sidewalk Design, Construction and Maintenance. Retrieved Sept 24, 2007, from http://sustainablecommunities.fcm.ca/files/Infraguide/Roads_and_Sidewalks/side walk_design_constr_maintenance.pdf 
Nester, C.J., van der Linden, M.L., Bowker, P. (2003). Effect of foot orthoses on the kinematics and kinetics of normal walking gait. Gait \& Posture, 17, 180-187.

Nicolaou, M., Pearsall, D.J, Loh, J. (2002, August). Gait adaptation to transverse slopes. Paper presented at the IVth World Congress for Biomechanics, Calgary, AB.

Ounpuu, S. (1994). The biomechanics of walking and running. Clinics in Sports Medicine,4(13).

Owings, T.M., \& Grabiner, M.D. (2004). Variability of step kinematics in young and older adults. Gait \& Posture, 20(1), 26-29.

Pearsall, D.J., Ouckama, R., Loh, J., Bouchard, C.E. (2007, July). Effects of cross slope on gait ground reaction forces. Paper presented at the International Society for Posture \& Gait Research, Burlington, VT.

Reeves, N.D., Spanjaard, M., Mohagheghi, A.A., Baltzopoulos, V., Maganaris, C.N. (2007). Older adults employ alternative strategies to operate within their maximum capabilities when ascending stairs. Journal of Electromyography \& Kinesiology, doi: 10.1016/j.jelekin.2007.09.009.

Riley, O.P., Paolini, G., Della Croce, U., Paylo, K.W., Kerrigan, D.C. (2007). A kinematic and kinetic comparison of overground and treadmill walking in healthy subjects. Gait \& Posture, 26, 17-24.

Rose, J., \& Gamble, J.G. (Eds.) (2006). Human Walking ( $3^{\text {rd }}$ ed) (pp. 44-57). Philadelphia: Lippincott Williams \&Wilkins.

Stokes, I.A., Allard, P.,\& Blanchi, J.P. (Eds) (1995). Three-Dimensional Analysis of Human Movement (ch.5). Champaign, IL: Human Kinetics.

Urrey, S.R. (2002). Redistribution of foot pressure in healthy adults during sideslope walking. Foot \& Ankle International, 23(12), 1112-8.

Vaughan, C.L., Davis, B.L., \& O'Connor, J.C. (1999). Dynamics of human gait (2 ${ }^{\text {nd }}$ ed.). (pp. 15-43, 83-106). Cape Town, South Africa: Kiboho.

Whittle, M.W. (2002). Gait Analysis: An introduction ( $3^{\text {rd }}$ ed.) (p 107). Oxford: Butterworth-Heinemann.

Winter, D.A. (1992). Foot trajectory in human gait: a precise and multifactorial motor control task. Physical Therapy, 72, 45-56.

Winter, D.A., Eng, J.J., Isshac, M.G. (1994). A review of kinetic parameters in human walking. In Levangie, P.K., \& Norkin, C.C. (Eds.) Joint Structure \& Function: A comprehensive Analysis (pp. 525-534). Philadelphia: F.A. Davis Company. 


\section{CHAPTER 5 - LOWER-LIMB KINETICS DURING FLAT AND CROSS-SLOPE WALKING IN HEALTHY INDIVIDUALS}

\subsection{Abstract}

The joint reaction forces (JRF) and moments (JRM), or kinetics, of the lower-limbs during walking have been identified as important gait parameters. This investigation focused on a three-dimensional kinetic analysis of the ankles, knees, and hips during flat $\left(0^{\circ}\right)$ walking versus walking on a transversely tilted surface (cross-slope of $6^{\circ}$ ). Passive optical markers placed on each subject were tracked with concurrent force plate recordings using a Vicon ${ }^{\mathrm{TM}}$ (Los Angeles, CA, USA) system to compute the joint kinetics using a standard Newtonian Inverse Dynamic approach. Ten healthy young adult males performed flat and cross-slope walking trials at their self-selected walking speed. Main kinetic changes occurred in the medio-lateral direction for the JRF and in the frontal plane for the JRM. Most precisely, the medio-lateral JRF at the ankles, knees, and hips were dramatically increased during cross-slope walking. The DS-limb generally reported large increases in lateral JRF, while the US-limb force reversed direction to produce large medial JRF. The JRM in the frontal plane at the knees and hips responded asymmetrically to presumably lean the body towards the US-side to maintain balance and minimize DS-slippage. This modest cross-slope walking condition induced important asymmetrical changes in the lower-limb locomotor patterns and may well represent a substantial physical obstacle to populations with restricted mobility. 


\subsection{Introduction}

The study's underlying purpose is to identify how cross-slopes affect gait. Cross-slopes are a regular feature of our physical environment. In the urban setting, it is common practice to tilt sidewalks and roadways to permit water drainage. Canadian national guidelines recommend a cross-slope inclination of $0.5-2.3^{\circ}$ for that purpose (National Guide to Sustainable Municipal Infrastructure, 2004). Further, the Ontario Building Code recommends curb ramps, such as driveway entrances, to possess a slope between $5-7^{\circ}$ for motor vehicle passage (Ministry of Municipal Affairs and Housing, 2006). Nonetheless, for a pedestrian, sidewalks with intermittent ramps may impede gait and/or present an increased risk of falls. For young adults cross-slopes do not represent a significant challenge, however for elderly and special populations (visually impaired, amputees, wheelchair users, etc) the asymmetrical demands of cross-slope walking may introduce functional muscular-skeletal and balance barriers. In particular, this may precipitate falls, a major cause of injury in elderly populations (Lockhart et al., 2007) with incidences increasing with age (Campbell et al., 1981; Donald and Bulpitt 1999). In addition, the decreased joint flexibility (most notably at the ankles) and strength of older populations (Reeves, et al., 2007) may make cross-slope walking a difficult task to perform. Furthermore, a better knowledge of lower-limb kinetics during non-level walking conditions could aid in the design of a variety of prostheses and walking aids.

An understanding of the forces and moments in all three dimensions at the lower-limb joints, often in conjunction with kinematics, provide researchers and clinicians insight of both normal and pathological gait mechanics (Eng and Winter, 1995). These forces and 
moments drive the kinematics and thus the former dependent variables are the focus of this present study. Repeatable kinetic patterns in flat walking have been shown (Kadaba et al., 1989) and numerous studies have also consistently reported similar characteristic kinetic patterns (Apkarian et al., 1989; Eng and Winter 1995; Vaughan et al., 1999, Nester et al., 2003).

To the knowledge of the authors no study has explored the kinetics of cross-slope walking. Previous studies involving the analysis of ground reaction forces (GRF) during cross-slope walking (Pearsall et al., 2007; chapter 3) as well as kinematics (DeGarie and Pearsall, 2000; Nicolaou et al., 2002; chapter 4) have shown significant departures from the flat walking condition to occur on the cross-slope. Further, a study involving foot pressure (Urrey, 2002) found significant redistribution of pressure on the cross-slope condition. From these previous cross-slope studies, differences in three-dimensional lower-limb kinetics are expected.

Generally, two methods are used to determine joint forces and moments: experimental approaches using invasive telemetric devices or indirect mathematical modeling (Komistek et al., 2005). Here, kinetics were calculated using the latter via an inverse dynamic analysis (IDA) approach using simultaneous collected GRF and kinematic data from previous studies (chapter 3, chapter 4). The aim of this study is therefore to quantify ankle, knee, and hip kinetics of both limbs in all anatomical three planes during crossslope walking. 


\subsection{Methods}

\subsubsection{Subjects}

A sample of ten young healthy adult males, with no history of gait abnormalities, were recruited among the McGill University student population. Excluded were any subjects with a LLD greater than $2.0 \mathrm{~cm}$. Leg length was measured as the distance between the greater trochanter and the lateral malleoli. This study was approved by the McGill University Research Ethics Board Office (Appendix 2) and all subjects signed a consent form before participating in this study (Appendix 1). Subjects wore non-obstructing clothing and walked barefoot along a wooden walkway. A summary of relevant anthropometric data is presented (Table 27).

Table 27 - Summary of subject anthropometrics $(n=10)$

\begin{tabular}{lccccc}
\hline & $\begin{array}{c}\text { Age } \\
\text { (years) }\end{array}$ & $\begin{array}{c}\text { Height } \\
(\mathrm{cm})\end{array}$ & $\begin{array}{c}\text { Body mass } \\
(\mathbf{k g})\end{array}$ & $\begin{array}{c}\text { Right leg length } \\
(\mathbf{c m})\end{array}$ & $\begin{array}{c}\text { Left leg length } \\
(\mathbf{c m})\end{array}$ \\
\hline Mean & 22.6 & 181.7 & 76.8 & 96.0 & 95.8 \\
\hline S.D. & $(3.1)$ & $(6.5)$ & $(8.2)$ & $(3.8)$ & $(3.9)$ \\
\hline
\end{tabular}

\subsubsection{Description of Walkway and Coordinate System}

A walkway was used of length $6.91 \mathrm{~m}$ and width $1.21 \mathrm{~m}$ containing two force plates (AMTI $^{\text {TM }}$, model 0R6-7-1000, Watertown, MA, USA) within its surface (Fig. 21). The force plates were positioned such that two consecutive steps during a stride were captured while each subject walked along the platform. Force plates were isolated from the platform's surface by means of small gaps $(0.5 \mathrm{~cm})$ and stabilized by several sub-platform braces within the walkway both when flat and inclined. To avoid slippage, seven parallel strips of tactile tape were placed along the direction of progression. Following 
conventions set by Vaughan et al. (1999), the Global Coordinate System (GCS) had its origin at the bottom right corner of the first force plate for both conditions.

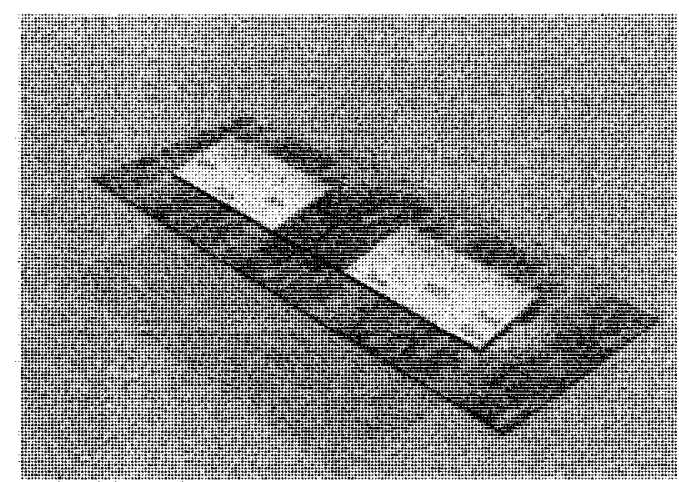

(a)

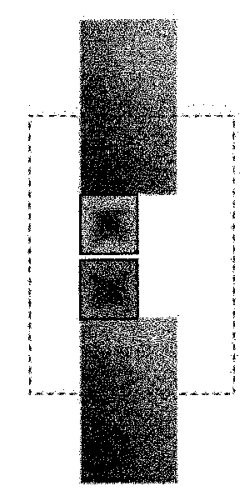

(b)

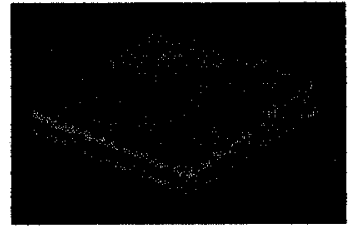

(c)

Figure 21 - Experimental Set-up: (a) cross-slope tilted walking platform with embedded force plates. Footprints show direction of locomotion. (b) Top view of walking platform with dotted outline showing approximate capture area. (c) Coordinate system with origin at bottom right corner of force plate $1 . \mathrm{x}$-axis (red), y-axis(green), z-axis (blue).

\subsubsection{Data Acquisition and Analysis}

After familiarization to both the flat and cross-slope walking conditions, subjects performed barefoot walking trials at their self-selected comfortable pace beginning with the flat condition. Trials were rejected if either foot did not land fully on the force plate during their respective step. In post-processing, five trials per condition for each subject were retained for analysis.

\subsubsection{Joint Reaction Forces and Moments}

Special coordinate data from passive optical markers placed according to the Vicon ${ }^{\mathrm{TM}}$ (Vicon, Los Angeles, USA) Plug-in Gait ${ }^{\mathrm{TM}}$ model were collected at $240 \mathrm{~Hz}$ using a six camera Vicon $^{\mathrm{TM}}$ (Vicon, Los Angeles, USA) system. Data were collected, labeled and 
filtered at $10 \mathrm{~Hz}$ using the Woltring filter, a filter similar in characteristics to the Butterworth filter (Stokes et al. 1995), within the Vicon ${ }^{\mathrm{TM}}$ (Vicon, Los Angeles, USA) software environment which generated lower-limb segment orientations (Fig. 22) as well as joint centre coordinates.

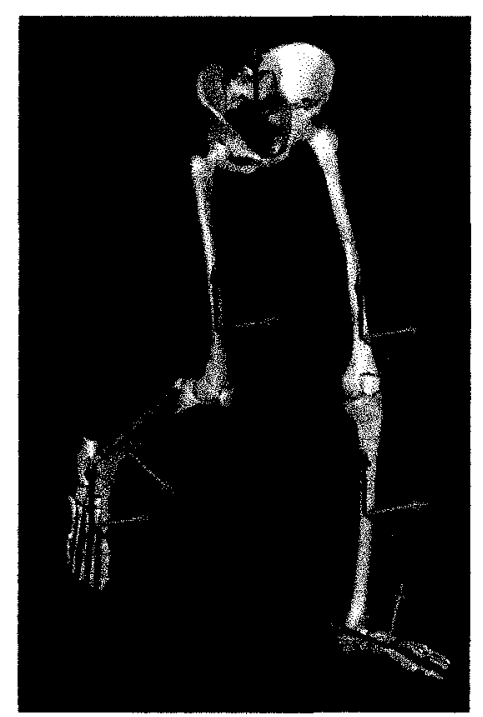

Figure 22 - LCS for each of the lower-limb segments. $x$-axis (blue), $y$-axis (red) and z-axis (green).

Data were then exported into MatLab® (v2006b, The Mathworks Inc., Natwick, MA, USA) where custom routines calculated JRF and JRM according to a standard Newtonian inverse dynamic method using Euler angles and vectors (Vaughan et al., 1999):

$F_{j}=m_{s}\left(a_{s}-g\right)-F_{d i s}$

$$
\text { where } \begin{array}{ll}
\mathrm{F}_{\mathrm{j}} & : \text { force at joint } j \text { (ankle, knee, hip) } \\
\mathrm{m}_{\mathrm{s}} & : \text { mass of segment } s \text { (foot, shank, thigh) } \\
\mathrm{a}_{\mathrm{s}} & : \text { acceleration vector of segment } s \\
\mathrm{~g} & : \text { gravity vector } \\
\mathrm{F}_{\mathrm{dis}} & : \text { force at the distal end of segment } s
\end{array}
$$


$M_{j}=\dot{L}_{s}-M_{\text {res }}$

$$
\begin{aligned}
& \text { where } \quad \mathrm{M}_{\mathrm{j}} \quad \text { : moment at joint } j \text { (ankle, knee, hip) } \\
& \mathrm{L}_{\mathrm{s}} \quad \text { : angular momentum of segment } s \text { (foot, shank, thigh) } \\
& \mathrm{M}_{\text {res }} \text { : residual moment including moment at distal segment, } \\
& \text { and moments produced by forces at proximal and distal } \\
& \text { joints. }
\end{aligned}
$$

The JRF and JRM are computed in terms of anatomical axes of rotation as per the Grood and Suntay method (Grood and Suntay, 1983). Kinetics reported are external JRF and JRM and represent the total quantity acting on the joint from various sources (bone, tendon, ligament and forces) and cannot be deconstructed into their individual components due to insufficient equations (Vaughan et al., 1982).

Between heel strike (HS) and toe-off (TO), JRF and JRM were evaluated at three major events based on the typical vertical GRF force curve (Rose and Gamble, 2006) (Table 30) with kinetic abbreviations noted in Table 28 . HS and TO were calculated as the first and last frame at which the magnitude of the GRF was nearest to $60 \mathrm{~N}$. Additional events based on curve characteristics, as noted on the individual figures, were also evaluated for certain curves. Representative gait cycle percentages based on Ounpuu (1994) and related abbreviations are presented in Table 29. Sign conventions are based on Eng and Winter (1995). Naming conventions for additional events were based on those of McIntosh et al. (2006) with each event having four alpha-numeric characters: The first representing the joint, the second the type of force (linear force or rotation moment), the third the plane and the fourth the event number. For example, $\mathrm{AF}_{\mathbf{x}} 1$ is the $1^{\text {st }}$ ankle JRF in the anteriorposterior direction during early stance. 
Table 28 - Kinetic abbreviations

\begin{tabular}{|l|l|l|l|}
\hline & \multicolumn{1}{|c|}{ Sagittal (x) } & \multicolumn{1}{c|}{ Frontal (y) } & \multicolumn{1}{c|}{ Transverse (z) } \\
\hline Ankle & $\begin{array}{l}\text { Plantarflexion (PF) } \\
\text { Dorsiflexion (DF) }\end{array}$ & $\begin{array}{l}\text { Inversion (Inv) } \\
\text { Eversion (Eve) }\end{array}$ & $\begin{array}{l}\text { External rotation (ERot) } \\
\text { Internal rotation (IRot) }\end{array}$ \\
\hline $\begin{array}{l}\text { Knee }+ \\
\text { Hip }\end{array}$ & $\begin{array}{l}\text { Flexion (Flx) } \\
\text { Extension (Ext) }\end{array}$ & $\begin{array}{l}\text { Abduction (Abd) } \\
\text { Adduction (Add) }\end{array}$ & $\begin{array}{l}\text { External rotation (ERot) } \\
\text { Internal rotation (IRot) }\end{array}$ \\
\hline
\end{tabular}

Table 29 - Gait cycle representative event percentages and abbreviations.

\begin{tabular}{|l|l|l|l|}
\hline Stance Phase (St) 0-60\% & Swing Phase (Sw): 61-100\% \\
\hline & percentage & Event & percentage \\
\hline Event & $0-10 \%$ & Early Swing (ESw): & $61-70 \%$ \\
Early Stance (ESt): & $11-30 \%$ & Midswing (MSw): & $71-85 \%$ \\
Midstance (MSt): & $31-50 \%$ & Terminal Swing (TSw): & $86-100 \%$ \\
Terminal stance (TSt): & $51-60 \%$ & & \\
Preswing (PSw): & & & \\
& & & \\
\hline
\end{tabular}

Table 30 - Representative gait cycle events used for data analysis including description and method of calculation.

\begin{tabular}{ll}
\hline Gait Cycle events & Description/Calculation \\
\hline Early Stance (ESt): & $\begin{array}{l}\text { Last contact of the contralateral foot with the ground during ipsilateral } \mathrm{St} \\
\text { phase, calculated as the first peak in vertical GRF }\left(\mathrm{MaxF}_{\mathrm{z}} 1\right) .\end{array}$ \\
Midstance (MSt): & $\begin{array}{l}\text { The minimum vertical GRF value during single support } \\
\left(\mathrm{MinF}_{\mathrm{z}}\right) .\end{array}$ \\
Terminal Stance (TSt): & $\begin{array}{l}\text { The second peak in vertical GRF as single support ends and double support } \\
\text { begins }\left(\mathrm{MaxF}_{\mathrm{z}} 2\right) .\end{array}$
\end{tabular}

\subsubsection{Statistical Analysis}

Analysis of joint kinetics at important gait events (Table 30) were made between conditions (flat $\left(0^{\circ}\right)$ and cross-slope $\left(6^{\circ}\right)$ ) and across limbs (DS and US) using a within subject analysis of variance (2X2 ANOVA) for repeated measures at an $\alpha=0.05$ level. Post-hoc analyses using a Bonferonni correction were computed for each multiple 
comparison in cases in which significant interaction between condition and side was achieved. Significance level was set at $\alpha=0.05$ (after Bonferonni adjustment). SPSS ${ }^{\mathrm{TM}}$ (version 15.0) was used for statistical analysis.

\subsection{Results}

\subsubsection{Antero-Posterior Reaction Forces}

\subsubsection{Ankle}

The ankle anterior-posterior JRF (in line with the long axis of the foot) (Fig. 23) showed significant interaction differences $(\mathrm{p}<0.001)$ between sides and conditions at all events. For the flat condition there were no significant differences between sides indicating symmetry between the ankles.

Pairwise comparisons revealed significant differences across conditions for the US and DS-ankles (Table 30). At $\mathrm{AF}_{\mathrm{x}} 1$, differences occurred between conditions for the DS-ankle only $(p=0.014)$. The DS-ankle experienced a decreased anterior JRF (from $1.31 \mathrm{~N} / \mathrm{kg}$ to $1.07 \mathrm{~N} / \mathrm{kg}$ ) on the cross-slope condition. At $\mathrm{MaxF}_{\mathrm{z}} 1$, differences were seen across conditions for the US-ankle and across ankles for the cross-slope condition $(p=0.014$ and $p=0.004$ respectively). The US-ankle had a posterior JRF of $-0.51 \mathrm{~N} / \mathrm{kg}$ on the flat condition and a smaller anterior JRF of $0.07 \mathrm{~N} / \mathrm{kg}$ on the cross-slope condition. The DSankle exhibited a posterior JRF of $-0.79 \mathrm{~N} / \mathrm{kg}$ at this event. At $\mathrm{MinF}_{\mathrm{z}}$ and $\mathrm{MaxF}_{\mathrm{z}} 2$, differences were seen across conditions for both the DS-ankle $(p=0.043$ and $p=0.037$ respectively) and US-ankle ( $p=0.003$ and $p<0.001$ respectively) as well as between ankles ( $p=0.004$ and $p=0.010$ respectively) during the cross slope condition. The DS- 
ankle revealed a change in direction of force going from an anterior JRF $(0.24 \mathrm{~N} / \mathrm{kg}$ and $0.41 \mathrm{~N} / \mathrm{kg}$ at $\mathrm{MinFz}$ and $\operatorname{MaxF}_{\mathrm{z}} 2$ respectively) on the flat condition to a posterior JRF ($0.18 \mathrm{~N} / \mathrm{kg}$ and $-0.30 \mathrm{~N} / \mathrm{kg}$ at $\mathrm{MinFz}$ and $\mathrm{MaxF}_{\mathrm{z}} 2$ respectively) on the cross-slope. The USankle experienced an increase in anterior JRF $(0.23 \mathrm{~N} / \mathrm{kg}$ to $0.63 \mathrm{~N} / \mathrm{kg}$ and from 0.37 $\mathrm{N} / \mathrm{kg}$ to $1.03 \mathrm{~N} / \mathrm{kg}$ for $\mathrm{MinFz}$ and $\mathrm{MaxF}_{\mathrm{z}} 2$ respectively) on the cross-slope. $\mathrm{At}_{\mathrm{AF}} 2$, the maximum posterior JRF in TSt, a significant decrease $(p=0.001)$ in posterior JRF for the US-ankle (from $-1.35 \mathrm{~N} / \mathrm{kg}$ to $-1.10 \mathrm{~N} / \mathrm{kg}$ ) was seen on the cross-slope.

Table 31 - Ankle antero-posterior JRF evaluated at representative gait cycle events and averaged across all trials and subjects for each side/condition permutation. Associated p-values for each relevant pairwise comparison are also presented.

\begin{tabular}{|c|c|c|c|c|c|c|c|c|}
\hline $\mathbf{A}_{\mathbf{x}}$ & $\begin{array}{l}\text { DS/ } \\
\text { Cross }\end{array}$ & $\begin{array}{l}\text { DS/ } \\
\text { Flat }\end{array}$ & $\begin{array}{l}\text { US/ } \\
\text { Cross }\end{array}$ & $\begin{array}{l}\text { US/ } \\
\text { Flat }\end{array}$ & $\begin{array}{l}\text { DS/ } \\
\text { Flat } \\
- \\
\text { US/ } \\
\text { Flat }\end{array}$ & $\begin{array}{c}\text { DS/ } \\
\text { Flat } \\
- \\
\text { DS/ } \\
\text { Cross }\end{array}$ & $\begin{array}{c}\text { DS/ } \\
\text { Cross } \\
- \\
\text { US/ } \\
\text { Cross }\end{array}$ & $\begin{array}{c}\text { US/ } \\
\text { Flat } \\
- \\
\text { US/ } \\
\text { Cross }\end{array}$ \\
\hline $\mathbf{A F}_{\mathbf{x}} \mathbf{1}$ & $\begin{array}{c}1.07 \\
(0.64)\end{array}$ & $\begin{array}{c}1.31 \\
(0.58)\end{array}$ & $\begin{array}{c}1.24 \\
(0.55)\end{array}$ & $\begin{array}{c}1.09 \\
(0.47)\end{array}$ & 0.068 & $0.014^{*}$ & 0.482 & 0.603 \\
\hline $\mathbf{M a x F}_{\mathrm{z}} \mathbf{1}$ & $\begin{array}{c}-0.79 \\
(0.88)\end{array}$ & $\begin{array}{c}-0.39 \\
(0.91)\end{array}$ & $\begin{array}{c}0.07 \\
(0.80)\end{array}$ & $\begin{array}{c}-0.51 \\
(0.81)\end{array}$ & 1.000 & 0.149 & 0.004 & $0.014^{\star}$ \\
\hline $\operatorname{MinF}_{\mathbf{z}}$ & $\begin{array}{c}-0.18 \\
(0.55)\end{array}$ & $\begin{array}{c}0.24 \\
(0.59)\end{array}$ & $\begin{array}{c}0.63 \\
(0.46)\end{array}$ & $\begin{array}{c}0.23 \\
(0.46)\end{array}$ & 1.000 & $0.043^{\star}$ & $0.004^{*}$ & $0.003^{*}$ \\
\hline $\operatorname{MaxF}_{\mathrm{z}} 2$ & $\begin{array}{c}-0.30 \\
(0.87)\end{array}$ & $\begin{array}{c}0.41 \\
(0.56)\end{array}$ & $\begin{array}{c}1.03 \\
(0.64)\end{array}$ & $\begin{array}{c}0.37 \\
(0.61)\end{array}$ & 1.000 & $0.037^{*}$ & $0.010^{*}$ & $<0.001$ \\
\hline $\mathbf{A F}_{\mathrm{x}} \mathbf{2}$ & $\begin{array}{c}-1.60 \\
(0.71)\end{array}$ & $\begin{array}{l}-1.19 \\
(0.31)\end{array}$ & $\begin{array}{l}-1.10 \\
(0.32)\end{array}$ & $\begin{array}{l}-1.35 \\
(0.34)\end{array}$ & 0.190 & 0.368 & 0.188 & 0.001 * \\
\hline
\end{tabular}

Group means and standard deviations (SD)

* Indicates significant difference at $\alpha<0.05$ for the post-hoc Bonferonni analysis. 


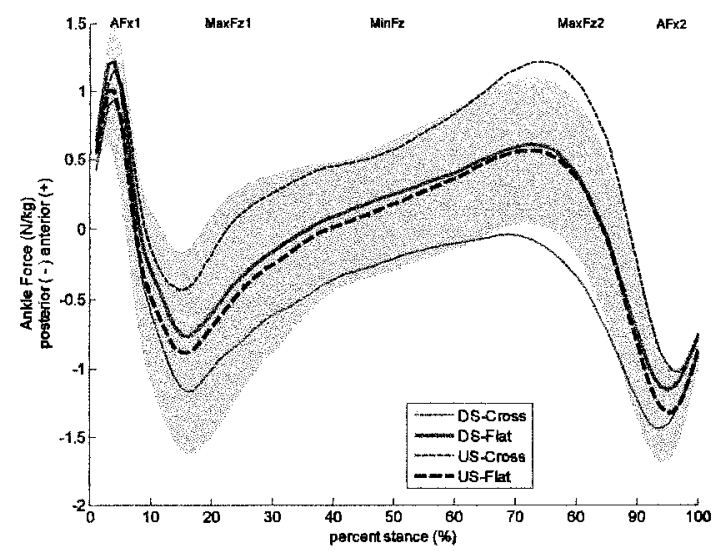

(a)

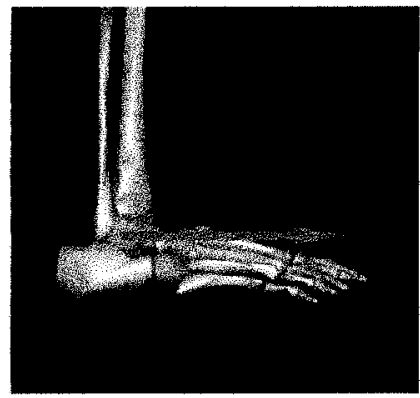

(b)

Figure 23 - (a) Ankle antero-posterior JRF (N/kg) averaged across all subjects and all trials for the DS and US-ankles under the flat and cross-slope conditions. The antero-posterior JRF at the ankle represents a force in line with the longitudinal axis of the foot. Anterior (positive), Posterior (negative). Grey region is the standard deviation of the US-flat condition. (b) An ankle anterior JRF vector.

\subsubsection{Knee}

The knee antero-posterior JRF (Fig. 24) showed significant interaction differences ( $p<0.009$ ) across sides and conditions at all events under study, but during post-hoc comparisons relevant differences were not seen at $\operatorname{MaxF}_{z} 2$ (Table 31). Symmetry was seen across knees for the flat condition.

At $\mathrm{KF}_{\mathrm{x}} 1$, differences were seen across conditions for the US-knee and across knees for the cross-slope condition $(\mathrm{p}=0.002$ and $\mathrm{p}=0.001$ respectively). The US-knee exhibited a reduced posterior JRF (from $-1.15 \mathrm{~N} / \mathrm{kg}$ to $-0.82 \mathrm{~N} / \mathrm{kg}$ ) on the cross-slope condition. The DS-knee disclosed a greater posterior JRF $(-1.39 \mathrm{~N} / \mathrm{kg})$ than the US-knee on the crossslope condition. At $\operatorname{MaxF}_{\mathrm{z}} 1$ and $\mathrm{MinF}_{\mathrm{z}}$ differences were seen across conditions for the US-limb only ( $p=0.001$ and $p=0.015$ respectively). The anterior JRF increased (from $1.00 \mathrm{~N} / \mathrm{kg}$ to $1.76 \mathrm{~N} / \mathrm{kg}$ at MaxFz1 and from $1.13 \mathrm{~N} / \mathrm{kg}$ to $1.56 \mathrm{~N} / \mathrm{kg}$ at MinFz) for the cross-slope condition. 
Table 32 - Knee antero-posterior JRF evaluated at representative gait cycle events and averaged across all trials and subjects for each side/condition permutation. Associated p-values for each relevant pairwise comparison are also presented.

\begin{tabular}{|c|c|c|c|c|c|c|c|c|}
\hline $\mathbf{K}_{\mathbf{x}}$ & $\begin{array}{l}\text { DS/ } \\
\text { Cross }\end{array}$ & $\begin{array}{l}\text { DS/ } \\
\text { Flat }\end{array}$ & $\begin{array}{l}\text { US/ } \\
\text { Cross }\end{array}$ & $\begin{array}{l}\text { US/ } \\
\text { Flat }\end{array}$ & $\begin{array}{c}\text { DS/ } \\
\text { Flat } \\
- \\
\text { US/ } \\
\text { Flat }\end{array}$ & $\begin{array}{c}\text { DS/ } \\
\text { Flat } \\
- \\
\text { DS/ } \\
\text { Cross }\end{array}$ & $\begin{array}{c}\text { DS/ } \\
\text { Cross } \\
- \\
\text { US/ } \\
\text { Cross }\end{array}$ & $\begin{array}{c}\text { US/ } \\
\text { Flat } \\
- \\
\text { US/ } \\
\text { Cross }\end{array}$ \\
\hline $\mathrm{KF}_{\mathbf{x}} \mathbf{1}$ & $\begin{array}{c}-1.39 \\
(0.42)\end{array}$ & $\begin{array}{l}-1.25 \\
(0.19)\end{array}$ & $\begin{array}{c}-0.82 \\
(0.28)\end{array}$ & $\begin{array}{c}-1.15 \\
(0.16)\end{array}$ & 0.341 & 1.000 & $0.001^{*}$ & $0.002^{*}$ \\
\hline $\operatorname{MaxF}_{\mathrm{z}} \mathbf{1}$ & $\begin{array}{c}1.01 \\
(0.72)\end{array}$ & $\begin{array}{c}1.25 \\
(0.54)\end{array}$ & $\begin{array}{c}1.76 \\
(0.63)\end{array}$ & $\begin{array}{c}1.00 \\
(0.95)\end{array}$ & 1.000 & 1.000 & 0.183 & 0.001 * \\
\hline $\operatorname{MinF}_{\mathbf{z}}$ & $\begin{array}{c}1.23 \\
(0.62)\end{array}$ & $\begin{array}{c}1.32 \\
(0.51)\end{array}$ & $\begin{array}{c}1.56 \\
(0.62)\end{array}$ & $\begin{array}{c}1.13 \\
(0.85)\end{array}$ & 1.000 & 1.000 & 0.540 & $0.015^{*}$ \\
\hline
\end{tabular}

Group means and standard deviations (SD)

* Indicates significant difference at $\alpha<0.05$ for the post-hoc Bonferonni analysis.

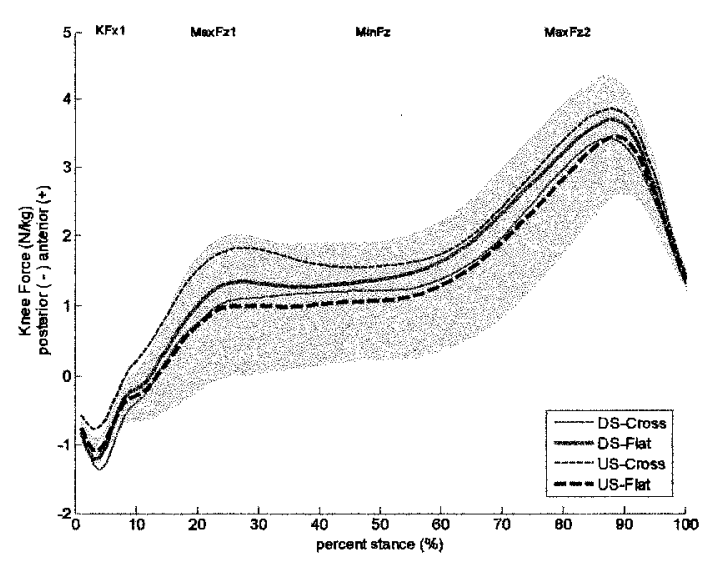

(a)



(b)

Figure 24 - (a) Knee antero-posterior JRF (N/kg) averaged across all subjects and all trials for the DS and US-knees under the flat and cross-slope conditions. The antero-posterior JRF at the knee represents a force in line with the floating axis perpendicular to both the medio-lateral axis of the thigh and the longitudinal axis of the shank. Anterior (positive), Posterior (negative). Grey region is the standard deviation of the USflat condition. (b) A knee anterior JRF vector.

\subsubsection{Hip}

No significant differences were found for all events under study for the hip anteroposterior JRF (Fig 25). 


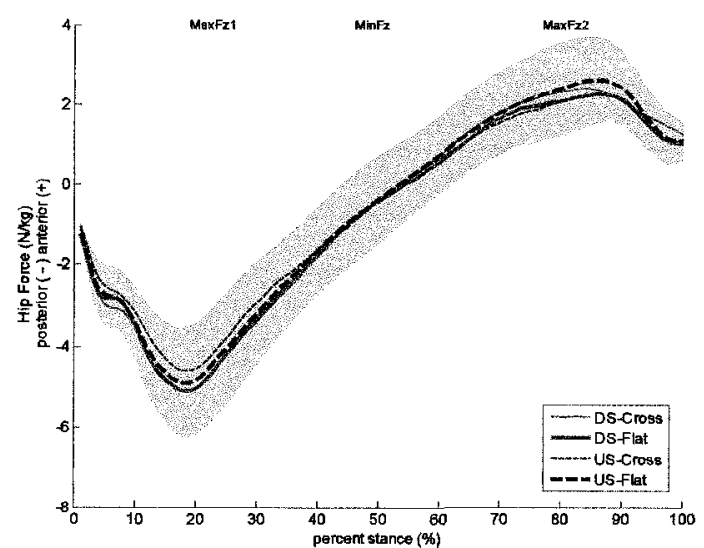

(a)

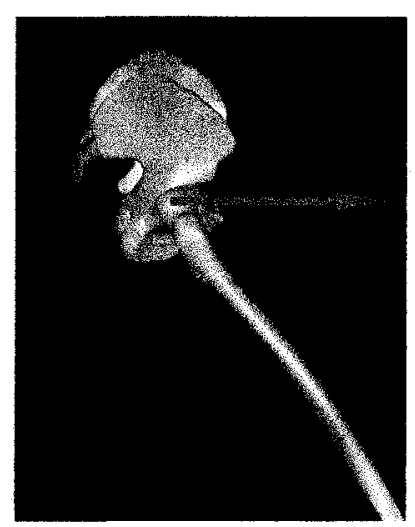

(b)

Figure 25 - (a) Hip antero-posterior JRF (N/kg) averaged across all subjects and all trials for the DS and US-hips under the flat and cross-slope conditions. The antero-posterior JRF at the hips represents a force in line with the floating axis perpendicular to both the medio-lateral axis of the pelvis and longitudinal axis of the thigh. Anterior (positive), Posterior (negative). Grey region is the standard deviation of the US-flat condition. (b) A hip anterior JRF vector.

\subsubsection{Medio-Lateral Reaction Forces}

\subsubsection{Ankle}

The ankle medio-lateral JRF (Fig. 26) showed significant differences $(p<0.001)$ across sides and condition at all events. Symmetry was maintained for the flat condition.

At all three events, differences were seen across conditions for both ankles as well as across ankles for the cross-slope condition $(\mathrm{p}<0.001)$ (Table 33). For the US-ankle, the lateral JRF reversed directions and increased substantially on the cross-slope (from -0.57 $\mathrm{N} / \mathrm{kg}$ to $1.62 \mathrm{~N} / \mathrm{kg}$ for $\mathrm{MaxF}_{\mathrm{z}} 1 ;-0.45 \mathrm{~N} / \mathrm{kg}$ to $0.96 \mathrm{~N} / \mathrm{kg}$ for $\mathrm{MinF}_{\mathrm{z}}$ and $-0.27 \mathrm{~N} / \mathrm{kg}$ to 1.83 $\mathrm{N} / \mathrm{kg}$ for $\mathrm{MaxF}_{\mathrm{z}} 2$ ). For the DS-ankle, a greater than three times increase in lateral JRF (from $-0.94 \mathrm{~N} / \mathrm{kg}$ to $-3.01 \mathrm{~N} / \mathrm{kg}$ for $\mathrm{MaxF}_{\mathrm{z}} 1 ;-0.65 \mathrm{~N} / \mathrm{kg}$ to $-2.05 \mathrm{~N} / \mathrm{kg}$ for $\mathrm{MinF}_{\mathrm{z}} ;-0.72$ $\mathrm{N} / \mathrm{kg}$ to $-2.73 \mathrm{~N} / \mathrm{kg}$ for $\mathrm{MaxF}_{\mathrm{z}} 2$ ) was experienced during the cross-slope conditions. 
Across ankles, for the cross-slope condition, large opposite JRF exist. The DS-ankle experiencing large lateral JRF while the US-ankle reports large medial JRF.

Table 33 - Ankle medio-lateral JRF evaluated at representative gait cycle events and averaged across all trials and subjects for each side/condition permutation. Associated p-values for each relevant pairwise comparison are also presented.

\begin{tabular}{|c|c|c|c|c|c|c|c|c|}
\hline $\mathbf{A}_{\mathbf{y}}$ & $\begin{array}{l}\text { DS/ } \\
\text { Cross }\end{array}$ & $\begin{array}{l}\text { DS/ } \\
\text { Flat }\end{array}$ & $\begin{array}{l}\text { US/ } \\
\text { Cross }\end{array}$ & $\begin{array}{l}\text { US/ } \\
\text { Flat }\end{array}$ & $\begin{array}{c}\text { DS/ } \\
\text { Flat } \\
- \\
\text { US/ } \\
\text { Flat }\end{array}$ & $\begin{array}{c}\text { DS/ } \\
\text { Flat } \\
- \\
\text { DS/ } \\
\text { Cross }\end{array}$ & $\begin{array}{c}\text { DS/ } \\
\text { Cross } \\
- \\
\text { US/ } \\
\text { Cross }\end{array}$ & $\begin{array}{c}\text { US/ } \\
\text { Flat } \\
- \\
\text { US/ } \\
\text { Cross }\end{array}$ \\
\hline $\operatorname{MaxF}_{z} 1$ & $\begin{array}{c}-3.01 \\
(0.85)\end{array}$ & $\begin{array}{c}-0.94 \\
(0.70)\end{array}$ & $\begin{array}{c}1.62 \\
(0.94)\end{array}$ & $\begin{array}{c}-0.57 \\
(0.72)\end{array}$ & 0.360 & $<0.001^{*}$ & $<0.001^{*}$ & $<0.001^{*}$ \\
\hline $\operatorname{MinF}_{z}$ & $\begin{array}{c}-2.05 \\
(0.67)\end{array}$ & $\begin{array}{c}-0.65 \\
(0.580\end{array}$ & $\begin{array}{c}0.96 \\
(0.60)\end{array}$ & $\begin{array}{c}-0.45 \\
(0.57)\end{array}$ & 1.000 & $<0.001^{*}$ & $<0.001^{*}$ & $<0.001^{*}$ \\
\hline $\operatorname{MaxF}_{z} 2$ & $\begin{array}{c}-2.73 \\
(0.98)\end{array}$ & $\begin{array}{c}-0.72 \\
(0.950\end{array}$ & $\begin{array}{c}1.83 \\
(1.19)\end{array}$ & $\begin{array}{c}-0.27 \\
(1.15)\end{array}$ & 0.780 & $<0.001$ * & $<0.001^{*}$ & $<0.001$ * \\
\hline
\end{tabular}

Group means and standard deviations (SD)

* Indicates significant difference at $\alpha<0.05$ for the post-hoc Bonferonni analysis.

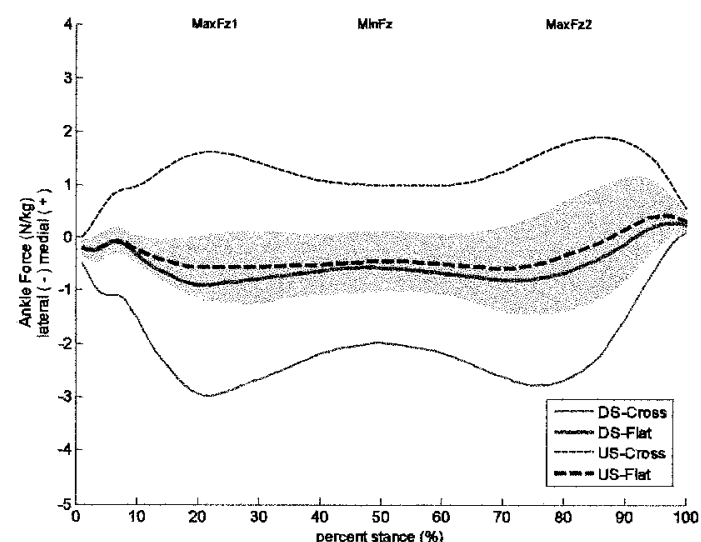

(a)

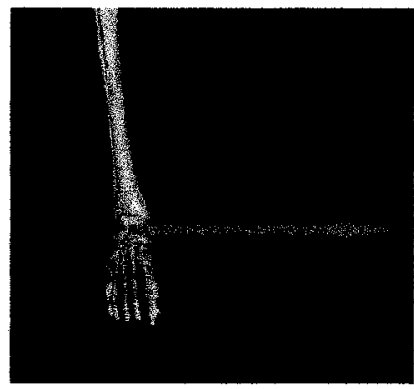

(b)

Figure 26 - (a) Ankle medio-lateral JRF (N/kg) averaged across all subjects and all trials for the DS and US-ankles under the flat and cross-slope conditions. The medio-lateral JRF at the ankle represents a force in line with the medio-lateral axis of the shank. Medial (positive), Lateral (negative). Grey region is the standard deviation of the US-flat condition. (b) An ankle medial JRF vector.

\subsubsection{Knee}

For the knee medio-lateral JRF (Fig. 27), significant interaction differences $(p<0.001)$ were seen at all events. Symmetry was also observed $(p=1.000)$ at all events. 
At all events, pairwise comparisons revealed differences to lie across conditions for both knees as well as across knees for the cross-slope condition ( $p<0.001)$ (Table 34). Beginning with the first two events $\left(\mathrm{KF}_{\mathrm{y}} 1\right.$ and $\left.\mathrm{MaxF}_{\mathrm{z}} 1\right)$, the US-knee simply experienced an increase in medial JRF (from 1.01 N/kg to $2.01 \mathrm{~N} / \mathrm{kg}$ and from $0.11 \mathrm{~N} / \mathrm{kg}$ to $2.30 \mathrm{~N} / \mathrm{kg}$ for $\mathrm{KF}_{\mathrm{y}} 1$ and $\mathrm{MaxF}_{\mathrm{z}} 1$ respectively). The DS-knee experienced a change in direction of force going from slightly medial $\left(0.88 \mathrm{~N} / \mathrm{kg}\right.$ and $0.04 \mathrm{~N} / \mathrm{kg}$ at $\mathrm{KF}_{\mathrm{y}} 1$ and $\mathrm{MaxF}_{\mathrm{z}} 1$ respectively) to a laterally directed $\left(-0.04 \mathrm{~N} / \mathrm{kg}\right.$ and $-2.23 \mathrm{~N} / \mathrm{kg}$ at $\mathrm{KF}_{\mathrm{y}} 1$ and $\mathrm{MaxF}_{\mathrm{z}} 1$ respectively) JRF on the cross-slope. At $\mathrm{MinF}_{\mathrm{z}}$ and $\mathrm{MaxF}_{\mathrm{z}} 2$, the US-knee experienced a change in direction of force $(-0.52 \mathrm{~N} / \mathrm{kg}$ to $0.96 \mathrm{~N} / \mathrm{kg}$ and $-1.05 \mathrm{~N} / \mathrm{kg}$ to $1.16 \mathrm{~N} / \mathrm{kg}$ for $\mathrm{MinF}_{\mathrm{z}}$ and $\left.\mathrm{MaxF}_{\mathrm{z}} 2\right)$ while the DS-knee increased lateral JRF (-0.46 N/kg to-2.06 N/kg and $-0.84 \mathrm{~N} / \mathrm{kg}$ to $-3.04 \mathrm{~N} / \mathrm{kg}$ for $\mathrm{MinF}_{\mathrm{Z}}$ and $\mathrm{MaxF}_{\mathrm{z}} 2$ ). The net result across sides for the cross-slope condition being oppositely directed JRF at all events.

Table 34 - knee medio-lateral JRF evaluated at representative gait cycle events and averaged across all trials and subjects for each side/condition permutation. Associated p-values for each relevant pairwise comparison are also presented.

\begin{tabular}{|c|c|c|c|c|c|c|c|c|}
\hline $\mathbf{K}_{\mathbf{y}}$ & $\begin{array}{l}\text { DS/ } \\
\text { Cross }\end{array}$ & $\begin{array}{l}\text { DS/ } \\
\text { Flat }\end{array}$ & $\begin{array}{l}\text { US/ } \\
\text { Cross }\end{array}$ & $\begin{array}{l}\text { US/ } \\
\text { Flat }\end{array}$ & $\begin{array}{c}\text { DS/ } \\
\text { Flat } \\
- \\
\text { US/ } \\
\text { Flat }\end{array}$ & $\begin{array}{c}\text { DS/ } \\
\text { Flat } \\
- \\
\text { DS/ } \\
\text { Cross }\end{array}$ & $\begin{array}{c}\text { DS/ } \\
\text { Cross } \\
- \\
\text { US/ } \\
\text { Cross }\end{array}$ & $\begin{array}{c}\text { US/ } \\
\text { Flat } \\
- \\
\text { US/ } \\
\text { Cross }\end{array}$ \\
\hline $\mathbf{K F}_{\mathbf{y}} \mathbf{1}$ & $\begin{array}{c}-0.04 \\
(0.45)\end{array}$ & $\begin{array}{c}0.88 \\
(0.47)\end{array}$ & $\begin{array}{c}2.01 \\
(0.44)\end{array}$ & $\begin{array}{c}1.01 \\
(0.49)\end{array}$ & 1.000 & $<0.001^{*}$ & $<0.001 *$ & $<0.001$ * \\
\hline $\operatorname{MaxF}_{z} 1$ & $\begin{array}{c}-2.23 \\
(0.89)\end{array}$ & $\begin{array}{c}0.04 \\
(0.72)\end{array}$ & $\begin{array}{c}2.30 \\
(0.47)\end{array}$ & $\begin{array}{c}0.11 \\
(0.83)\end{array}$ & 1.000 & $<0.001^{*}$ & $<0.001$ * & $<0.001 *$ \\
\hline $\operatorname{MinF}_{z}$ & $\begin{array}{c}-2.06 \\
(0.55)\end{array}$ & $\begin{array}{c}-0.46 \\
(0.38)\end{array}$ & $\begin{array}{c}0.96 \\
(0.35)\end{array}$ & $\begin{array}{l}-0.52 \\
(0.34)\end{array}$ & 1.000 & $<0.001 *$ & $<0.001^{*}$ & $<0.001^{*}$ \\
\hline $\operatorname{MaxF}_{z} 2$ & $\begin{array}{c}-3.04 \\
(0.91)\end{array}$ & $\begin{array}{c}-0.84 \\
(0.62)\end{array}$ & $\begin{array}{c}1.16 \\
(0.69)\end{array}$ & $\begin{array}{l}-1.05 \\
(0.76)\end{array}$ & 1.000 & $<0.001 *$ & $<0.001^{*}$ & $<0.001^{*}$ \\
\hline
\end{tabular}

Group means and standard deviations (SD)

* Indicates significant difference at $\alpha<0.05$ for the post-hoc Bonferonni analysis. 


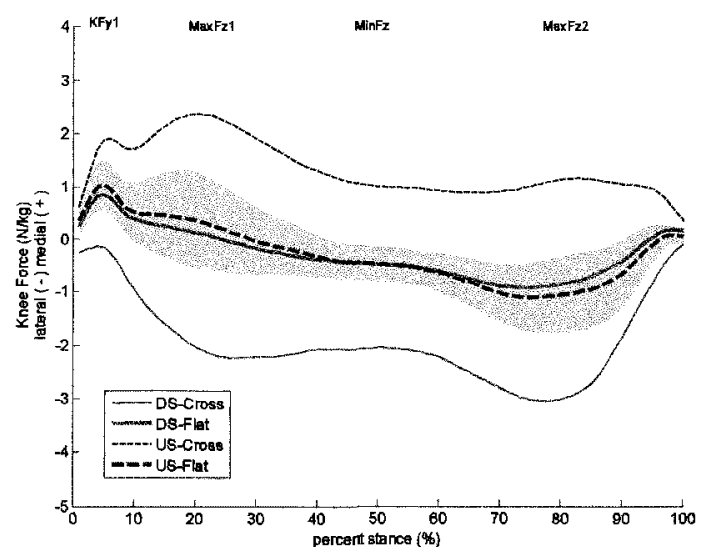

(a)

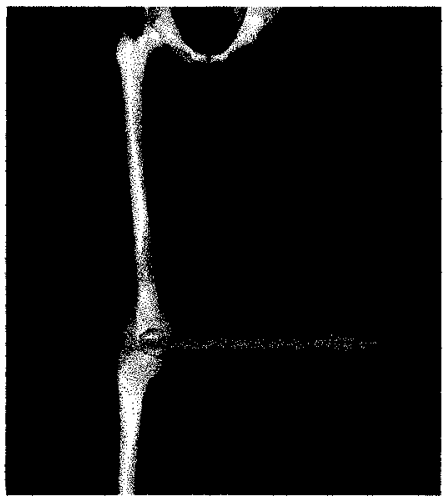

(b)

Figure 27 - (a) Knee medio-lateral JRF (N/kg) averaged across all subjects and all trials for the DS and US-knees under the flat and cross-slope conditions. The medio-lateral JRF at the knee represents a force in line with the medio-lateral axis of the thigh. Medial (positive), Lateral (negative). Grey region is the standard deviation of the US-flat condition. (b) A knee medial JRF vector.

\subsubsection{Hip}

Hip medio-lateral JRF (Fig. 28) showed significant interaction across sides and conditions ( $p<0.001)$ at all events. A small asymmetry was seen across the DS and US-hips during the flat condition (approximately $0.8 \mathrm{~N} / \mathrm{kg}$ ), however the intra-limb differences across conditions were substantial (approximately $2.6 \mathrm{~N} / \mathrm{kg}$ ).

Pairwise comparisons revealed large differences $(\mathrm{p}<0.001)$ across conditions for both hips as well as across hips for the cross-slope condition at all events under study (Table 35). At $\operatorname{MaxF}_{\mathrm{z}} 1$, the US-hip saw an increase in medial JRF (from $0.86 \mathrm{~N} / \mathrm{kg}$ to 3.62 $\mathrm{N} / \mathrm{kg}$ ) on the cross-slope. The DS-hip JRF changed directions from a medial to a lateral JRF (from $0.11 \mathrm{~N} / \mathrm{kg}$ to $-2.72 \mathrm{~N} / \mathrm{kg}$ ) on the cross-slope condition. At $\mathrm{MinF}_{\mathrm{z}}$, the US-hip increased its medial JRF (from $0.09 \mathrm{~N} / \mathrm{kg}$ to $2.17 \mathrm{~N} / \mathrm{kg}$ ), while the DS-hip increased its lateral JRF (from $-0.48 \mathrm{~N} / \mathrm{kg}$ to $-2.60 \mathrm{~N} / \mathrm{kg}$ ) on the cross-slope. At $\mathrm{MaxF}_{\mathrm{z}} 2$, the US-hip 
started with a near neutral JRF of $-0.03 \mathrm{~N} / \mathrm{kg}$ on the flat and experienced a dramatic increase to $3.02 \mathrm{~N} / \mathrm{kg}$ on the cross-slope. The DS-hip also increased its lateral JRF (from $-0.86 \mathrm{~N} / \mathrm{kg}$ to $-3.91 \mathrm{~N} / \mathrm{kg}$ ) on the cross-slope condition. Inspecting across sides, near equal and oppositely directed JRF are experienced by the hips. The US-hip is exposed to a medial lateral JRF whereas the DS-hip experiences a lateral JRF.

Table 35 - Hip medio-lateral JRF evaluated at representative gait cycle events and averaged across all trials and subjects for each side/condition permutation. Associated p-values for each relevant pairwise comparison are also presented.

\begin{tabular}{|c|c|c|c|c|c|c|c|c|}
\hline $\mathbf{H}_{\mathbf{y}}$ & $\begin{array}{l}\text { DS/ } \\
\text { Cross }\end{array}$ & $\begin{array}{l}\text { DS/ } \\
\text { Flat }\end{array}$ & $\begin{array}{l}\text { US/ } \\
\text { Cross }\end{array}$ & $\begin{array}{l}\text { US/ } \\
\text { Flat }\end{array}$ & $\begin{array}{c}\text { DS/ } \\
\text { Flat } \\
- \\
\text { US/ } \\
\text { Flat }\end{array}$ & $\begin{array}{c}\text { DS/ } \\
\text { Flat } \\
- \\
\text { DS/ } \\
\text { Cross }\end{array}$ & $\begin{array}{c}\text { DS/ } \\
\text { Cross } \\
- \\
\text { US/ } \\
\text { Cross }\end{array}$ & $\begin{array}{c}\text { US/ } \\
\text { Flat } \\
- \\
\text { US/ } \\
\text { Cross }\end{array}$ \\
\hline $\operatorname{MaxF}_{z} 1^{\dagger}$ & $\begin{array}{c}-2.72 \\
(0.66)\end{array}$ & $\begin{array}{c}0.11 \\
(0.40)\end{array}$ & $\begin{array}{c}3.62 \\
(0.73)\end{array}$ & $\begin{array}{c}0.86 \\
(0.47)\end{array}$ & $0.013^{*}$ & $<0.001^{*}$ & $<0.001$ * & $<0.001$ * \\
\hline $\operatorname{MinF}_{z}^{+}$ & $\begin{array}{c}-2.60 \\
(0.33)\end{array}$ & $\begin{array}{l}-0.48 \\
(0.29)\end{array}$ & $\begin{array}{c}2.17 \\
(0.44)\end{array}$ & $\begin{array}{c}0.09 \\
(0.33)\end{array}$ & $0.03^{*}$ & $<0.001^{*}$ & $<0.001^{*}$ & $<0.001^{*}$ \\
\hline $\operatorname{MaxF}_{z} 2^{+}$ & $\begin{array}{c}-3.91 \\
(0.64)\end{array}$ & $\begin{array}{c}-0.86 \\
(0.35)\end{array}$ & $\begin{array}{c}3.02 \\
(0.73)\end{array}$ & $\begin{array}{l}-0.03 \\
(0.45)\end{array}$ & $0.015^{\star}$ & $<0.001^{*}$ & $<0.001$ " & $<0.001$ * \\
\hline
\end{tabular}

Group means and standard deviations (SD)

* Indicates significant difference at $\alpha<0.05$ for the post-hoc Bonferonni analysis.

${ }^{\dagger}$ Represents an asymmetry between limbs on the flat condition at this event.

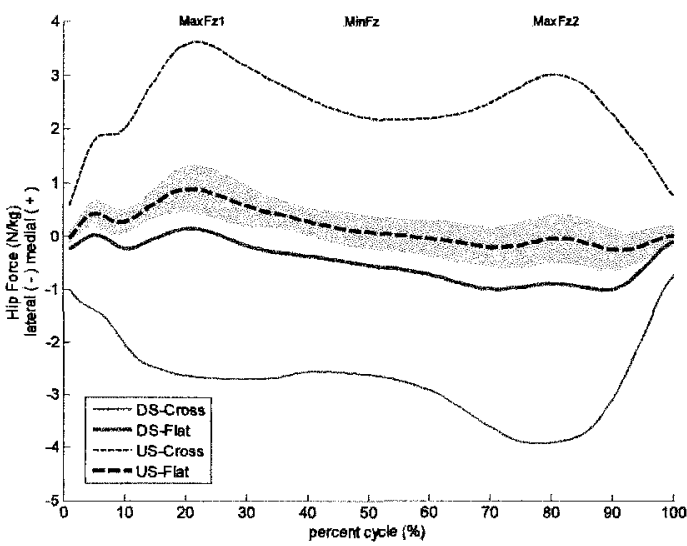

(a)

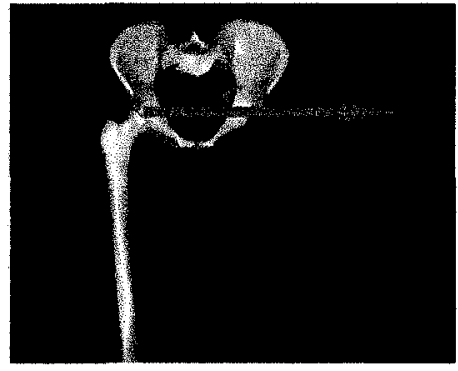

(b)

Figure 28 - (a) Hip medio-lateral JRF (N/kg) averaged across all subjects and all trials for the DS and UShips under the flat and cross-slope conditions. The medio-lateral JRF at the hip represents a force in line with the medio-lateral axis of the pelvis. Medial (positive), Lateral (negative). Grey region is the standard deviation of the US-flat condition. (b) A hip medial JRF vector. 


\subsubsection{Vertical Reaction Forces}

\subsubsection{Ankle}

No differences were seen in ankle vertical JRF at all events under study (Fig. 29).

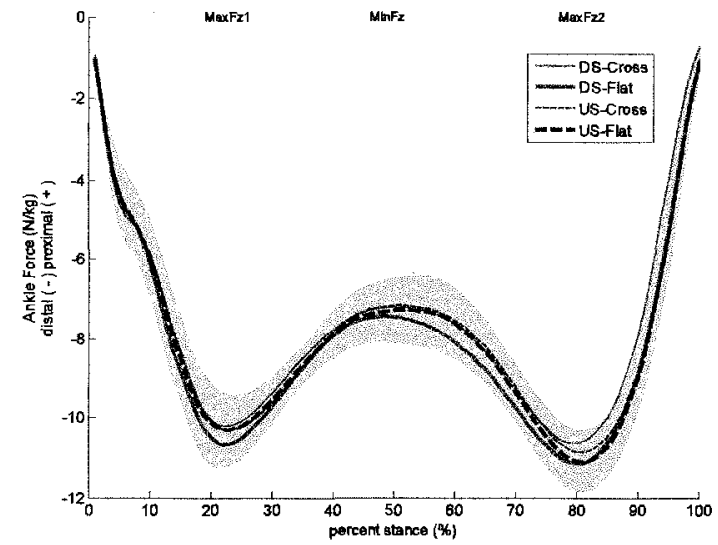

(a)

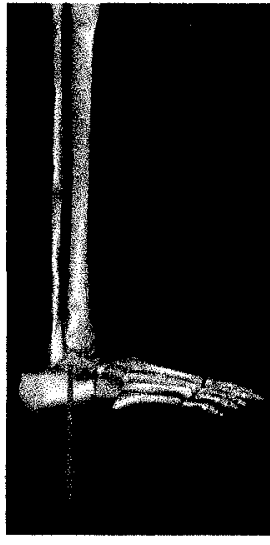

(b)

Figure 29 - (a) Ankle vertical JRF (N/kg) averaged across all subjects and all trials for the DS and USankles under the flat and cross-slope conditions. The vertical JRF at the ankle represents a force that is perpendicular to both the medio-lateral axis of the shank and the longitudinal axis of the foot. Proximal (positive), Distal (negative). Grey region is the standard deviation of the US-flat condition. (b) An ankle vertical JRF vector.

\subsubsection{Knee}

Knee vertical JRF (Fig. 30) showed significant differences between sides and conditions at $\operatorname{MaxF}_{\mathrm{z}} 2$ only $(\mathrm{p}=0.020)$. Symmetry was seen across knees for the flat condition. At $\mathrm{MaxF}_{\mathrm{z}} 2$ differences were seen across conditions for the DS-knee as well as across knees for the cross-slope condition (Table 36). The DS-knee had a decrease in vertical JRF (from $-11.06 \mathrm{~N} / \mathrm{kg}$ to $-10.56 \mathrm{~N} / \mathrm{kg}$ ) while on the cross-slope. The US-knee revealed a greater amount of vertical JRF (-11.32 N/kg) than the DS-knee while on the cross slope. 
Table 36 - Ankle antero-posterior JRF evaluated at representative gait cycle events and averaged across all trials and subjects for each side/condition permutation. Associated p-values for each relevant pairwise comparison are also presented.

\begin{tabular}{|c|c|c|c|c|c|c|c|c|}
\hline $\mathbf{K}_{\mathbf{z}}$ & $\begin{array}{l}\text { DS/ } \\
\text { Cross }\end{array}$ & $\begin{array}{l}\text { DS/ } \\
\text { Flat }\end{array}$ & $\begin{array}{l}\text { US/ } \\
\text { Cross }\end{array}$ & $\begin{array}{l}\text { US/ } \\
\text { Flat }\end{array}$ & $\begin{array}{c}\text { DS/ } \\
\text { Flat } \\
- \\
\text { US/ } \\
\text { Flat }\end{array}$ & $\begin{array}{c}\text { DS/ } \\
\text { Flat } \\
- \\
\text { DS/ } \\
\text { Cross }\end{array}$ & $\begin{array}{c}\text { DS/ } \\
\text { Cross } \\
- \\
\text { US/ } \\
\text { Cross }\end{array}$ & $\begin{array}{c}\text { US/ } \\
\text { Flat } \\
- \\
\text { US/ } \\
\text { Cross }\end{array}$ \\
\hline $\operatorname{MaxF}_{z} 2$ & $\begin{array}{c}-10.56 \\
(0.71)\end{array}$ & $\begin{array}{c}-11.06 \\
(0.59)\end{array}$ & $\begin{array}{r}-11.32 \\
(0.77)\end{array}$ & $\begin{array}{r}-11.35 \\
(0.79)\end{array}$ & 0.051 & $0.004^{*}$ & $0.005^{*}$ & 1.000 \\
\hline
\end{tabular}

Group means and standard deviations (SD)

* Indicates significant difference at $\alpha<0.05$ for the post-hoc Bonferonni analysis.

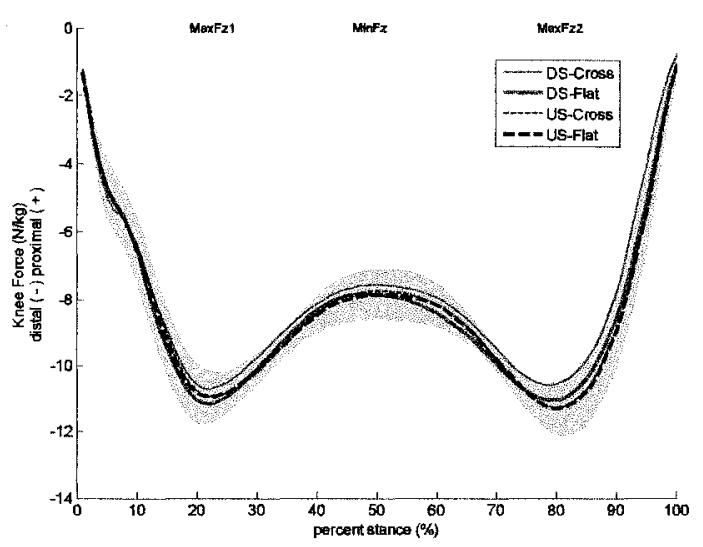

(a)

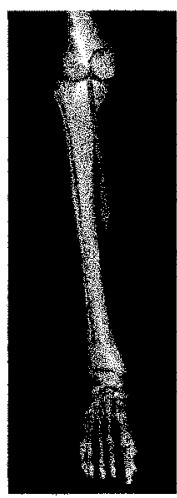

(b)

Figure 30 - (a) Knee vertical JRF (N/kg) averaged across all subjects and all trials for the DS and USknees under the flat and cross-slope conditions. The vertical JRF at the knee represents a force that is in line with the longitudinal axis of the shank. Proximal (positive), Distal (negative). Grey region is the standard deviation of the US-flat condition. (b) A knee vertical JRF vector.

\subsubsection{Hip}

Hip vertical JRF (Fig. 31) showed significant differences $(p=0.041)$ between sides and conditions at $\operatorname{MaxF}_{\mathrm{z}} 2$ only. Symmetry remained present across hips for the flat condition. At $\operatorname{MaxF}_{\mathrm{z}} 2$, the DS-hip decreased vertical JRF $(-12.72 \mathrm{~N} / \mathrm{kg}$ to $-12.28 \mathrm{~N} / \mathrm{kg})$ while on the cross-slope Table 37) 
Table 37 - Hip vertical JRF evaluated at representative gait cycle events and averaged across all trials and subjects for each side/condition permutation. Associated p-values for each relevant pairwise comparison are also presented.

\begin{tabular}{|c|c|c|c|c|c|c|c|c|}
\hline $\mathbf{H}_{\mathbf{z}}$ & $\begin{array}{l}\text { DS/ } \\
\text { Cross }\end{array}$ & $\begin{array}{l}\text { DS/ } \\
\text { Flat }\end{array}$ & $\begin{array}{l}\text { US/ } \\
\text { Cross }\end{array}$ & $\begin{array}{l}\text { US/ } \\
\text { Flat }\end{array}$ & $\begin{array}{c}\text { DS/ } \\
\text { Flat } \\
- \\
\text { US/ } \\
\text { Flat }\end{array}$ & $\begin{array}{c}\text { DS/ } \\
\text { Flat } \\
- \\
\text { DS/ } \\
\text { Cross }\end{array}$ & $\begin{array}{c}\text { DS/ } \\
\text { Cross } \\
- \\
\text { US/ } \\
\text { Cross }\end{array}$ & $\begin{array}{c}\text { US/ } \\
\text { Flat } \\
- \\
\text { US/ } \\
\text { Cross }\end{array}$ \\
\hline $\operatorname{MaxF}_{\mathrm{z}} 2$ & $\begin{array}{c}-12.28 \\
(0.55)\end{array}$ & $\begin{array}{r}-12.72 \\
(0.47)\end{array}$ & $\begin{array}{c}-12.74 \\
(0.60)\end{array}$ & $\begin{array}{c}-12.83 \\
(0.54)\end{array}$ & 1.000 & $0.005^{*}$ & 0.157 & 1.000 \\
\hline
\end{tabular}

Group means and standard deviations (SD)

* Indicates significant difference at $\alpha<0.05$ for the post-hoc Bonferonni analysis.

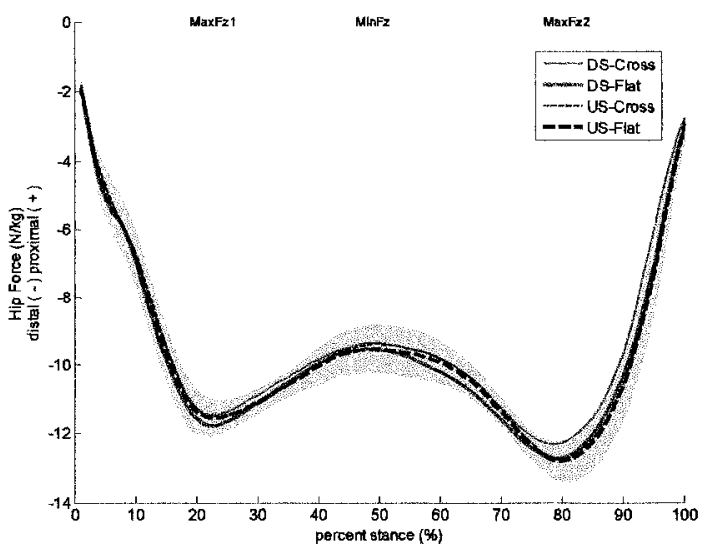

(a)

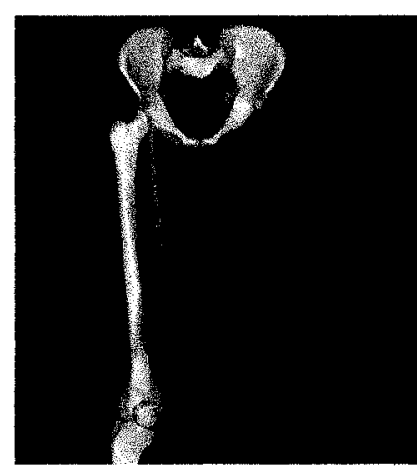

(b)

Figure 31 - (a) Hip vertical JRF (N/kg) averaged across all subjects and all trials for the DS and US-hips under the flat and cross-slope conditions. The vertical JRF at the hips represents a force that is in line with the longitudinal axis of the thigh. Proximal (positive), Distal (negative). Grey region is the standard deviation of the US-flat condition. (b) A hip vertical JRF vector.

\subsubsection{Sagittal Plane Joint Reaction Moments}

\subsubsection{Ankle}

Sagittal plane ankle moments (Fig. 32) presented differences across sides and conditions at $\operatorname{MaxF}_{\mathrm{z}} 2(\mathrm{p}=0.028)$. Ankle moment remained symmetric across sides for the flat condition. 
Pairwise comparison of the $\mathrm{MaxF}_{z} 2$ event unveiled differences to lie across conditions for the DS-ankle and across ankles for the cross-slope condition (Table 38). The PF moment decreased (from $1.45 \mathrm{Nm} / \mathrm{kg}$ to $1.33 \mathrm{Nm} / \mathrm{kg}$ ) for the DS-ankle while on the cross-slope. In addition the US-ankle showed greater PF moment $(1.49 \mathrm{Nm} / \mathrm{kg})$ than the DS-ankle on the cross-slope condition.

Table 38 - Ankle sagittal plane moment evaluated at representative gait cycle events and averaged across all trials and subjects for each side/condition permutation. Associated p-values for each relevant pairwise comparison are also presented.

\begin{tabular}{|c|c|c|c|c|c|c|c|c|}
\hline $\mathbf{A}_{\mathbf{x}}$ & $\begin{array}{l}\text { DS/ } \\
\text { Cross }\end{array}$ & $\begin{array}{l}\text { DS/ } \\
\text { Flat }\end{array}$ & $\begin{array}{l}\text { US/ } \\
\text { Cross }\end{array}$ & $\begin{array}{l}\text { US/ } \\
\text { Flat }\end{array}$ & $\begin{array}{c}\text { DS/ } \\
\text { Flat } \\
- \\
\text { US/ } \\
\text { Flat }\end{array}$ & $\begin{array}{c}\text { DS/ } \\
\text { Flat } \\
- \\
\text { DS/ } \\
\text { Cross }\end{array}$ & $\begin{array}{c}\text { DS/ } \\
\text { Cross } \\
- \\
\text { US/ } \\
\text { Cross }\end{array}$ & $\begin{array}{c}\text { US/ } \\
\text { Flat } \\
- \\
\text { US/ } \\
\text { Cross }\end{array}$ \\
\hline $\operatorname{MaxF}_{z} 2$ & $\begin{array}{c}1.33 \\
(0.17)\end{array}$ & $\begin{array}{c}1.45 \\
(0.17)\end{array}$ & $\begin{array}{c}1.49 \\
(0.20)\end{array}$ & $\begin{array}{c}1.52 \\
(0.21)\end{array}$ & 0.295 & $0.002^{*}$ & 0.001 * & 1.000 \\
\hline
\end{tabular}

Group means and standard deviations (SD)

* Indicates significant difference at $\alpha<0.05$ for the post-hoc Bonferonni analysis.

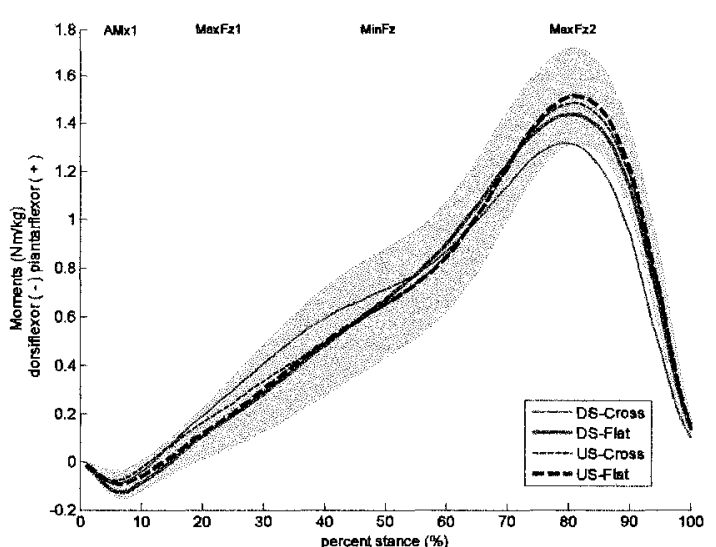

(a)

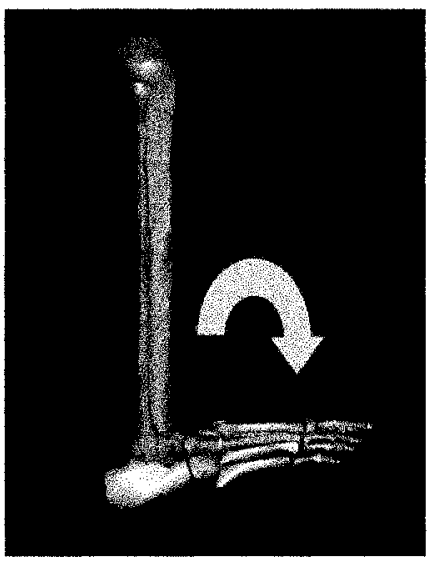

(b)

Figure 32 - (a) Ankle moment $(\mathrm{Nm} / \mathrm{kg}$ ) averaged across all subjects and all trials for the DS and US-ankles under the flat and cross-slope conditions. The ankle sagittal plane moment is the moment about the mediolateral axis of the shank. DF moment (negative), PF moment (positive). Grey region is the standard deviation of the US-flat condition. (b) An ankle PF moment. 


\subsubsection{Knee}

For the knee sagittal plane moments (Fig. 33), significant interaction $(p<0.026)$ between sides and conditions were seen at all events under study, but relevant comparisons in poshoc analysis revealed differences only at $\mathrm{KM}_{\mathrm{x}} 1$ and $\mathrm{MaxF}_{\mathrm{z}} 2$ (Table 39). Symmetry was maintained between the US and DS-knees at these events.

At $\mathrm{KM}_{\mathrm{x}} 1$ differences were seen across conditions for the US-knee as well as between knees for the cross-slope condition $(p=0.008$ and $p=0.016$ respectively). The US-knee decreased the Flx moment (from $-0.38 \mathrm{Nm} / \mathrm{kg}$ to $-0.30 \mathrm{Nm} / \mathrm{kg}$ ) on the cross-slope. During cross-slope walking, the DS-knee had a greater Flx moment $(-0.46 \mathrm{Nm} / \mathrm{kg})$ than the USknee. At $\mathrm{MaxF}_{\mathrm{z}}$ 2, differences were seen across conditions for the US-knee as it experienced a change in direction of its moment from a DF moment $(-0.12 \mathrm{Nm} / \mathrm{kg})$ to a PF moment $(0.06 \mathrm{Nm} / \mathrm{kg})$ on the cross-slope.

Table 39 - Knee sagittal moment evaluated at representative gait cycle events and averaged across all trials and subjects for each side/condition permutation. Associated p-values for each relevant pairwise comparison are also presented.

\begin{tabular}{|c|c|c|c|c|c|c|c|c|}
\hline $\mathbf{K}_{\mathbf{x}}$ & $\begin{array}{l}\text { DS/ } \\
\text { Cross }\end{array}$ & $\begin{array}{l}\text { DS/ } \\
\text { Flat }\end{array}$ & $\begin{array}{l}\text { US/ } \\
\text { Cross }\end{array}$ & $\begin{array}{l}\text { US/ } \\
\text { Flat }\end{array}$ & $\begin{array}{c}\text { DS/ } \\
\text { Flat } \\
- \\
\text { US/ } \\
\text { Flat }\end{array}$ & $\begin{array}{c}\text { DS/ } \\
\text { Flat } \\
- \\
\text { DS/ } \\
\text { Cross }\end{array}$ & $\begin{array}{c}\text { DS/ } \\
\text { Cross } \\
- \\
\text { US/ } \\
\text { Cross }\end{array}$ & $\begin{array}{c}\text { US/ } \\
\text { Flat } \\
- \\
\text { US/ } \\
\text { Cross }\end{array}$ \\
\hline $\mathbf{K} \mathbf{M}_{\mathbf{x}} \mathbf{1}$ & $\begin{array}{l}-0.46 \\
(0.18)\end{array}$ & $\begin{array}{c}-0.43 \\
(0.09)\end{array}$ & $\begin{array}{c}-0.30 \\
(0.08)\end{array}$ & $\begin{array}{c}-0.38 \\
(0.07)\end{array}$ & 0.498 & 1.000 & $0.016^{*}$ & $0.008^{*}$ \\
\hline $\operatorname{MaxF}_{z} 2$ & $\begin{array}{c}-0.08 \\
(0.27)\end{array}$ & $\begin{array}{l}-0.05 \\
(0.25)\end{array}$ & $\begin{array}{c}0.06 \\
(0.27)\end{array}$ & $\begin{array}{c}-0.12 \\
(0.37)\end{array}$ & 1.000 & 1.000 & 1.000 & $0.009^{*}$ \\
\hline
\end{tabular}

Group means and standard deviations (SD)

* Indicates significant difference at $\alpha<0.05$ for the post-hoc Bonferonni analysis. 


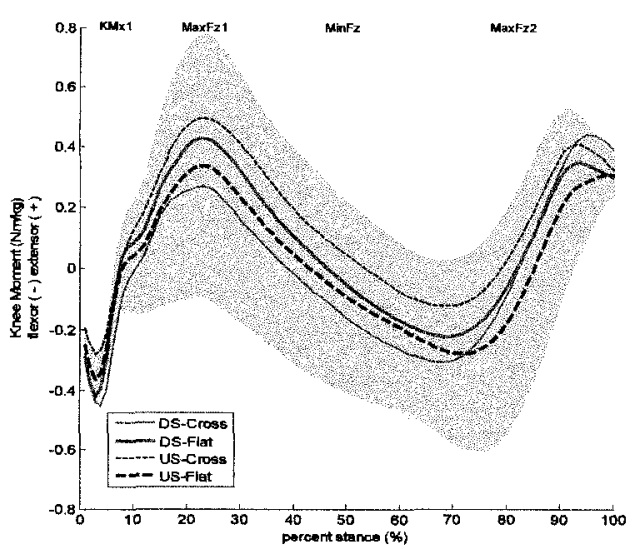

(a)

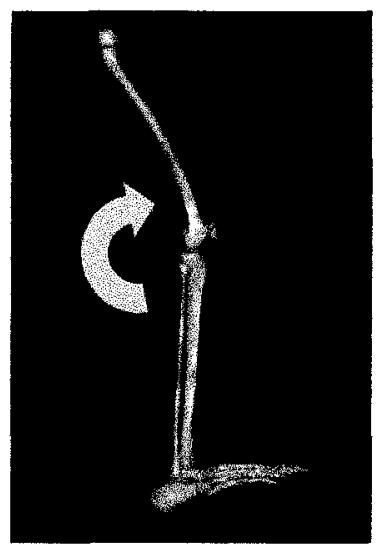

(b)

Figure 33 - (a) Knee moment ( $\mathrm{Nm} / \mathrm{kg}$ ) averaged across all subjects and all trials for the DS and US-knee under the flat and cross-slope conditions. The knee sagittal plane moment is the moment about the mediolateral axis of the thigh. Ext moment (positive), Flx moment (negative). Grey region is the standard deviation of the US-flat condition. (b) A knee Flx moment.

\subsubsection{Hip}

The hip sagittal plane moments (Fig. 34) revealed significant differences $(p<0.009)$ at $\mathrm{HM}_{\mathrm{x}} 1, \mathrm{MaxF}_{\mathrm{z}} 1$ and $\mathrm{MaxF}_{\mathrm{z}} 2$. However, in pos-hoc analysis relevant differences were only found at $\mathrm{HM}_{\mathrm{x}} 1$. The DS and US-hips were symmetric during the flat walking condition. At $\mathrm{HM}_{\mathrm{x}} 1$, differences were seen between sides for the cross-slope condition $(\mathrm{p}=0.008)$ (Table 40). The US-hip had a lesser Flx moment than the DS-hip (1.38 Nm/kg compared to $1.62 \mathrm{Nm} / \mathrm{kg}$ ).

Table 40 - Hip sagittal moment evaluated at representative gait cycle events and averaged across all trials and subjects for each side/condition permutation. Associated p-values for each relevant pairwise comparison are also presented.

\begin{tabular}{|c|c|c|c|c|c|c|c|c|}
\hline $\mathbf{H}_{\mathbf{x}}$ & $\begin{array}{l}\text { DS/ } \\
\text { Cross }\end{array}$ & $\begin{array}{l}\text { DS/ } \\
\text { Flat }\end{array}$ & $\begin{array}{l}\text { US/ } \\
\text { Cross }\end{array}$ & $\begin{array}{l}\text { US/ } \\
\text { Flat }\end{array}$ & $\begin{array}{c}\text { DS/ } \\
\text { Flat } \\
- \\
\text { US/ } \\
\text { Flat }\end{array}$ & $\begin{array}{c}\text { DS/ } \\
\text { Flat } \\
- \\
\text { DS/ } \\
\text { Cross }\end{array}$ & $\begin{array}{c}\text { DS/ } \\
\text { Cross } \\
- \\
\text { US/ } \\
\text { Cross }\end{array}$ & $\begin{array}{c}\text { US/ } \\
\text { Flat } \\
- \\
\text { US/ } \\
\text { Cross }\end{array}$ \\
\hline$H M_{y} 1$ & $\begin{array}{c}1.62 \\
(0.40)\end{array}$ & $\begin{array}{c}1.52 \\
(0.29)\end{array}$ & $\begin{array}{c}1.38 \\
(0.31)\end{array}$ & $\begin{array}{c}1.49 \\
(0.31)\end{array}$ & 1.000 & 1.000 & $0.008^{*}$ & 0.613 \\
\hline
\end{tabular}

Group means and standard deviations (SD)

* Indicates significant difference at $\alpha<0.05$ for the post-hoc Bonferonni analysis. 


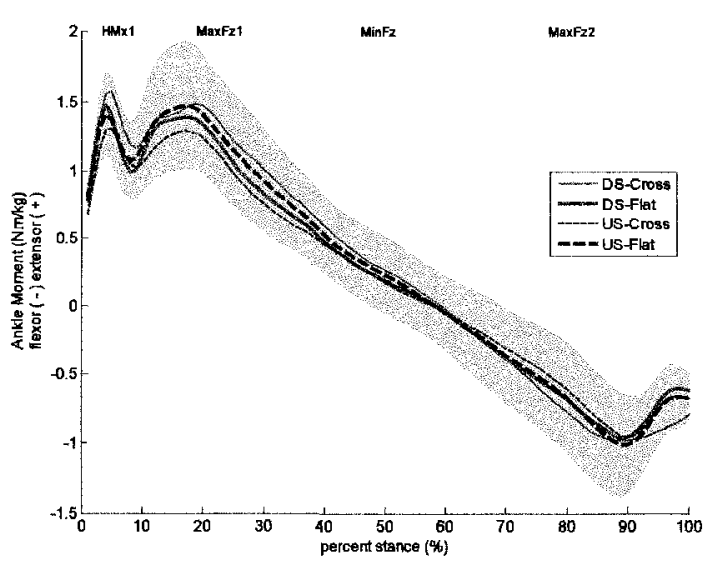

(a)

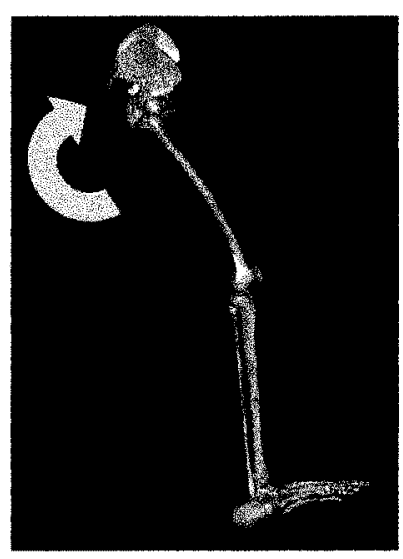

(b)

Figure 34 - (a) Hip moment $(\mathrm{Nm} / \mathrm{kg}$ ) averaged across all subjects and all trials for the DS and US-hip under the flat and cross-slope conditions. The hip sagittal plane moment is the moment about the mediolateral axis of the pelvis. Flx moment (positive), Ext moment (negative). Grey region is the standard deviation of the US-flat condition. (b) A Hip Ext moment.

\subsubsection{Frontal Plane Joint Reaction Moments}

\subsubsection{Ankle}

For the ankle frontal plane moments (Fig. 35), significant interaction differences were seen at all events under study $(\mathrm{p}<0.042)$ (Table 41$)$. Small asymmetry between sides occurred at $\mathrm{MaxF}_{\mathrm{z}} 1$ and $\mathrm{MinF}_{\mathrm{z}}$ during the flat condition $(\mathrm{p}=0.013$ and $\mathrm{p}=0.033$ respectively) with the US-ankle reporting slight Eve $(0.11 \mathrm{Nm} / \mathrm{kg}$ and $0.08 \mathrm{Nm} / \mathrm{kg}$ for $\operatorname{MaxF}_{\mathrm{z}} 1$ and $\mathrm{MinF}_{\mathrm{z}}$ respectively).

At $\mathrm{MaxF}_{\mathrm{z}} 1$ differences were seen across conditions for the US-ankle, across ankles for the cross-slope condition and across sides for the flat condition ( $p<0.001, \mathrm{p}<0.001$ and $\mathrm{p}$ $=0.013$ respectively). The US-ankle increased the Eve moment (from $0.11 \mathrm{Nm} / \mathrm{kg}$ to 0.17 $\mathrm{Nm} / \mathrm{kg}$ ) on the cross-slope. On the cross-slope condition, the DS-ankle experienced an Inv moment $(-0.03 \mathrm{Nm} / \mathrm{kg})$ while, as stated above, the US-ankle revealed an Eve moment. 
At $\mathrm{MinF}_{\mathrm{z}}$, differences were also seen across conditions for the US-ankle and across ankles for the cross-slope and flat condition. On the cross-slope, the US-ankle increased its Eve moment $(0.08 \mathrm{Nm} / \mathrm{kg}$ to $0.13 \mathrm{Nm} / \mathrm{kg})$ while the DS-ankle remained nearly unchanged $(0.01 \mathrm{Nm} / \mathrm{kg}$ to $0.00 \mathrm{Nm} / \mathrm{kg})$. At $\mathrm{MaxF}_{\mathrm{z}} 2$, differences were seen across conditions for the US-ankle and across ankles for the cross-slope condition. The US-ankle increased its Eve moment on the cross slope (from $0.03 \mathrm{Nm} / \mathrm{kg}$ to $0.10 \mathrm{Nm} / \mathrm{kg}$ ) while the unchanged DS-ankle revealed an Inv moment $(-0.06 \mathrm{Nm} / \mathrm{kg})$.

Table 41 - Ankle frontal plane moment evaluated at representative gait cycle events and averaged across all trials and subjects for each side/condition permutation. Associated p-values for each relevant pairwise comparison are also presented.

\begin{tabular}{|c|c|c|c|c|c|c|c|c|}
\hline $\mathbf{A}_{\mathbf{y}}$ & $\begin{array}{l}\text { DS/ } \\
\text { Cross }\end{array}$ & $\begin{array}{l}\text { DS/ } \\
\text { Flat }\end{array}$ & $\begin{array}{l}\text { US/ } \\
\text { Cross }\end{array}$ & $\begin{array}{l}\text { US/ } \\
\text { Flat }\end{array}$ & $\begin{array}{c}\text { DS/ } \\
\text { Flat } \\
- \\
\text { US/ } \\
\text { Flat }\end{array}$ & $\begin{array}{c}\text { DS/ } \\
\text { Flat } \\
- \\
\text { DS/ } \\
\text { Cross }\end{array}$ & $\begin{array}{c}\text { DS/ } \\
\text { Cross } \\
- \\
\text { US/ } \\
\text { Cross }\end{array}$ & $\begin{array}{c}\text { US/ } \\
\text { Flat } \\
- \\
\text { US/ } \\
\text { Cross }\end{array}$ \\
\hline $\operatorname{MaxF}_{z} 1^{\dagger}$ & $\begin{array}{c}-0.03 \\
(0.09)\end{array}$ & $\begin{array}{c}-0.01 \\
(0.08)\end{array}$ & $\begin{array}{c}0.17 \\
(0.08)\end{array}$ & $\begin{array}{c}0.11 \\
(0.08)\end{array}$ & $0.013^{*}$ & 0.493 & $<0.001^{*}$ & $<0.001^{*}$ \\
\hline $\operatorname{MinF}_{z}^{+}$ & $\begin{array}{c}0.00 \\
(0.08)\end{array}$ & $\begin{array}{c}0.01 \\
(0.08)\end{array}$ & $\begin{array}{c}0.13 \\
(0.08)\end{array}$ & $\begin{array}{c}0.08 \\
(0.07)\end{array}$ & $0.033^{*}$ & 1.000 & $0.004^{*}$ & $<0.001$ * \\
\hline $\operatorname{MaxF}_{\mathrm{z}} 2$ & $\begin{array}{c}-0.06 \\
(0.15)\end{array}$ & $\begin{array}{c}-0.06 \\
(0.16)\end{array}$ & $\begin{array}{c}0.10 \\
(0.13)\end{array}$ & $\begin{array}{c}0.03 \\
(0.11)\end{array}$ & 0.320 & 1.000 & $0.036^{*}$ & $0.007^{*}$ \\
\hline
\end{tabular}

Group means and standard deviations (SD)

* Indicates significant difference at $\alpha<0.05$ for the post-hoc Bonferonni analysis.

${ }^{+}$Represents an asymmetry between limbs on the flat condition at this event. 


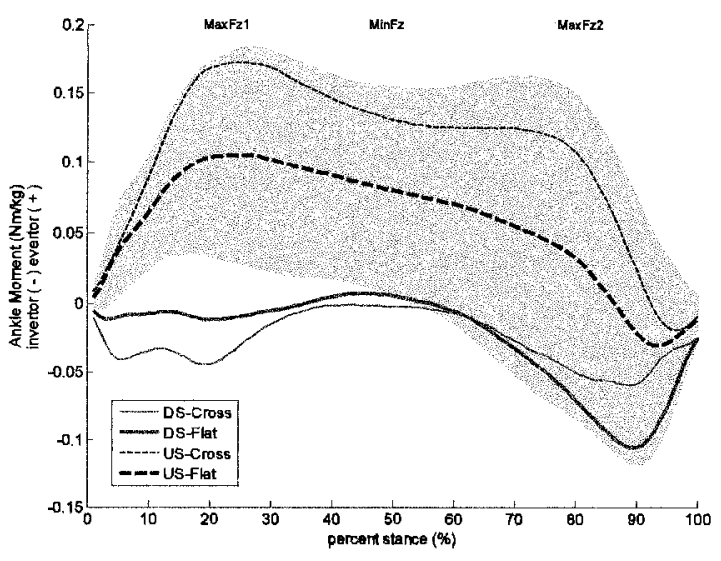

(a)

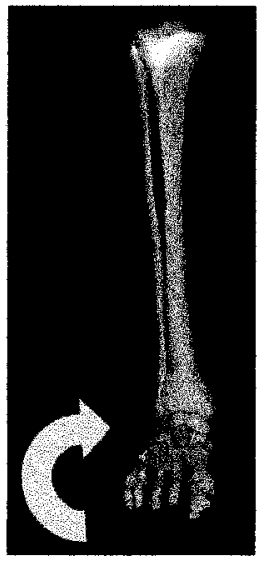

(b)

Figure 35 - (a) Ankle moment ( $\mathrm{Nm} / \mathrm{kg}$ ) averaged across all subjects and all trials for the DS and US-ankles under the flat and cross-slope conditions. The ankle frontal plane moment is the moment about the longitudinal axis of the foot. Eve moment (positive), Inv moment (negative). Grey region is the standard deviation of the US-flat condition. (b) An ankle Eve moment.

\subsubsection{Knee}

For the knee frontal plane moments (Fig. 36), interaction differences were significant at all events under study $(\mathrm{p}<0.001)$. Asymmetries across knees were seen at $\mathrm{MinF}_{\mathrm{z}}$ and $\operatorname{MaxF}_{z} 2$ during the flat walking condition with differences of approximately $0.035 \mathrm{Nm} / \mathrm{kg}$. However, intra-limb differences across conditions are ten times larger (approximately $0.41 \mathrm{Nm} / \mathrm{kg})$.

Pairwise comparisons revealed significant differences across conditions for both knees as well as between knees during the cross-slope condition at all events under study ( $p$ <0.001) (Table 42). At $\operatorname{MaxF}_{\mathrm{z}} 1, \mathrm{MinF}_{\mathrm{z}}$ and $\mathrm{MaxF}_{\mathrm{z}} 2$ similar patterns were observed. The US-knee went from an Abd moment to an Add moment on the cross-slope $(0.35 \mathrm{Nm} / \mathrm{kg}$ to $-0.17 \mathrm{Nm} / \mathrm{kg}$ for $\mathrm{MaxF}_{\mathrm{z}} 1 ; 0.12 \mathrm{Nm} / \mathrm{kg}$ to $-0.23 \mathrm{Nm} / \mathrm{kg}$ for $\mathrm{MinF}_{\mathrm{z}} ; 0.23 \mathrm{Nm} / \mathrm{kg}$ to -0.28 $\mathrm{Nm} / \mathrm{kg}$ for $\left.\operatorname{MaxF}_{\mathrm{z}} 2\right)$, while the DS-knee faced an increase in Abd moment $(0.57 \mathrm{Nm} / \mathrm{kg}$ to 
$1.02 \mathrm{Nm} / \mathrm{kg}$ for $\operatorname{MaxF}_{\mathrm{z}} 1 ; 0.26 \mathrm{Nm} / \mathrm{kg}$ to $0.56 \mathrm{Nm} / \mathrm{kg}$ for $\mathrm{MinF}_{\mathrm{z}} ; 0.44 \mathrm{Nm} / \mathrm{kg}$ to 0.93

$\mathrm{Nm} / \mathrm{kg}$ for $\mathrm{MaxF}_{\mathrm{z}} 2$ ) on the cross-slope. Thus on the cross-slope the two knees experienced oppositely directed moments.

Table 42 - knee frontal plane moment evaluated at representative gait cycle events and averaged across all trials and subjects for each side/condition permutation. Associated p-values for each relevant pairwise comparison are also presented.

\begin{tabular}{|c|c|c|c|c|c|c|c|c|}
\hline $\mathbf{K}_{\mathbf{y}}$ & $\begin{array}{l}\text { DS/ } \\
\text { Cross }\end{array}$ & $\begin{array}{l}\text { DS/ } \\
\text { Flat }\end{array}$ & $\begin{array}{l}\text { US/ } \\
\text { Cross }\end{array}$ & $\begin{array}{l}\text { US/ } \\
\text { Flat }\end{array}$ & $\begin{array}{c}\text { DS/ } \\
\text { Flat } \\
- \\
\text { US/ } \\
\text { Flat }\end{array}$ & $\begin{array}{c}\text { DS/ } \\
\text { Flat } \\
- \\
\text { DS/ } \\
\text { Cross }\end{array}$ & $\begin{array}{c}\text { DS/ } \\
\text { Cross } \\
- \\
\text { US/ } \\
\text { Cross }\end{array}$ & $\begin{array}{c}\text { US/ } \\
\text { Flat } \\
- \\
\text { US/ } \\
\text { Cross }\end{array}$ \\
\hline $\operatorname{MaxF}_{\mathrm{z}} 1$ & $\begin{array}{c}1.02 \\
(0.16)\end{array}$ & $\begin{array}{c}0.57 \\
(0.19)\end{array}$ & $\begin{array}{l}-0.17 \\
(0.26)\end{array}$ & $\begin{array}{c}0.35 \\
(0.22)\end{array}$ & 0.064 & $<0.001$ * & $<0.001^{*}$ & $<0.001$ * \\
\hline $\mathbf{M i n F}_{\mathbf{z}}{ }^{+}$ & $\begin{array}{c}0.56 \\
(0.12)\end{array}$ & $\begin{array}{c}0.26 \\
(0.15)\end{array}$ & $\begin{array}{c}-0.23 \\
(0.15)\end{array}$ & $\begin{array}{c}0.12 \\
(0.16)\end{array}$ & $0.023^{*}$ & $<0.001^{*}$ & $<0.001 *$ & $<0.001^{*}$ \\
\hline $\operatorname{MaxF}_{z} 2^{+}$ & $\begin{array}{c}0.93 \\
(0.16)\end{array}$ & $\begin{array}{c}0.44 \\
(0.19)\end{array}$ & $\begin{array}{c}-0.28 \\
(0.24)\end{array}$ & $\begin{array}{c}0.23 \\
(0.17)\end{array}$ & $0.028^{*}$ & $<0.001$ * & $<0.001^{*}$ & $<0.001^{*}$ \\
\hline
\end{tabular}

Group means and standard deviations (SD)

* Indicates significant difference at $\alpha<0.05$ for the post-hoc Bonferonni analysis.

${ }^{+}$Represents an asymmetry between limbs on the flat condition at this event.

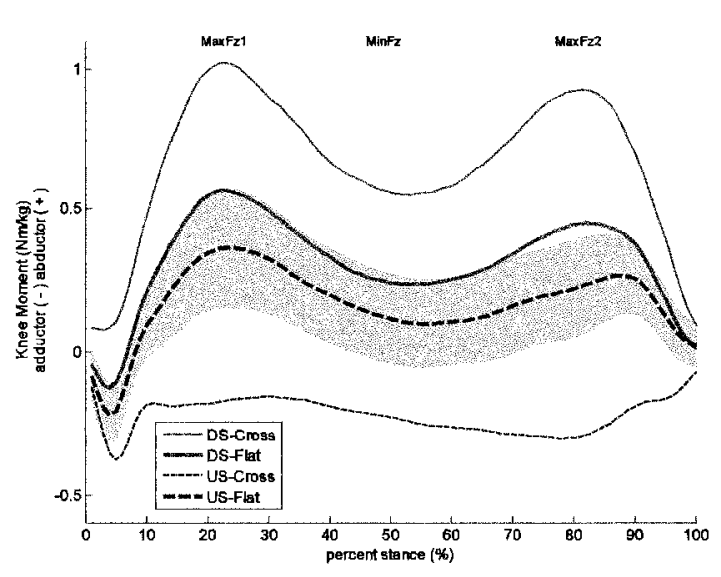

(a)

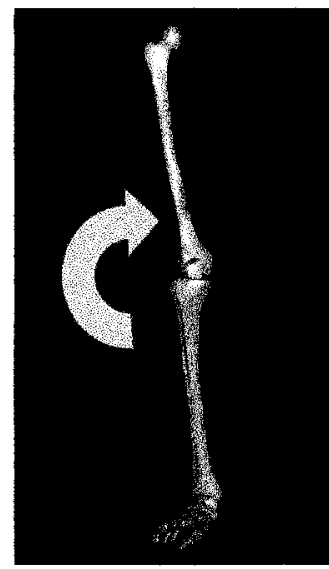

(b)

Figure 36 - (a) Knee moment ( $\mathrm{Nm} / \mathrm{kg}$ ) averaged across all subjects and all trials for the DS and US-knees under the flat and cross-slope conditions. The knee frontal plane moment is the moment about the floating axis perpendicular to both the medio-lateral axis of the thigh and the longitudinal axis of the shank. Abd moment (positive), Add moment (negative). Grey region is the standard deviation of the US-flat condition. (b) A Knee Abd moment. 
Hip frontal plane moments (Fig. 37) showed significant interaction $(\mathrm{p}<0.001)$ at all events under study. Symmetry was maintained at all events under study.

Pairwise comparisons revealed significant differences across conditions for both hips as well as between hips during the cross-slope condition at all events under study $(\mathrm{p}<0.001)$ (Table 43). At $\operatorname{MaxF}_{\mathrm{z}} 1, \mathrm{MinF}_{\mathrm{z}}$ and $\mathrm{MaxF}_{\mathrm{z}} 2$ similar patterns were observed. The US-hip reversed the moment it experienced across conditions, with an Abd on the flat condition $\left(0.42 \mathrm{Nm} / \mathrm{kg}, 0.37 \mathrm{Nm} / \mathrm{kg}, 0.53 \mathrm{Nm} / \mathrm{kg}\right.$ for $\mathrm{MaxF}_{\mathrm{z}} 1, \mathrm{MinF}_{\mathrm{z}}$ and $\mathrm{MaxF}_{\mathrm{z}} 2$ respectively) and an Add moment on the cross-slope $\left(-1.07 \mathrm{Nm} / \mathrm{kg},-0.67 \mathrm{Nm} / \mathrm{kg},-1.00 \mathrm{Nm} / \mathrm{kg}\right.$ for $\mathrm{MaxF}_{z} 1$, $\mathrm{MinF}_{\mathrm{z}}$ and $\mathrm{MaxF}_{\mathrm{z}} 2$ respectively). The DS-hip increased its Abd on the cross-slope $(0.70$ $\mathrm{Nm} / \mathrm{kg}$ to $2.15 \mathrm{Nm} / \mathrm{kg} ; 0.50 \mathrm{Nm} / \mathrm{kg}$ to $1.54 \mathrm{Nm} / \mathrm{kg} ; 0.73 \mathrm{Nm} / \mathrm{kg}$ to $2.20 \mathrm{Nm} / \mathrm{kg}$ for $\operatorname{MaxF}_{\mathrm{z}} 1, \mathrm{MinF}_{\mathrm{z}}$ and $\mathrm{MaxF}_{\mathrm{z}} 2$ respectively).

Table 43 - Hip frontal plane moments evaluated at representative gait cycle events and averaged across all trials and subjects for each side/condition permutation. Associated p-values for each relevant pairwise comparison are also presented.

\begin{tabular}{|c|c|c|c|c|c|c|c|c|}
\hline $\mathbf{H}_{\mathbf{y}}$ & $\begin{array}{l}\text { DS/ } \\
\text { Cross }\end{array}$ & $\begin{array}{l}\text { DS/ } \\
\text { Flat }\end{array}$ & $\begin{array}{l}\text { US/ } \\
\text { Cross }\end{array}$ & $\begin{array}{l}\text { US/ } \\
\text { Flat }\end{array}$ & $\begin{array}{c}\text { DS/ } \\
\text { Flat } \\
- \\
\text { US/ } \\
\text { Flat }\end{array}$ & $\begin{array}{c}\text { DS/ } \\
\text { Flat } \\
- \\
\text { DS/ } \\
\text { Cross }\end{array}$ & $\begin{array}{c}\text { DS/ } \\
\text { Cross } \\
- \\
\text { US/ } \\
\text { Cross }\end{array}$ & $\begin{array}{c}\text { US/ } \\
\text { Flat } \\
- \\
\text { US/ } \\
\text { Cross }\end{array}$ \\
\hline $\operatorname{MaxF}_{\mathrm{z}} 1$ & $\begin{array}{c}2.15 \\
(0.22)\end{array}$ & $\begin{array}{c}0.70 \\
(0.12)\end{array}$ & $\begin{array}{c}-1.07 \\
(0.20)\end{array}$ & $\begin{array}{c}0.42 \\
(0.20)\end{array}$ & 0.057 & $<0.001 *$ & $<0.001 *$ & $<0.001$ * \\
\hline $\mathbf{M i n F}_{\mathbf{z}}$ & $\begin{array}{c}1.54 \\
(0.21)\end{array}$ & $\begin{array}{c}0.50 \\
(0.10)\end{array}$ & $\begin{array}{c}-0.67 \\
(0.14)\end{array}$ & $\begin{array}{c}0.37 \\
(0.10)\end{array}$ & 0.209 & $<0.001^{*}$ & $<0.001^{*}$ & $<0.001^{*}$ \\
\hline $\operatorname{MaxF}_{z} 2$ & $\begin{array}{c}2.20 \\
(0.40)\end{array}$ & $\begin{array}{c}0.73 \\
(0.19)\end{array}$ & $\begin{array}{l}-1.00 \\
(0.24)\end{array}$ & $\begin{array}{c}0.53 \\
(0.17)\end{array}$ & 0.349 & $<0.001^{*}$ & $<0.001^{*}$ & $<0.001$ * \\
\hline
\end{tabular}

Group means and standard deviations (SD)

* Indicates significant difference at $\alpha<0.05$ for the post-hoc Bonferonni analysis.

${ }^{\dagger}$ Represents an asymmetry between limbs on the flat condition at this event. 


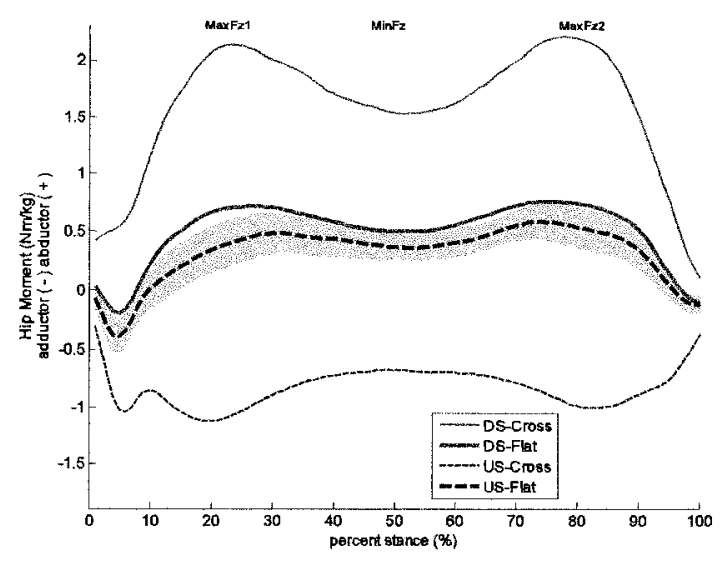

(a)

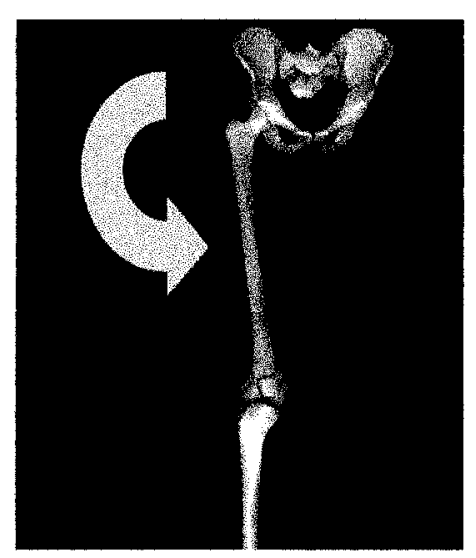

(b)

Figure 37 - (a) Hip moment $(\mathrm{Nm} / \mathrm{kg})$ averaged across all subjects and all trials for the DS and US-hips under the flat and cross-slope conditions. The hip frontal plane moment is a moment about the floating axis perpendicular to both the medio-lateral axis of the pelvis and the longitudinal axis of the thigh. Abd moment (positive), Add moment (negative). Grey region is the standard deviation of the US-flat condition. (b) Hip Add moment.

\subsubsection{Transverse Plane Joint Reaction Moments}

\subsubsection{Ankle moment}

For the ankle transverse plane moments (Fig. 38), significant interaction was seen ( $p$ $<0.001)$ at all events under study. Symmetry was maintained across sides during the flat walking condition.

Differences were seen across conditions for the US and DS-ankles as well as between ankles during the cross-slope condition at all events under study (Table 44) $(\mathrm{p}<0.001$ for all pairwise comparisons except $\mathrm{p}=0.003$ and $\mathrm{p}=0.016$ for the DS/Flat-DS/Cross and US/Flat-US/Cross comparisons for $\mathrm{MaxF}_{\mathrm{z}} 1$ ). The US-ankle revealed a change in direction of its moment from an IRot moment $(0.02 \mathrm{Nm} / \mathrm{kg}, 0.07 \mathrm{Nm} / \mathrm{kg}$ and $0.07 \mathrm{Nm} / \mathrm{kg}$ at $\operatorname{MaxF}_{\mathrm{z}} 1, \operatorname{MinF}_{\mathrm{z}}$ and $\mathrm{MaxF}_{\mathrm{z}} 2$ respectively) on the flat condition to an ERot moment (-0.03 $\mathrm{Nm} / \mathrm{kg},-0.06 \mathrm{Nm} / \mathrm{kg}$ and $-0.22 \mathrm{Nm} / \mathrm{kg}$ at $\mathrm{MaxF}_{\mathrm{z}} 1, \mathrm{MinF}_{\mathrm{z}}$ and $\mathrm{MaxF}_{\mathrm{z}} 2$ respectively) on 
the cross-slope. The DS-ankle revealed an increase in ERot moment $(0.00 \mathrm{Nm} / \mathrm{kg}$ to 0.09 $\mathrm{Nm} / \mathrm{kg}, 0.06 \mathrm{Nm} / \mathrm{kg}$ to $0.23 \mathrm{Nm} / \mathrm{kg}$ and $0.11 \mathrm{Nm} / \mathrm{kg}$ to $0.42 \mathrm{Nm} / \mathrm{kg}$ at $\mathrm{MaxF}_{\mathrm{z}} 1, \mathrm{MinF}_{\mathrm{z}}$ and $\operatorname{MaxF}_{z} 2$ respectively) on the cross-slope condition. Thus, during cross-slope walking each ankle exhibited oppositely rotating moments in the transverse plane.

Table 44 - Ankle transverse plane moments evaluated at representative gait cycle events and averaged across all trials and subjects for each side/condition permutation. Associated p-values for each relevant pairwise comparison are also presented.

\begin{tabular}{|c|c|c|c|c|c|c|c|c|}
\hline $\mathbf{A}_{\mathbf{z}}$ & $\begin{array}{l}\text { DS/ } \\
\text { Cross }\end{array}$ & $\begin{array}{l}\text { DS/ } \\
\text { Flat }\end{array}$ & $\begin{array}{l}\text { US/ } \\
\text { Cross }\end{array}$ & $\begin{array}{l}\text { US/ } \\
\text { Flat }\end{array}$ & $\begin{array}{c}\text { DS/ } \\
\text { Flat } \\
- \\
\text { US/ } \\
\text { Flat }\end{array}$ & $\begin{array}{c}\text { DS/ } \\
\text { Flat } \\
- \\
\text { DS/ } \\
\text { Cross }\end{array}$ & $\begin{array}{c}\text { DS/ } \\
\text { Cross } \\
- \\
\text { US/ } \\
\text { Cross }\end{array}$ & $\begin{array}{c}\text { US/ } \\
\text { Flat } \\
- \\
\text { US/ } \\
\text { Cross }\end{array}$ \\
\hline $\mathbf{M a x F}_{\mathrm{z}} \mathbf{1}$ & $\begin{array}{c}0.09 \\
(0.05)\end{array}$ & $\begin{array}{c}0.00 \\
(0.02)\end{array}$ & $\begin{array}{c}-0.03 \\
(0.02)\end{array}$ & $\begin{array}{c}0.02 \\
(0.04)\end{array}$ & 0.906 & $0.003^{*}$ & $<0.001 *$ & $0.016^{*}$ \\
\hline $\operatorname{MinF}_{\mathrm{z}}$ & $\begin{array}{c}0.23 \\
(0.05)\end{array}$ & $\begin{array}{c}0.06 \\
(0.04)\end{array}$ & $\begin{array}{c}-0.06 \\
(0.07)\end{array}$ & $\begin{array}{c}0.07 \\
(0.06)\end{array}$ & 1.000 & $<0.001$ * & $<0.001 *$ & $<0.001 *$ \\
\hline $\operatorname{MaxF}_{z} 2$ & $\begin{array}{c}0.42 \\
(0.11)\end{array}$ & $\begin{array}{c}0.11 \\
(0.14)\end{array}$ & $\begin{array}{c}-0.22 \\
(0.18) \\
\end{array}$ & $\begin{array}{c}0.07 \\
(0.17)\end{array}$ & 1.000 & $<0.001 *$ & $<0.001^{*}$ & $<0.001 *$ \\
\hline
\end{tabular}

Group means and standard deviations (SD)

* Indicates significant difference at $\alpha<0.05$ for the post-hoc Bonferonni analysis.

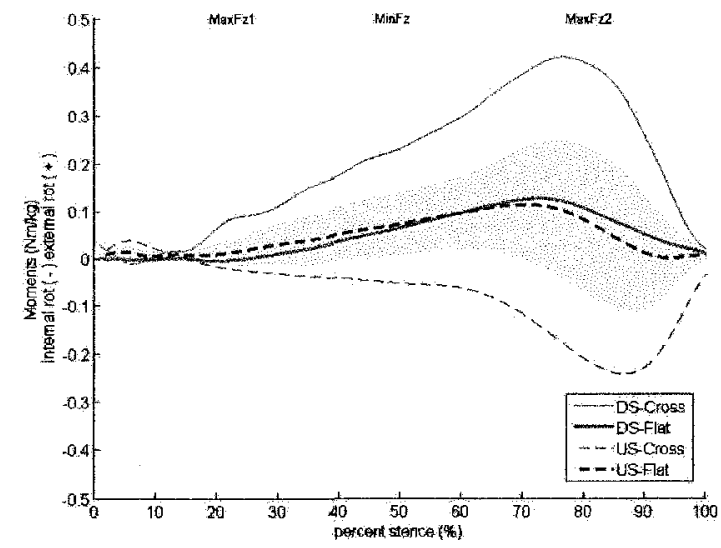

(a)

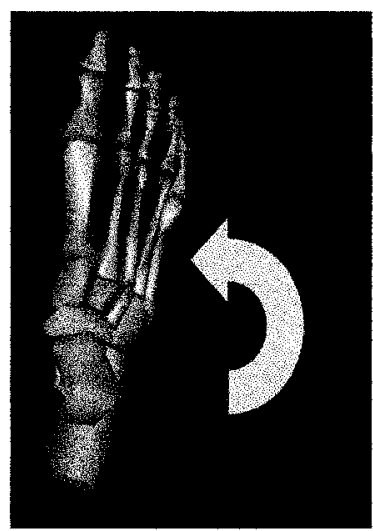

(b)

Figure 38 - (a) Ankle moment ( $\mathrm{Nm} / \mathrm{kg}$ ) averaged across all subjects and all trials for the DS and US-ankles under the flat and cross-slope conditions. The ankle transverse plane moment is a moment about a floating axis perpendicular to the medio-lateral axis of the shank and the longitudinal axes of the foot. ERot (positive), IRot (negative). Grey region is the standard deviation of the US-flat condition. (b) Ankle IRot moment. 


\subsubsection{Knee moment}

The knee transverse plane moments (Fig. 39) unveiled differences across sides and conditions at $\operatorname{MinF}_{\mathrm{z}}$ and $\mathrm{MaxF}_{\mathrm{z}} 2(\mathrm{p}<0.001)$. Symmetry was maintained at these events during flat walking.

At $\mathrm{MinF}_{\mathrm{z}}$ and $\mathrm{MaxF}_{\mathrm{z}} 2$ differences were seen across conditions for the US and DS-knees as well as between knees for the cross-slope condition (Table 45). The US-knee reversed the sign of its moment, going from an IRot moment $(-0.07 \mathrm{Nm} / \mathrm{kg}$ and $-0.14 \mathrm{Nm} / \mathrm{kg})$ on the flat condition to an ERot moment $(0.01 \mathrm{Nm} / \mathrm{kg}$ and $0.02 \mathrm{Nm} / \mathrm{kg})$ on the cross-slope. The DS-knee increased its IRot moment on the cross-slope (from $-0.06 \mathrm{Nm} / \mathrm{kg}$ to -0.17 $\mathrm{Nm} / \mathrm{kg}$ and from $-0.17 \mathrm{Nm} / \mathrm{kg}$ to $-0.34 \mathrm{Nm} / \mathrm{kg}$ at $\mathrm{MinF}_{\mathrm{z}}$ and $\mathrm{MaxF}_{\mathrm{z}} 2$ respectively). Thus, once again, oppositely rotating moments were produced on the cross-slope condition.

Table 45 - Knee transverse plane moments evaluated at representative gait cycle events and averaged across all trials and subjects for each side/condition permutation. Associated p-values for each relevant pairwise comparison are also presented.

\begin{tabular}{|c|c|c|c|c|c|c|c|c|}
\hline $\mathbf{K}_{\mathbf{z}}$ & $\begin{array}{l}\text { DS/ } \\
\text { Cross }\end{array}$ & $\begin{array}{l}\text { DS/ } \\
\text { Flat }\end{array}$ & $\begin{array}{l}\text { US/ } \\
\text { Cross }\end{array}$ & $\begin{array}{l}\text { US/ } \\
\text { Flat }\end{array}$ & $\begin{array}{c}\text { DS/ } \\
\text { Flat } \\
- \\
\text { US/ } \\
\text { Flat }\end{array}$ & $\begin{array}{c}\text { DS/ } \\
\text { Flat } \\
- \\
\text { DS/ } \\
\text { Cross }\end{array}$ & $\begin{array}{c}\text { DS/ } \\
\text { Cross } \\
- \\
\text { US/ } \\
\text { Cross }\end{array}$ & $\begin{array}{c}\text { US/ } \\
\text { Flat } \\
- \\
\text { US/ } \\
\text { Cross }\end{array}$ \\
\hline $\mathbf{M i n F}_{\mathbf{z}}$ & $\begin{array}{c}-0.17 \\
(0.070\end{array}$ & $\begin{array}{l}-0.06 \\
(0.04)\end{array}$ & $\begin{array}{c}0.01 \\
(0.04)\end{array}$ & $\begin{array}{c}-0.07 \\
(0.05)\end{array}$ & 1.000 & $0.003^{*}$ & $<0.001 *$ & $0.001 *$ \\
\hline $\operatorname{MaxF}_{z} 2$ & $\begin{array}{c}-0.34 \\
(0.08)\end{array}$ & $\begin{array}{l}-0.17 \\
(0.07)\end{array}$ & $\begin{array}{c}0.02 \\
(0.08)\end{array}$ & $\begin{array}{c}-0.14 \\
(0.09)\end{array}$ & 1.000 & $<0.001^{*}$ & $<0.001 *$ & $<0.001$ * \\
\hline
\end{tabular}

Group means and standard deviations (SD)

* Indicates significant difference at $\alpha<0.05$ for the post-hoc Bonferonni analysis.

${ }^{\dagger}$ Represents an asymmetry between limbs on the flat condition at this event. 


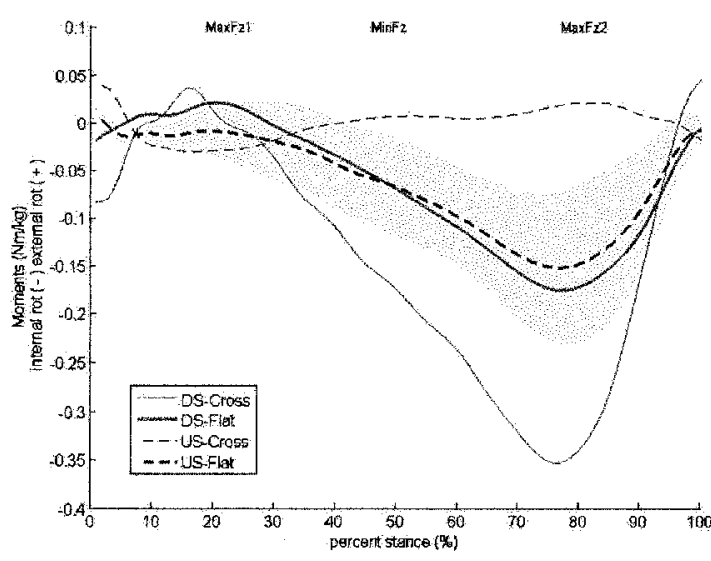

(a)

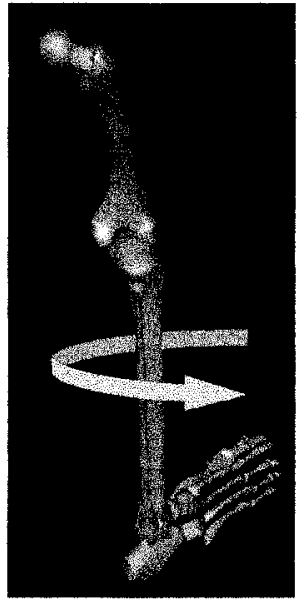

(b)

Figure 39 - (a) Knee moment $(\mathrm{Nm} / \mathrm{kg})$ averaged across all subjects and all trials for the DS and US-knees under the flat and cross-slope conditions. The knee transverse plane moment is a moment about the longitudinal axis of the shank. ERot (positive), IRot (negative). Grey region is the standard deviation of the US-flat condition. (b) A knee IRot moment.

\subsubsection{Hip moment}

For the hip transverse plane moments (Fig. 40), interaction between sides and conditions were found to be significant at $\operatorname{MaxF}_{\mathrm{z}} 1$ and $\mathrm{MaxF}_{\mathrm{z}} 2(\mathrm{p}<0.004)$. Symmetry was maintained at these events.

Pairwise comparisons revealed differences at both $\operatorname{MaxF}_{z} 1$ and $\operatorname{MaxF}_{z} 2$ (Table 46). At $\operatorname{MaxF}_{\mathrm{z}} 1$, differences were exhibited across conditions for the US and DS-hip as well as across hips for the cross-slope condition ( $\mathrm{p}<0.001)$. The US-hip underwent a change in direction in moment from an ERot moment $(0.15 \mathrm{Nm} / \mathrm{kg})$ on the flat condition to an IRot moment $(-0.11 \mathrm{Nm} / \mathrm{kg})$ on the cross-slope. The DS-hip increased its ERot moment on the cross-slope (from $0.18 \mathrm{Nm} / \mathrm{kg}$ to $0.39 \mathrm{Nm} / \mathrm{kg}$ ). At $\mathrm{MaxF}_{\mathrm{z}} 2$, differences were only significant across conditions for the DS-hip ( $p=0.003$ ). The DS-hip experienced a greater 
IRot moment on the cross slope $(-0.14 \mathrm{Nm} / \mathrm{kg}$ compared to $-0.06 \mathrm{Nm} / \mathrm{kg})$. Thus, during cross-slope walking the hip experienced oppositely rotating moments.

Table 46 - Hip transverse plane moments evaluated at representative gait cycle events and averaged across all trials and subjects for each side/condition permutation. Associated p-values for each relevant pairwise comparison are also presented.

\begin{tabular}{|c|c|c|c|c|c|c|c|c|}
\hline $\mathbf{H}_{\mathbf{z}}$ & $\begin{array}{l}\text { DS/ } \\
\text { Cross }\end{array}$ & $\begin{array}{l}\text { DS/ } \\
\text { Flat }\end{array}$ & $\begin{array}{l}\text { US/ } \\
\text { Cross }\end{array}$ & $\begin{array}{l}\text { US/ } \\
\text { Flat }\end{array}$ & $\begin{array}{c}\text { DS/ } \\
\text { Flat } \\
- \\
\text { US/ } \\
\text { Flat }\end{array}$ & $\begin{array}{c}\text { DS/ } \\
\text { Flat } \\
- \\
\text { DS/ } \\
\text { Cross }\end{array}$ & $\begin{array}{c}\text { DS/ } \\
\text { Cross } \\
- \\
\text { US/ } \\
\text { Cross }\end{array}$ & $\begin{array}{c}\text { US/ } \\
\text { Flat } \\
- \\
\text { US/ } \\
\text { Cross }\end{array}$ \\
\hline $\mathbf{M a x F}_{\mathrm{z}} \mathbf{1}$ & $\begin{array}{c}0.39 \\
(0.10)\end{array}$ & $\begin{array}{c}0.18 \\
(0.06)\end{array}$ & $\begin{array}{l}-0.11 \\
(0.10)\end{array}$ & $\begin{array}{c}0.15 \\
(0.08)\end{array}$ & 1.000 & $<0.001^{*}$ & $<0.001^{*}$ & $<0.001^{*}$ \\
\hline $\operatorname{MaxF}_{\mathrm{z}} 2$ & $\begin{array}{c}-0.14 \\
(0.09)\end{array}$ & $\begin{array}{c}-0.06 \\
(0.06)\end{array}$ & $\begin{array}{c}-0.04 \\
(0.05)\end{array}$ & $\begin{array}{l}-0.10 \\
(0.05)\end{array}$ & 0.419 & $0.003^{*}$ & 0.138 & 0.523 \\
\hline
\end{tabular}

Group means and standard deviations (SD)

* Indicates significant difference at $\alpha<0.05$ for the post-hoc Bonferonni analysis.

${ }^{\dagger}$ Represents an asymmetry between limbs on the flat condition at this event.

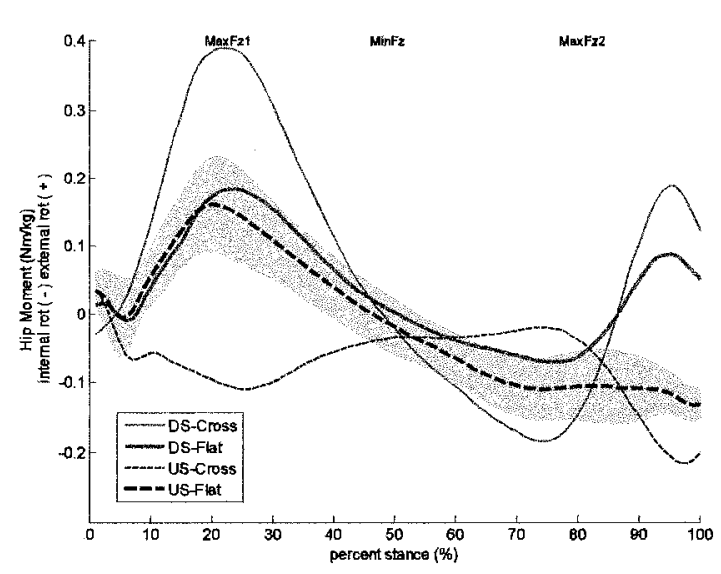

(a)

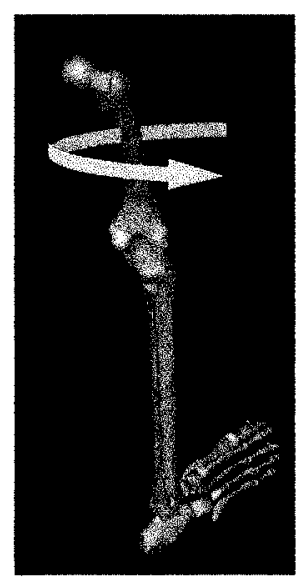

(b)

Figure 40 - (a) Hip moment $(\mathrm{Nm} / \mathrm{kg}$ ) averaged across all subjects and all trials for the DS and US-hips under the flat and cross-slope conditions. The hip transverse plane moment is a moment about the longitudinal axes of the thigh. ERot (positive), IRot (negative). Grey region is the standard deviation of the US-flat condition. (b) A hip IRot moment. 


\subsection{Discussion}

Repeatable level walking kinetics have been demonstrated in past research (Apkarian et al., 1989; Kadaba et al., 1989; Eng and Winter, 1995; Vaughan et al., 1999). It is known however, that kinetic results are sensitive to both the method of calculation (Dumas et al., 2007) as well as the coordinate system used (Liu and Lockhart, 2006; Schache and Baker, 2007; Schache et al., 2007). As a consequence, estimates of kinetics between various studies may differ and derivation differences must be taken into account when comparing data from different studies. Nonetheless, the JRF and JRM reported herein were consistent with prior publications on gait (Eng and Winter, 1995; Vaughan et al., 1999).

\subsubsection{Joint Reaction Forces}

During the level walking condition, the results agreed well with kinetic gait cycle profiles calculated by other researchers (Vaughan et al., 1999; Pearsall and Costigan, 1999). In general, the shape of the JRF curves in each plane possessed the characteristic curve patterns of the GRF (chapter 3).

Beginning with the most substantial changes, the differences seen on the cross-slope for the medio-lateral JRF were largely dominated by the changes in the GRF medio-lateral component previously reported (chapter 3 ). All of the cross-slope ankle, knee, and hip JRF magnitudes were double or triple that of the level walking condition. More specifically, the DS-limb exhibited large lateral JRF and the US-limb large medial JRF. 
The concomitant increase in medio-lateral JRF was necessary for both maintenance of equilibrium and joint structural integrity.

In addition there were numerous antero-posterior and vertical JRF changes at the ankles, knees, and hips that were unanticipated given that no differences in antero-posterior or vertical GRF had occurred (chapter 3). However, both the kinematic changes reported earlier (chapter 4) and the use of non-orthogonal LCS could explain in large part the differences occurring here. The former mentioned reorientation of the lower-limb segments would in turn alter loading directions. The latter being the result of noncoincident LCS and GCS axes allowing for a different repartition of the GRF vector.

\subsubsection{Joint Reaction Moments}

The flat walking JRM presented here were in agreement with those of other researchers (Eng and Winter, 1995; Vaughan et al., 1999; Pearsall and Costigan, 1999). The JRM changes due to the cross-slope condition can be more easily understood taking the previous kinematic hypotheses into account (chapter 4). Hence, the asymmetrical limb joint excursions and respective coordination are reflected in the US and DS-JRM differences.

In the sagittal plane, differences in JRM due to the cross-slope at the ankles, knees, and hips corresponded to the altered kinematic pattern previously reported (chapter 4). For instance, the DS-ankle decrease in PF moment towards TO is understandable given that the ankle was already more PF. Also, the US-knee decrease in Flx moment during weight acceptance is logical given the increased Flx reported. Towards TO, the DS-knee joint 
reversed its moment from a Flx moment to an Ext moment perhaps in anticipation of the cross-slope obstacle making toe-clearance more difficult. Similarly, at the hip, the Ext moment during weight acceptance was greater for the DS-hip than for the US-hip during cross-slope walking potentially to maintain level pelvic orientation for upper body balance.

In the frontal plane, accommodations in JRM were seen at all three lower-limb joints. The ankle (foot complex) produced oppositely rotating moments to account for the crossslope surface with the DS-ankle providing an Inv moment while an Eve moment was produced at the US-ankle. The cross-slope adaptations at the knees and hips are consistent with the kinematic adaptations to maintain vertical body orientation such that the body leans towards the US-side. The DS-knee and hip responded to the cross-slope by increasing their Abd moment while the US-knee and hip produced an Add moment.

It is more difficult to interpret the transverse plane moments given the large inter-subject variability. This variability was expected given that prior studies (Winter, 1995) showed similarly variable results even during level walking. The precise role of the transverse moments remain unclear, however it is believed the asymmetrical transverse plane JRM rotate the body towards the US-side in an attempt to control DS-slippage and help provide US-body lean. This is seen in the ankle as the DS-ankle increased its ERot moment producing a greater torque to push the body US, while the US-ankle IRot moment provided the medial push to keep the body progressing forward and minimizing DSexcursion. 


\subsection{Conclusion}

The modest cross-slope examined in this study produced large increases in medio-lateral GRF that were transmitted distal to proximal throughout the lower-limbs placing augmented and asymmetrical loads at the joints. During cross-slope walking, the lowerlimbs must not only support the body to avoid collapse over the stance limb (Sadeghi et al., 2001), but must effectively modify their JRF and JRM to create the changing kinematic patterns previously seen.

Attempts to minimize errors in IDA were made throughout this paper. Some of the variability in the transverse and fontal plane IDA may result from inter-subject variability in foot anatomy (Eng and Winter, 1995). More importantly, it is known that that frontal plane JRM are sensitive to the position of the COP and that a small error in COP global coordinates could lead to reversals in the direction of rotation of these moments (Eng and Winter, 1995). COP variation was particularly spurious when the GRF were below 60N; so this condition was excluded from ESt and TSt in IDA. Using this criterion, little trialto-trial variability was seen.

The above dramatic kinetic changes, due to cross-slope walking, in healthy young individuals identifies cross-slopes as a factor for further attention. It is unknown how special populations would react to the cross-slope conditions. The increased joint strength demands, especially the shear loads in the medio-lateral direction may represent an increase injury risk subsequent to falls. Further, it is possible that special populations (diabetics, elderly, prosthetic wearers, cane users, etc) develop alternate strategies, such 
as adopting a wider stance and decreasing locomotor speed to minimize the risk of injury during cross-slope walking. It has been shown for other activities of daily living such as stair climbing that locomotor strategies may vary among different populations (Reeves et al., 2007).

Further studies of cross-slope walking could explore the use of several populations and the effect of foot anatomy, footwear, surface friction and varied cross-slope inclinations to provide a greater understanding of cross-slope walking mechanics. 


\subsection{References}

Apkarian, J., Naumann, S., Cairns, B. (1989). A three dimensional kinematic and dynamic model of the lower limb. Journal of Biomechanics, 22(2), 143-155.

Campbell, A.J., Reinken, J., Allan, B.C., Martinez, G.S. (1981). Falls in old age: a Frequency and related factors. Age and Ageing, 10, 264-70.

DeGarie, L., Pearsall, D.J. (2000, August). Gait analysis on a transversely tilted platform. Paper presented at the XIth Congress of the Canadian Society for Biomechanics, Montreal, $Q C$.

Donald, I.P., Bulpitt, C.J. (1999). The prognosis of falls in elderly people living at home. Age and Ageing, 28, 121-5.

Dumas, R., Nico, E., Chèze, L. (2007). Influence of the 3D inverse dynamic method on the joint forces and moments during gait. Journal Biomechanical Engineering, $129(5), 786-790$.

Eng, J.J., Winter, D.A. (1995). Kinetic analysis of the lower limb during walking: What information can be gained from a three-dimensional model. Journal of Biomechanics, 28, 753-758.

Grood, E., Suntay, W. (1983). A joint coordinate system for the clinical description of three-dimensional motion. Applications to the knee. Journal of Biomechanical Engineering, 105, 136-143.

Kadaba, M.P., Ramakrishnan, H.K., Wooten, M.E., Gainey, J., Gorton, G., Cochran, G.V. (1989). Repeatability of kinematic, kinetic, and electromyographic data in normal adult gait. Journal of Orthopaedic Research, 8(6), 849-860.

Komistek, R.D., Kane, T.R., Mahfouz, M., Ochea, J.A., Dennis, D.A. (2005). Knee mechanics: a review of past and present techniques to determine in vivo loads. Journal of Biomechanics, 38, 215-228.

Lockhart, T.E., Spaulding, J.M., Park, S.H. (2007). Age-related slip avoidance while walking over a known slippery floor surface. Gait \& Posture, 26, 142-149.

Liu, J., \& Lockhart, T.E. (2006). Comparison of 3D joint moments using local and global inverse dynamics approaches among three different age groups. Gait $\&$ Posture, $23,480-485$.

McIntosh, A.S., Beatty, K.T., Dwan, L.N., Vickers, D.R. (2006). Gait dynamics on an inclined walkway. Journal of Biomechanics, 39, 2491-2502. 
Ministry of municipal affairs and housing (Ontario), Building and development branch. (2006). Building Code Compendium, Ontario. Vol I (sec 3.8.3.2). Toronto: Publications Ontario.

National Guide to Sustainable Municipal Infrastructure. (2004, July). Sidewalk Design, Construction and Maintenance. Retrieved Sept 24, 2007, from http://sustainablecommunities.fcm.ca/files/Infraguide/Roads_and_Sidewalks/side walk_design_constr_maintenance.pdf

Nester, C.J., van der Linden, M.L., Bowker, P. (2003). Effect of foot orthoses on the kinematics and kinetics of normal walking gait. Gait \& Posture, 17, 180-187.

Nicolaou, M., Pearsall, D.J, Loh, J. (2002, August). Gait adaptation to transverse slopes. Paper presented at the IVth World Congress for Biomechanics, Calgary, AB.

Pearsall, D.J., \& Costigan, P.A. (1999). The effect of segment parameter error on gait analysis results. Gait and Posture, 9, 173-183.

Pearsall, D.J., Ouckama, R., Loh, J., Bouchard, C.E. (2007, July). Effects of cross slope on gait ground reaction forces. Paper presented at the International Society for Posture \& Gait Research, Burlington, VT.

Reeves, N.D., Spanjaard, M., Mohagheghi, A.A., Baltzopoulos, V., Maganaris, C.N. (2007). Older adults employ alternative strategies to operate within their maximum capabilities when ascending stairs. Journal of Electromyography \& Kinesiology, doi: 10.1016/j.jelekin.2007.09.009.

Rose, J., \& Gamble, J.G. (Eds.) (2006). Human Walking ( ${ }^{\text {rd }}$ ed.) (pp. 44-57). Philadelphia: Lippincott Williams \&Wilkins.

Sadeghi, H., Sadeghi, S., Price, F., Allard, P., Labelle, H., Vaughan, C.L. (2001). Functional roles of ankle and hip sagittal muscle moments in able-bodied gait. Clinical Biomechanics, 16, 688-695.

Schache, A.G., \& Baker, R. (2007). On the expression of joint moments during walking. Gait \& Posture, 25, 440-452.

Schache, A.G., Baker, R., Vaughan, C.L. (2007). Differences in lower limb transverse plane joint moments during gait when expressed in two alternative reference frames. Journal of Biomechanics, 40, 9-19

Stokes, I.A., Allard, P.,\& Blanchi, J.P. (Eds) (1995). Three-Dimensional Analysis of Human Movement (ch.5). Champaign, IL: Human Kinetics.

Urrey, S.R. (2002). Redistribution of foot pressure in healthy adults during sideslope walking. Foot \& Ankle International, 23(12), 1112-8. 
Vaughan, C.L., Hay, J.G., Andrews, J.G. (1982). Closed loop problems in biomechanics. Part I-A classification system. Journal of Biomechanics, 15, 197-200.

Vaughan, C.L., Davis, B.L., \& O'Connor, J.C. (1999). Dynamics of human gait ( $2^{\text {nd }}$ ed.). (pp. 15-43, 83-106). Cape Town, South Africa: Kiboho. 


\section{CHAPTER 6 - CONCLUSION}

To the knowledge of the authors, this thesis provides the most exhaustive study of the biomechanics of cross-slopes walking to date. A thorough analysis of GRF, lower-limb kinematics and kinetics has revealed that the modest cross-slope walking condition produces significant asymmetrical changes between the US and DS-limbs, most notably in the sagittal and frontal plane. The body adopts a functional leg length discrepancy (LLD), presumably to maintain an upright trunk position, causing main kinematic and kinetic changes in the lower-limb sagittal plane profiles. The medio-lateral GRF are modified due to the cross-slope, producing a cascading effect of asymmetrical and substantially greater joint loads in all the lower-limb joints particularly in the frontal plane.

\subsection{Leg length Discrepancy}

Due to the cross-slope, the sagittal plane joint adaptations created a functional LLD such that the DS-limb acted as the shorter limb and the US-limb the longer one. An analysis of both kinematics and kinetics supported the LLD hypothesis. Similar to a study in which shoe wedges induced a LLD (Walsh et al., 2000), the subjects in this study increased Flx of the US-limb, while increasing Ext of the DS-limb. Additionally, the kinetic profiles corresponded to the kinematic changes elicited. For instance, an US-limb in increased Flx need not produce a large Flx moment, while a DS-limb in increased Ext requires a decreased Ext moment. In addition, a secondary compensatory change in gait was observed; that is, decreased step width. On the modest cross-slope used in this study, 
subjects presumably reduced their step width to minimize the LLD. This latter strategy may be abandoned under steeper cross-slope conditions, wherein the maintenance of balance may become a more pressing issue requiring the opposite response of increased step width for a large base of support at the expense of gait efficiency.

The group of subjects used in the present study, were easily able to traverse the crossslope platform; however this LLD strategy may lead to increased energy expenditure (Gurney et al., 2001) making cross-slope walking energetically costly and perhaps exhausting for elderly and disabled populations. Prolonged exposure to cross-slope walking with LLD like adaptations may exacerbate musculoskeletal disorders such as lower-back pain, hip pain, arthritis of the spine, and stress fractures (Gurney, 2002).

\subsection{Avoidance of Down-Slope Slippage}

From the analysis of GRF data, the lower-limbs modify the GRF to avoid DS-slippage. A $300 \%$ increase in DS-limb medial GRF and a reversal of the US-limb GRF to a lateral force support this hypothesis. Furthermore, the DS-limb increased its Abd moment resulting in increased Abd of the DS-hip, while the US-limb increased its Add moment creating an increased Add of the US-hip. These adaptations allowed subjects to both stay true to their forward course without slippage and, more importantly, without falling.

The asymmetrical loads induced by the cross-slope in particular augmented shear forces at the ankles, knees, and hips. The combined kinematic compliance of the ankles, or more precisely the rear foot by way of the subtalar joints, and the increased medio-lateral forces 
to the cross-slope walking surface may expose the ankle to an increase in medio-lateral ligament strain. The frontal plane kinematics of cross-slope walking could thus place the ankles at risk for both lateral (DS-ankle) and medial (US-ankle) ankle complex ligament injury (Pollard, 2002). The altered ankle kinematics, due to reduced joint flexibility (Reeves et al., 2007), could make cross-slope walking dangerous for the elderly. The increased medio-lateral JRF and JRM at the knees and hips could also increase injury risk in persons with pre-existing joint instability, muscular weaknesses or other pathologies. Furthermore, increased shear stress on the knee has been linked to the development of osteoarthritis (Lynn et al., 2008), while increased forces at the hip joint may result in hip pain and instability (Lewis et al., 2007). It is also stated that an increase in knee Add moment augments the load on the medial compartment of the knee possibly leading to cartilage wear, knee varus and medial osteoarthritis (Lynn et al., 2008). As a dramatic rise of shear forces (in both knees and hips) and Add moment (US-knee) were seen during cross-slope walking, both acute and long-term exposure to the condition might be of concern to certain populations.

\subsection{Future Directions}

The findings of this study are limited to the modest $6^{\circ}$ cross-slope and to a young healthy male population. It is unknown how different cross-slope inclinations would affect the outcome measures nor how elderly and special populations (visually impaired, amputee, wheel chair users, etc) would adapt to the added stresses placed on the body during the cross-slope perturbation. Moreover, an analysis of pelvis kinematics and BCOM movement could solidify the conclusions of this present study. Further studies are thus warranted in order to deepen the understanding of cross-slope walking. 


\section{CHAPTER 7 - REFERENCES}

Apkarian, J., Naumann, S., Cairns, B. (1989). A three dimensional kinematic and dynamic model of the lower limb. Journal of Biomechanics, 22(2), 143-155.

Baker, R. (2007). The history of gait analysis before the advent of modern computers. Gait \& Posture, 26, 331-42.

Beaulieu, F.D., Pelland, L., Robertson, D.G. (2007). Kinetic analysis of forward and backwards stair descent. Gait \& Posture, doi:10.1016/j.gaitpost.2007.07.010.

Cavagna, G.A., Heglund, N.C., Taylor, C.R. (1977). Mechanical work in terrestrial locomotion, two basic mechanisms for minimizing energy expenditure. American Journal of Physiology, 233, R243-R261.

Chao, E.Y., Laughman, R.K., Schneider, E., Stauffer, R.N. (1983). Normative data of knee Joint motion and ground reaction forces in adult level walking. Journal of Biomechanics, 16(3), 219-233.

Chandler, R.F., Clauser, C.E., McConville, J.T., Reynolds, H.M., Young, J.W. (1975). Investigation of inertial properties of the human body. AMRL-TR-74-137, Ohio.

Chaudhari, A.M., Briant, P.L., Bevill, S.L., Koo, S., Andriacchi, T.P. (2008). Knee Kinematics, Cartilage Morphology, and Osteoarthritis after ACL Injury. Medicine and Science in Sports and Exercise, 40(2), 215-222.

Davis III, R.B., Ounpuu, S., Tyburski, D., Gage, J.R. (1991). A gait analysis data collection and reduction technique. Human Movement Science, 10, 575-587.

DeGarie, L., \& Pearsall, D.J. (2000, August). Gait analysis on a transversely tilted platform. Paper presented at the XIth Congress of the Canadian Society for Biomechanics, Montreal, $Q C$.

De Leva, P. (1996). Adjustments to Zatsiorsky-Seluyanov's segment inertia parameters. Journal of Biomechanics, 29(9), 1223-1230.

Demspter, W.E. (1955). Space requirements of the seated operator. WADC-TR-55-159, Wright Air Development, Ohio.

Dumas, R., Aissaoui, R., Mitton, D., Skalli, W., de Guise, J.A. (2004). Personalized Body Segment Parameters from Bi-Planar Low Dose Radiography International Congress Series, 1268, 19-24.

Dumas, R., Nico, E., Chèze, L. (2007). Influence of the 3D inverse dynamic method on the joint forces and moments during gait. Journal of Biomechanical Engineering, $129(5), 786-790$. 
Dumas, R., \& Chèze, L. (2007). 3D inverse dynamics in non-orthogonal segment coordinate system. Medical and Biological Engineering and Computing, 45, 315 322.

Eng, J.J., \& Winter, D.A. (1995). Kinetic analysis of the lower limb during walking: What information can be gained from a three-dimensional model. Journal of Biomechanics, 28, 753-758.

Fong, D.T., Li, J.X., Hong, Y. (2005). Lower-extremity gait kinematics on slippery surfaces in construction worksites. Medicine and Science in Sports and Exercise, $37(3), 447-54$.

Fujii, N., Enomoto, Y., Yokozawa, T., Michiyoshi, A.E. (1999, August). Biomechanical analysis of running on the banked gound. Paper presented at the XVIIth International Society of Biomechanics Congress. Calgary, AB.

Gagnon, M., Desjardins, P., Larrive, A. (2001). Joint coordinate systems of axes for coherence in reporting kinematic and kinetic data. Clinical Biomechanics, 16, 349-50.

Ganley, K.J., \& Powers, C.M. (2004). Determination of lower extremity anthropometric parameters using dual energy X-ray absorptiometry : the influence of the net joint moments during gait. Clinical Biomechanics, 19, 50-56.

Gehlsen, G.M., Stewart, L.B., Van Nelson, C., Bratz, J.S. (1988). Knee kinematics: the effects of running on cambers. Medicine and Science in Sports and Exercise, 21(4), 463-6.

Goujon-Pillet, H., Sapin, E., Fodé, P., Lavaste, F. (2008). Three-dimensional motions of trunk and pelvis during transfemoral amputee gait. American Journal of Physical Medicine \& Rehabilitation, 89(1), 87-94.

Grood, E., \& Suntay, W. (1983). A joint coordinate system for the clinical description of three-dimensional motion. Applications to the knee. Journal of Biomechanical Engineering, 105, 136-143.

Gurney, A.B., Mermier, C.M., Robergs, R.A., Gibson, A.L., Rivero, D.P. (2001). Effects of leg length discrepancy on gait economy and lower extremity muscle activity in older adults. Journal of Bone and Joint surgery American Edition, 83, 907-915.

Gurney, A.B. (2002). Leg length discrepancy. Gait and Posture, 15, 195-206.

Halliday,D., Resnick, R., \& Walker, J. (1993). Fundamentals of Physics (4 ${ }^{\text {th }}$ ed.) (pp 300301).New York: John Wiley \& Sons, inc.

Hanavan, E.P. (1964). A Mathematical Model of the Human Body. Aerospace Medical Division. Ohio, pp. 64-102. 
Howell, D.C. (2002). Statistical Methods for Psychology (5 ${ }^{\text {th }}$ ed.) (pp 372-373). Belmont, CA: Duxbury Press.

Huiskes, R., \& Mow, V.C. (2005). Basic orthopaedic biomechanics \& mechano-biology $\left(3^{\text {rd }}\right.$ ed.) ( p.40). Philadelphia: Lippincott, Williams \& Wilkins.

Kadaba, M.P., Ramakrishnan, H.K., Wooten, M.E., Gainey, J., Gorton, G., Cochran, G.V. (1989). Repeatability of kinematic, kinetic, and electromyographic data in normal adult gait. Journal of Orthopaedic Research, 8(6), 849-860.

Komistek, R.D., Kane, T.R., Mahfouz, M., Ochoa, J.A., Dennis, D.A. (2005). Knee mechanics: a review of past and present techniques to determine in vivo loads. Journal of Biomechanics, 38, 215-228.

Kawamura, K., Tokuhiro, A., Takechi, H. (1991). Gait analysis of slope walking: a study of step length, stride width, time factors and deviation in the centre of pressure. Acta Medica Okayama, 45(93), 179-184.

Lay, A.N., Hass, C.J., Gregor, R.J. (2006). The effects of sloped surfaces on locomotion: A kinematics and kinetic analysis. Journal of Biomechanics, 39, 1621-1628.

Leroux, A., Fung, J., Barbeau, H. (1999). Adaptation of the walking pattern to uphill walking in normal and spinal-cord injured subjects. Experimental Brain Research, 126(3), 359-368.

Leroux, A., Fung, J., Barbeau, H. (2002). Postural adaptations to walking on inclined surfaces: I. Normal strategies. Gait \& Posture, 15(1), 64-74.

Levangie, P.K., \& Norkin, C.C. (Eds.) (2005). Joint Structure \& Function: A Company. comprehensive Analysis ( $4^{\text {th }}$ ed.) (pp 517-527). Philadelphia: F.A. Davis

Lewis, C.L., Sahrmann, S.A., Moran, D.W. (2007). Anterior hip joint force increases with hip extension, decreased gluteal force, or decreased iliopsoas force. Journal of Biomechanics, 40, 3725-3731.

Liu, J., Lockhart, T.E. (2006). Comparison of 3D joint moments using local and global inverse dynamics approaches among three different age groups. Gait \& Posture, $23,480-485$.

Lockhart, T.E., Spaulding, J.M., Park, S.H. (2007). Age-related slip avoidance strategy while walking over known slippery floor surface. Gait \& Posture, 26, 142-149.

Lu, T.W., Chen, H.L., Chen, S.C. (2006). Comparisons of the lower limb kinematics between young and older adults when crossing obstacles of different heights. Gait \& Posture, 23(4), 471-9. 
Lynn, S.K. et al. (2007). The effect of internal and external foot rotation on the adduction moment and lateral-medial shear force at the knee during gait. Journal of Science and Medicine in Sport, doi:10.1016/j.jsams.2007.03.004.

MacLellan, \& M.J., Patla, A.E. (2006). Stepping over an obstacle on a compliant travel surface reveals adaptive and maladaptive changes in locomotion patterns. Experimental Brain Research, 173(3), 531-8.

McFadyen, B.J., Bouyer, L., Bent, L.R., Inglis, J.T. (2007). Visual-vestibular influences on locomotor adjustments for stepping over an obstacle. Experimental Brain Research, 179(2), 235-43.

McIntosh, A.S., Beatty, K.T., Dwan, L.N., Vickers, D.R. (2006). Gait dynamics on an inclined walkway. Journal of Biomechanics, 39, 2491-2502.

Ministry of municipal affairs and housing (Ontario), Building and development branch. (2006). Building Code Compendium, Ontario. Vol I ( $\sec 3.8 .3 .2)$. Toronto: Publications Ontario.

Monaghan, K., Delahunt, E., Caulfeld, B. (2006). Ankle function during gait in patients with chronic ankle instability compared to controls. Clinical Biomechanics, 2, 168-74.

National Guide to Sustainable Municipal Infrastructure. (2004, July). Sidewalk Design, Construction and Maintenance. Retrieved Sept 24, 2007, from http://sustainablecommunities.fcm.ca/files/Infraguide/Roads and Sidewalks/side walk_design_constr_maintenance.pdf

Nester, C.J., van der Linden, M.L., Bowker, P. (2003). Effect of foot orthoses on kinematics and kinetics of normal walking gait. Gait and Posture, 17, 180-187.

Nicolaou, M., Pearsall, D.J, Loh, J. (2002, August). Gait adaptation to transverse slopes. Paper presented at the IVth World Congress for Biomechanics, Calgary, AB.

Ounpuu, S., 1994. The biomechanics of walking and running. Clinics in Sports Medicine, $4(13)$.

Pearsall, D.J., \& Costigan, P.A. (1999). The effect of segment parameter error on gait analysis results. Gait and Posture, 9, 173-183.

Pearsall, D.J., Ouckama, R., Loh, J., Bouchard, C.E. (2007, July). Effects of cross slope on gait ground reaction forces. Paper presented at the International Society for Posture \& Gait Research, Burlington, VT.

Pollard, H., Sim, P., McHardy, A. (2002). LATERAL ANKLE INJURY: Litterature Review and Report of Two Cases. Australasian Chiropractic \& Osteopathy, 10(1), 21-30. 
Protopapadaki, A., Drechsler, W.I., Cramp, M.C., Coutts, F.J., Scott, O.M. (2007). Hip, knee, ankle kinematics and kinetics during stair ascent and descent in healthy young individuals. Clinical Biomechanics, 22(2), 203-10.

Rao, G., Amarantini, D., Berton, E., Favier, D. (2006). Influence of body segments' parameters estimation models on inverse dynamics solutions during gait. Journal of Biomechanics, 39, 1631-1536.

Reeves, N.D., Spanjaard, M., Mohagheghi, A.A., Baltzopoulos, V., Maganaris, C.N. (2007). Older adults employ alternative strategies to operate within their maximum capabilities when ascending stairs. Journal of Electromyography \& Kinesiology, doi: 10.1016/j.jelekin.2007.09.009.

Riley, O.P., Paolini, G., Della Croce, U., Paylo, K.W., Kerrigan, D.C. (2007). A kinematic and kinetic comparison of overground and treadmill walking in healthy subjects. Gait \& Posture, 26, 17-24.

Riemer, R., Hsiao-Wecksler, E.T., Zhang, X. (2007). Uncertainties in inverse dynamics solutions: A comprehensive analysis and an application to gait. Gait \& Posture doi:10.1016/j.gaitpost.2007.07.012.

Rose, J., \& Gamble, J.G. (Eds.) (2006). Human Walking ( $3^{\text {rd }}$ ed.) (pp. 44-57). Philadelphia: Lippincott Williams \&Wilkins.

Schache, A.G., \& Baker, R. (2007). On the expression of joint moments during walking. Gait \& Posture, 25, 440-452.

Schache, A.G., Baker, R., Vaughan, C.L. (2007). Differences in lower limb transverse plane joint moments during gait when expressed in two alternative reference frames. Journal of Biomechanics, 40, 9-19.

Silva, M.P.T., Ambrosio, J.A.C. (2004). Sensitivity of the results produced by the inverse dynamic analysis of a human stride to perturbed input data. Gait and Posture, 19, 35-49.

Sun, J., Walters, M., Svensson, N., Lloyd, D. (1996). The influence of surface slope on human gait characteristics: a study of urban pedestrians walking on an inclined surface. Ergonomics, 39(4), 677-692

Sussman, D.H. Walker, M., Tamburello, M., VanLunen, B., Dowling, E.A., Atkinson, R., Koss, E., Mulholland, M., VanSchoych, K. (2001, June). The effect of road camber on running kinematics. Paper presented at the XIXth International Symposium on Biomechanics in Sports. San Francisco, CA.

Urrey, S.R. (2002). Redistribution of foot pressure in healthy adults during sideslope walking. Foot Ankle International, 23(12), 1112-8. 
Vaughan, C.L., Hay, J.G., Andrews, J.G. (1982). Closed loop problems in biomechanics. Part I-A classification system. Journal of Biomechanics, 15, 197-200.

Vaughan, C.L., Davis, B.L., \& O'Connor, J.C. (1999). Dynamics of human gait $\left(2^{\text {nd }}\right.$ ed.). (pp. 15-43, 83-106). Cape Town, South Africa: Kiboho.

Walsh, M., Connolly, P., Jenkinson, A., O'Brien, T. (2000). Leg length discrepancy - an experimental study of compensatory changes in three dimensions using gait analysis. Gait and Posture, 12, 156-161

Whittle, M.W. (2002). Gait Analysis: An introduction ( $3^{r d}$ ed.) (p 107). Oxford: Butterworth-Heinemann.

Wilcox, R.R. (1987). New statistical procedures for the social sciences: Modern solutions to basic problems ( $\mathrm{p}$ 173). Hillsdale, NJ: Lawrence Erlbaum Associates.

Winter, D.A., Eng, J.J., Isshac, M.G. (1994). A review of kinetic parameters in human walking. In Levangie, P.K., \& Norkin, C.C. (Eds.) Joint Structure \& Function: A comprehensive Analysis (pp. 525-534). Philadelphia: F.A. Davis Company.

Winter, D.A. (2005). Biomechanics and motor control of human movement $\left(3^{\text {rd }}\right.$ ed) (pp. 180-202). Waterloo, ON: Wiley-Interscience.

Zatsiorsky, V., \& Seluyanov, V. (1983). The mass and inertia characteristics of the main Segments of the human body. In Biomechanics VIII-B (Edited by Matsui, H., Kobayashi, K., 1152-1159. Human Kinetics, Illinois. 


\section{APPENDIX 1 - Consent Form \\ MCGILL UNIVERSITY \\ FACULTY OF EDUCATION \\ RESEARCH SUBJECT CONSENT FORM}

Comparison of walking gait on level to cross slopes surfaces

Participation in this study consists of walking across a $7 \mathrm{~m}$ platform. You will be asked to perform these travels under controlled conditions within the lab. The risk of injury is minimal. In order to insure your safety, the exact tasks will be explained verbally and demonstrated to you.

All personal information collected will be confidential. The use of a number code will maintain anonymity of yourself when data are presented in abstracts, publications or reports presented at conferences or in journals. The only personal information required will be the age, height, weight and leg length.

Your participation in this study is voluntary and not mandatory. You are free to withdraw from participating in any part or all of the study at any time.

During testing, you will wear your own shirt and will be provided with a pair of spandex shorts while standing on a paneled platform. You will be asked to complete 20 trials of walking under both a flat and cross inclined platform. Successful trials will include those that include recording of one complete stride on top of force plates. For each task, performance measures will include near-infrared video recording to obtain kinematic data.

I, , have both read the above testing conditions and have had the testing conditions verbally explained and demonstrated to me. I understand that my participation in this study is voluntary and that I may withdraw from participating in any part or all of the study at any time. I understand that all personal information collected will be confidential. If I have any questions or concerns regarding the above tests, I should contact Dr. David J. Pearsall, Associate Professor, of the Department of Kinesiology \& Physical Education (Room 404, Currie Memorial Gym, phone: 398-4184 ext. 09976, or email: david.pearsall@mcgill.ca)

Participant's signature date

Tester's signature 